Paula Homem de Mello

\title{
"Estudo teórico sobre corantes catiônicos e possíveis modelos que expliquem a interação com a argila do tipo montmorilonita"
}

Tese apresentada ao Instituto de Química de São Carlos, Universidade de São Paulo, para obtenção do título de Doutor em Ciências (Físico-Química).

Orientador: Prof. Dr. Albérico Borges Ferreira da Silva

SÃO CARLOS

2006 
Este exemplar foi revisado e alterado em relação à versão original, sob a exclusiva responsabilidade do autor

São Carlos, 11 de julho de 2006

Paula Homem de Mello

Ficha Catalográfica elaborada pela Seção de Referência e Atendimento ao Usuário do SBI/IQSC

Mello, Paula Homem de

Estudo teórico sobre corantes catiônicos e possíveis modelos que expliquem a interação com a argila do tipo montmorilonita./ Paula Homem de Mello. -São Carlos, IQSC, 2006.

$118 \mathrm{p}$.

Tese (Doutorado) - Instituto de Química de São Carlos /

Universidade de São Paulo, 2006.

Orientador: Prof. Dr.Albério Borges Ferreira da Silva

1. Corantes catiônicos. 2. Química quântica. 3. Simulação. I. Título.

Referências Bibliográficas conferidas pelo $S B$ IIIOSC 
Aos meus amores Hugo, Thais, Mamma, Mau e Fê. 


\section{Agradecimentos}

+ A Albérico Borges Ferreira da Silva, pela orientação, confiança, amizade, paciência e oportunidades.

+ A Benedetta Mennucci e Jacopo Tomasi, da Università di Pisa, pela colaboração e receptividade.

+ A Rodrigo de Santis Neves por todo o trabalho com as simulações, sugestões e discussões.

+ A Hugo Barbosa Suffredini, Káthia M. Honório, Agnaldo Arroio e Karen C. Weber pela colaboração neste trabalho e em diversos outros, pelas oportunidades de novos saberes e, principalmente, pela amizade.

+ Aos queridos amigos Melissa F. S. Pinto, Vânia C. Fernandes e Marco Caricato pela colaboração essencial a este trabalho.

+ Aos amigos e colaboradores Luiz Nunes de Oliveira, Klaus Capelle, Osvaldo N. de Oliveira Jr., Fergus Gessner, Marcel Tabak, Patricia Santiago, Daniel R. Cardoso, Mauro Coelho dos Santos, Djenaine de Souza, Lucia Codognoto, Josiane Caetano, Andressa Galli, Luis Alberto Avaca e Sergio A. S. Machado pelas oportunidades.

+ A todo o Grupo de Quimica Quântica e Cristalografia, em especial a Ednilsom, Manu, Marcello, Ângela, Teca, Regina Santos, Regina Porto, Nana, Joel e ao GMEME, pelo apoio e pelos momentos de tanta alegria.

+ Ao pessoal da Biblioteca e da Seção de Alunos pelo apoio carinhoso.

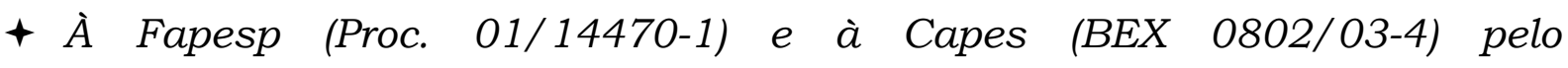
financiamento e pelas sugestões dos assessores.

+ Ao Instituto de Química de São Carlos e à Universidade de São Paulo pelo apoio institucional e facilidades oferecidas.

+ A toda a minha família, Homem de Mello, Vieira, Suffredini e Soares de Campos, e a meus amigos pelo apoio, incentivo e amor. 


\section{RESUMO}

Neste trabalho, são utilizados diversos métodos de química teórica para estudar as propriedades eletrônicas e o espectro de absorção de seis corantes catiônicos: laranja de acridina (LA), proflavina (PF), safranina (SF), vermelho neutro (VN), azul de metileno (AM) e tionina (TN). Inicialmente é realizado um estudo para verificar a influência do solvente na geometria e no espectro desses corantes utilizando diversos métodos de química quântica, o método de solvatação contínuo IEFPCM e a simulação de Monte Carlo (MC). A seguir são estudados a diprotonação, a dimerização e alguns modelos para a argila do tipo montmorilonita e para a interação desta com os corantes, fenômenos esses que explicam a metacromasia observada experimentalmente. 


\section{ABSTRACT}

This work presents a theoretical study on the electronic properties and the absorption spectra of six cationic dyes: acridine orange, proflavine, safranine, neutral red, methylene blue and thionine. First of all, we have carried out calculations to verify the solvent effects on geometries and spectra employing methods of Quantum Chemistry and including solvent effects with the polarizable continnum model and Monte Carlo (MC) simulation. Also, we have studied diprotonation, dimerization and some models of the montmorillonite clay and its interaction with the cationic dyes under study here, phenomena that explain the experimental methacromatic behavior of these dyes. 


\section{LISTA DE FIGURAS}

Figura 1. Estruturas dos corantes catiônicos estudados com a orientação adotada.

Figura 2. Representação das folhas de um argilomineral [7].

Figura 3. Espectro de absorção do Azul de Metileno $\left(1,2 \times 10^{-5}\right.$ mol. $\left.L^{-1}\right)$ em suspensão aquosa de argila do tipo montmorilonita SWy-1 (0,11 g. $\left.L^{-1}\right)$ em função do tempo em minutos $(0$ a 240) e em dias (1 a 30) [6,7,37]. _— 9

Figura 4. Estrutura do corante catiônico estudado por Guillaumont e Nakamura [55].__ 10

Figura 5. Máximos de absorção experimental e teórico (em $\mathrm{nm})$ para os corantes catiônicos estudados. __ 34

Figura 6. Representação gráfica dos orbitais moleculares HOMO e LUMO para os corantes catiônicos estudados.

Figura 7. Estruturas dos clusters (a) $\mathrm{MB}+2 \mathrm{H}_{2} \mathrm{O}$ e (b) $\mathrm{TN}+2 \mathrm{H}_{2} \mathrm{O}$.

Figura 8. Estrutura e numeração adotada para o 9-fenilantraceno [135].

Figura 9. Geometria obtida para a SF pela otimizaça como método AMl mantendo-se $\alpha=30^{\circ}$.

Figura 10. Representações gráficas dos orbitais moleculares envolvidos na transição principal do espectro de absorção do corante SF e contribuições para o dipolo de transição $(\mu)$ para as conformações com $\alpha=30^{\circ}$ e $70^{\circ}$.

Figura 11. Gráfico do MEP para os corantes catiônicos estudados com carga $=+1$ (energia eletrostática de interação $=100 \mathrm{kcal} . \mathrm{mol}^{-1}$ ).

Figura 12. Numeração adotada para o corante AM nesta seção do trabalho.

igura 13. Energia ao longo dos ciclos MC para o corante AM otimizado com AMI e com DFT/IEFPCM. _ 50

Figura 14. Função de auto-correlação entre as estruturas geradas pelos ciclos MC para o AM. __ 51

Figura 15. Função de distribuição radial para alguns átomos do AM e hidrogênio da água. __ 52

Figura 16. Máximos de absorção calculados para as configurações selecionadas da simulação de MC para o corante AM com potencial construído a partir de cálculos DFT/IEFPCM.

Figura 17. Superestruturas A e B, selecionadas da simulação MC para o AM com potencial construído a partir de cálculos DFT/IEFPCM.

Figura 18. Cargas derivadas do potencial eletrostático calculadas para os corantes catiônicos LA e TN.

Figura 19. Energia ao longo dos ciclos MC para os corantes LA e TN com potencial construído a partir de cálculos DFT/IEFPCM.

Figura 20. Gráfico de barras com os comprimentos de onda (nm) calculados com ZINDO para as superestruturas selecionadas da simulação de MC para o corante LA; conformações $A$ e B e respectivas propriedades.

Figura 21. Gráfico de barras com os comprimentos de onda (nm) calculados com ZINDO para as superestruturas selecionadas da simulação de MC para o corante TN; conformações $A$ e $B$ e respectivas propriedades.

Figura 22. Estrutura geral e numeração adotada.

Figura 23. Estruturas dos dímeros extraídos dos cristais de AM (Mapaz e Mbluet), LA (Cesmao e Cesmes) e PF

(Proflc e Proflv) com a orientação adotada.

Figura 24. Representação gráfica dos OM de fronteira para os dímeros de AM.

Figura 25. Representação gráfica dos OM de fronteira para os dímeros de LA.__ 71

Figura 26. Representação gráfica dos $O M$ de fronteira para os dímeros de PF. ___ 72

Figura 27. Energia ao longo dos ciclos MC para as simulações do dímero do corante.__ 74

Figura 28. Gráfico de barras com os comprimentos de onda (nm) calculados com ZINDO para as configurações selecionadas das duas simulações para o dímero do AM. __ 75

Figura 29. Configurações selecionadas da simulação para o dímero do AM com a caixa pequena (cp).__ 76

Figura 30. Configurações selecionadas da simulação para o dímero do AM com a caixa grande (cg). __ 77

Figura 31. Estrutura da argila montmorilonita determinada por Tsipursky et al. [142,143].___ 80

Figura 32. Cargas atômicas calculadas para o cluster extraído da estrutura proposta por Tsipursky et al.

[142,143] para a montmorilonita.__ 80

Figura 33. Plano siloxano da argila montmorilonita. ___ 82

Figura 34. Cargas atômicas calculadas para o plano siloxano. ___ 82

Figura 35. (a) Estrutura otimizada (vista lateral e superior) e (b) cargas atômicas do cluster formado pelo plano siloxano e o corante LA.

Figura 36. Plano siloxano após otimização com os corantes: (a) projeção superior e (b) projeção lateral. _ 84

Figura 37. Geometria obtida para cada corante após otimização com plano siloxano. 


\section{LISTA DE TABELAS}

Tabela 1. Comprimento de onda de absorção experimental em solução aquosa para os monômeros mono $\left(\lambda_{\text {exp }+1}\right.$ em $\mathrm{nm}$ ) e diprotonados $\left(\lambda_{\text {exp }+2}\right.$ em $\mathrm{nm}$ ) e para os dímeros $\left(\lambda_{\text {exp dim }}\right.$ em $\left.\mathrm{nm}\right)$ dos corantes catiônicos estudados__ 5 Tabela 2. Raios (em $\AA$ ) das esferas utilizadas na construção das cavidades dos corantes catiônicos estudados 25 Tabela 3. Parâmetros geométricos para os corantes catiônicos estudados obtidos no vácuo (v) e em meio aquoso $(s)$

Tabela 4. Comprimento de onda de absorção $(\lambda$, em $\mathrm{nm})$ para o AM e para a LA calculado com TD-HF, TDDFT e ZINDO no vácuo (v) e em meio aquoso $(s)$ para quatro diferentes geometrias 32

Tabela 5. Comprimento de onda de absorção ( $\lambda$, em nm, obtido com o ZINDO) para PF, TN, VN e SF calculado no vácuo (v) e em meio aquoso ( $s$ ) para as duas diferentes geometrias obtidas com DFT 33

Tabela 6. Comprimento de onda do máximo ( $\lambda$, em $\mathrm{nm}$ ) teórico obtido para os corantes AM e TN___ 37 Tabela 7. Diferença entre as energias de excitação $\left(\Delta \varepsilon_{\text {solv }}\right.$, em eV) e momentos de dipolo $\left(\mu_{x}\right.$, em u.a. $)$ calculados com ZINDO no vácuo (v) e em meio aquoso (s). As geometrias utilizadas foram obtidas com DFT 38

Tabela 8. Comprimento de absorção $(\lambda$, em $\mathrm{nm})$, força do oscilador $(f)$ e energia total do estado excitado $\left(E_{T}\right.$ ZINDO, em u.a.) obtidos com o método ZINDO para as várias conformações da SF 41 Tabela 9. Deslocamento da banda de absorção experimental do monômero diprotonado em relação à banda do monômero monoprotonado $\left(\Delta \lambda_{\text {exp }}\right.$, em $\left.\mathrm{nm}\right)$, comprimentos de onda calculados para monômero monoprotonado $\left(\lambda_{+1}\right.$, em $\left.\mathrm{nm}\right)$ e previsão para o comprimento de onda do corante diprotonado $\left(\lambda_{+2}\right.$, em $\left.\mathrm{nm}\right)$

Tabela 10. Energia total ( $E_{T}$, em u.a. obtida de cálculo DFT em meio aquoso) e máximo de absorção $(\lambda)$ para cada estrutura diprotonada proposta

Tabela 11. Cargas derivadas do potencial eletrostático (CHELPG) calculadas para o corante AM para as geometrias obtidas com AMI e DFT no vácuo e com DFT em meio aquoso (IEFPCM) e correspondente momento de dipolo (em Debye)

Tabela 12. Dados da simulação de MC (número de ciclos e de configurações selecionadas), resultados dos cálculos ZINDO para as configurações selecionadas da simulação MC, máximo de absorção obtido com ZINDO e IEFPCM e máximo de absorção experimental para os corantes LA e TN

Tabela 13. Parâmetros estruturais selecionados para cada monômero cristalino e para o monômero otimizado de $A M$

Tabela 14. Parâmetros estruturais selecionados para cada monômero cristalino e para o monômero otimizado de LA 61

Tabela 15. Parâmetros estruturais selecionados para cada monômero cristalino e para o monômero otimizado de $P F$ 62

Tabela 16. Energias de absorção $(\varepsilon$, em eV) e comprimentos de onda $(\lambda$, em $\mathrm{nm})$ com as respectivas forças de oscilador $(f)$ e contribuições aos momentos de transição $\left(\mu_{x}, \mu_{y}\right.$ e $\mu_{z}$ em u.a.) calculados com ZINDO/IEFPCM para cada monômero extraído dos cristais 63

Tabela 17. Energia total calculada com B3LYP/6-31G(d)/IEFPCM para os monômeros ( $E_{T, M o n}$ em u.a. $) e$ dimeros $\left(E_{T, D i m}\right.$ em u.a.) extraídos dos cristais

Tabela 18. Energias de absorção ( $\mathcal{E}$, em $\mathrm{eV})$ e comprimentos de onda $(\lambda$, em $\mathrm{nm})$ com respectivos força do oscilador $(f)$, contribuições ao momento de transição $\left(\mu_{x}, \mu_{y}\right.$ e $\mu_{z}$, em u.a.) e orbitais moleculares $(H=H O M O$ e $L=L U M O$ ) envolvidos no principais estados excitados (E.E.) calculados com ZINDO/IEFPCM para cada dímero extraído dos cristais

Tabela 19. Comprimento de onda de absorção $(\lambda$, em $\mathrm{nm})$ e correspondente erro em relação ao valor experimental calculado para os corantes otimizados com o plano siloxano, energia total ( $E_{T}$, em eV) e calor de formação $\left(\Delta H_{f}\right.$, em kcal) para os corantes otimizados com AM1 no vácuo e na presença da argila 86

Tabela 20. Alguns ângulos diedros selecionados dos corantes otimizados com o plano siloxano 87 


\section{LISTA DE ABREVIATURAS E SÍMBOLOS}

\begin{tabular}{ll} 
AM & Azul de metileno \\
AM1 & Austin Model 1 \\
CHELPG & Charges from Electrostatic Potential Grid based \\
DFT & Density Functional Theory \\
DM & Dinâmica Molecular \\
HOMO & Highest Occupied Molecular Orbital \\
IEFPCM & Integral Equation Formulation version of the Polarizable Continuum Model \\
LA & Laranja de acridina \\
LUMO & Lowest Unoccupied Molecular Orbital \\
MC & Monte Carlo \\
MEP & Mapa de Potencial Eletrostático \\
PF & Proflavina \\
SF & Safranina \\
VN & Vermelho neutro \\
TD-DFT & Time-dependent DFT \\
TD-HF & Time-dependent Hartree-Fock \\
TN & Tionina \\
ZINDO & Zerner's Intermediate Neglect of Differential Overlap \\
$\mathrm{N}_{\mathrm{t}}$ & Nitrogênio de amina terciária \\
$\mathrm{N}_{\mathrm{p}}$ & Nitrogênio de amina primária \\
$\mathrm{N}_{\mathrm{a}}$ & Nitrogênio de anel central (heteroátomo) \\
$\lambda$ & Comprimento de onda do máximo de absorção \\
$f$ & Energia de excitação \\
& Força do oscilador \\
\hline &
\end{tabular}




\section{SUMÁRIO}

\section{RESUMO}

ABSTRACT

LISTA DE FIGURAS

LISTA DE TABELAS

\section{LISTA DE ABREVIATURAS E SÍMBOLOS}

Agradecimentos

1. INTRODUÇ̃̃O

1.1. Considerações Iniciais

1.2. Corantes catiônicos $[3,4,6,7] \_$_ 2

1.3. Argilas $[5,25,29-36,39-41] \_6$

1.4. A interação de corantes catiônicos e argilas $[6,7,25,26] \_$_ 8

1.5. Revisão da Literatura __ 10

1.6. Objetivos_—_ 14

2. Métodos__ 15

2.1. Métodos baseados no Modelo Contínuo [80-89] __ 17

2.2. Simulação computacional de líquidos __ 20

3. METODOLOGIA__ 23

4. RESULTADOS E DISCUSSÃO __ 28

4.1. Estudo dos monômeros dos corantes catiônicos _ 29

4.1.1. Efeito do solvente na geometria e no espectro dos corantes catiônicos utilizando o modelo contínuo (IEFPCM)

4.1.2. Rotação do anel fenílico da SF__ação dos corantes cationticos_ 39

4.1.3. Estudo da diprotonação dos corantes catiônicos___ 44

4.1.4. Simulações de MC para os monômeros___ 48

4.1.5. Estudo dos monômeros "extraídos" de cristais___ 58

4.2. Estudo dos dímeros dos corantes catiônicos — 64

4.2.1. Estudo dos dímeros “extraídos” de cristais___ 64

4.2.2. Simulações MC do dímero de $\mathbf{A M} \_73$

4.3. Modelos para a argila montmorilonita — 79

4.4. Interação corante-argila

5. CONCLUSÕES___ 89

6. TRABALHOS FUTUROS _

7. REFERÊNCIAS BIBLIOGRÁFICAS___ 
1. INTRODUÇÃO 


\subsection{Considerações Iniciais}

Este trabalho é fruto de uma proposta do Grupo de Fotoquímica ao Grupo de Química Quântica, ambos do IQSC/USP, com o intuito de realizar cálculos teóricos que pudessem caracterizar as propriedades eletrônicas e o espectro de absorção de seis corantes catiônicos: laranja de acridina (LA), proflavina (PF), safranina (SF), vermelho neutro (VN), azul de metileno (AM) e tionina (TN), visando um entendimento da interação desses corantes catiônicos com a argila do tipo montmorilonita.

$\mathrm{Na}$ próxima seção é apresentada uma introdução dos aspectos experimentais dos corantes, da argila e das interações entre eles, seguida de uma revisão dos estudos teóricos sobre esses sistemas encontrados na literatura e dos objetivos deste trabalho. No Capítulo 2 é feita uma breve descrição dos métodos de solvatação utilizados. Nos capítulos subseqüentes são apresentados os resultados obtidos, as conclusões e as perspectivas para trabalhos futuros.

\subsection{Corantes catiônicos $[3,4,6,7]$}

A classificação dos corantes catiônicos pode ser feita em função das suas estruturas, dos cromóforos ou dos heteroátomos presentes. Neste trabalho, foram estudados dois corantes tiazínicos (azul de metileno, AM, e tionina, TN), dois acridínicos (laranja de acridina, LA, e proflavina, PF) e dois diazínicos (vermelho neutro, VN, e safranina, SF), cujas estruturas são apresentadas na Figura 1. 


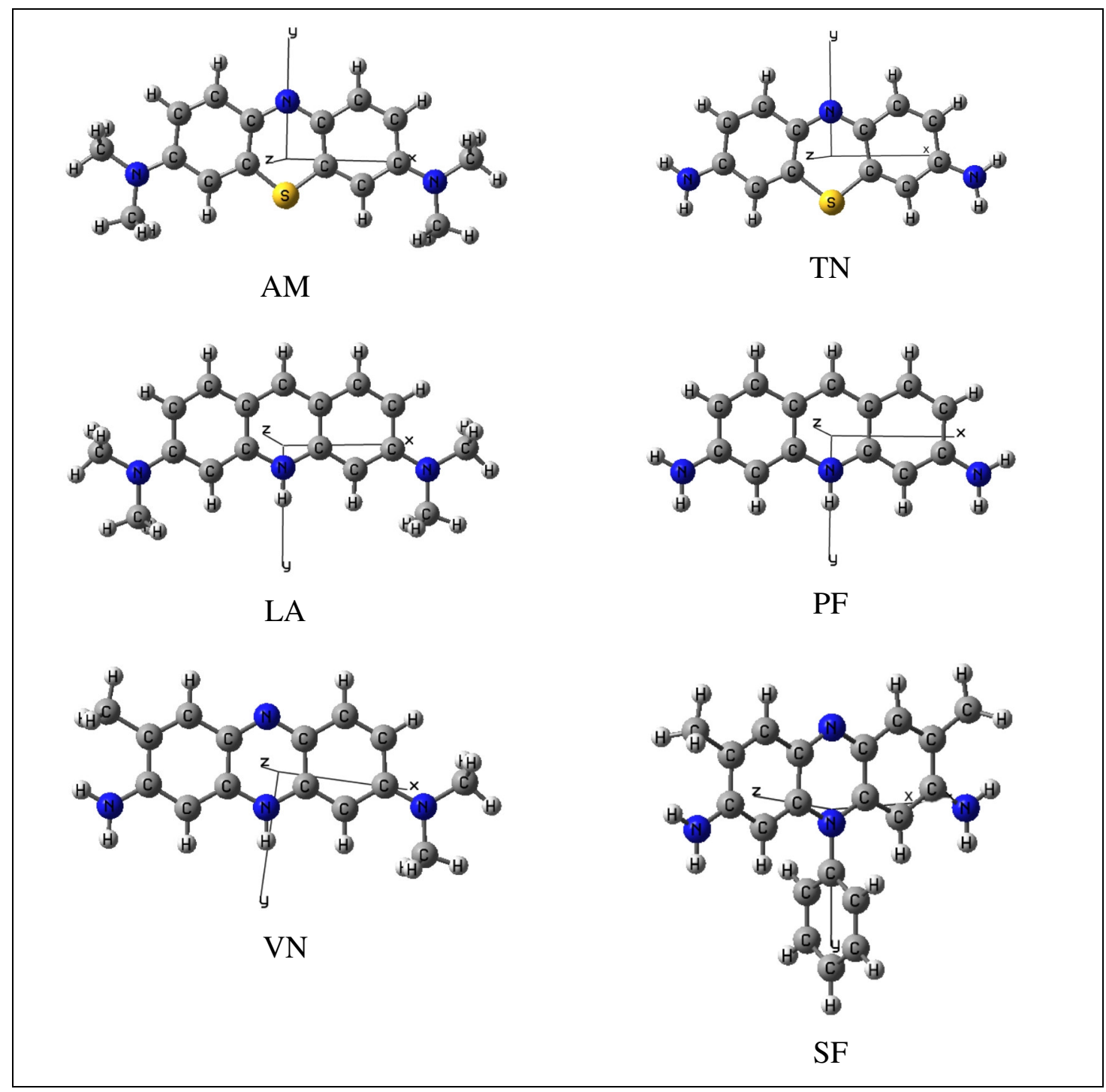

Figura 1. Estruturas dos corantes catiônicos estudados com a orientação adotada.

Historicamente, os corantes catiônicos foram inicialmente utilizados no tingimento de algodão, couro e papel, mas foram descobertas aplicações em diversas áreas, desde a indústria alimentícia até medicina, biologia e química analítica.

Alguns desses corantes apresentam atividade bacteriostática e bactericida. Graças à sua absorção por tecidos animais, eles têm sido utilizados como corantes de organelas celulares (ácidos nucléicos, cromatina e lisossomos), pois o espectro desses corantes se modifica quando ocorre a interação com os sítios ácidos presentes nesses sistemas biológicos. Foi observado que o vermelho neutro inibe o crescimento de carcinomas, a proflavina tem 
importantes propriedades anti-sépticas e o azul de metileno e a tionina foto-inativam vírus, podendo, dessa maneira, ser utilizados para descontaminar plasma fresco na presença de luz [8-11].

Vários corantes catiônicos têm sido incorporados a outros materiais para serem utilizados em, por exemplo, fotodegradação de poluentes orgânicos, em eletrocatálise, em células solares e em biosensores [12-16]. Além disso, têm sido utilizados também como sondas de sistemas micro-heterogêneos (argilas, micelas, microemulsões) $[6,7,17,18,20,21,37]$, pois suas propriedades fotofísicas e fotoquímicas dependem muito do meio em que se encontram. Todas essas aplicações demonstram a importância do estudo dos corantes catiônicos, particularmente na determinação das propriedades fotofísicas e fotoquímicas.

Uma característica muito importante dos corantes é o seu comportamento metacromático (ou seja, o surgimento de novas bandas no espectro de absorção) como consequiência da formação de agregados termodinamicamente estáveis em solução aquosa, mesmo em concentrações baixas. Essa tendência que os corantes iônicos têm em se agregar em solução não pode ser atribuída a uma única força. Em geral, estão envolvidas forças do tipo van der Waals, ligações hidrogênio inter-moleculares, ligações hidrogênio com o solvente e interações hidrofóbicas, de dispersão e de elétrons $\pi$ [19], sendo, na maioria das vezes, difícil avaliar a contribuição individual das forças envolvidas. Esses agregados apresentam espectros eletrônicos de absorção diferente dos corantes na forma monomérica. A agregação de duas (dímeros), três (trímeros) ou mais moléculas de corante provoca modificações nos estados eletrônicos fundamental e excitado das moléculas que compõe o agregado. Surgem, então, novas bandas no espectro de absorção, em comprimentos de onda menores e maiores do que a banda do monômero. Desta forma, as técnicas espectrofotométricas, como a absorção em UV-visível, são bastante úteis no estudo destes sistemas. 
A teoria para atribuição das transições eletrônicas [5] prevê duas transições para os dímeros, uma em energia mais alta e outra em energia mais baixa que o monômero, ou seja, há um split da banda do monômero. A intensidade das duas bandas depende das orientações relativas dos dipolos de transição dos cromóforos nos dímeros. E como os momentos de transição se posicionam no plano do sistema aromático, a intensidade fornece informações sobre a orientação dos cromóforos no dímero. No limite da orientação exatamente paralela de dois cromóforos idênticos, e tendo o dímero, portanto, um centro de simetria, a banda de energia mais baixa é proibida.

A metacromasia dos corantes catiônicos também pode ser causada pela diprotonação em meio ácido. O AM em solução ácida, por exemplo, apresenta uma banda de absorção intensa na região de $750 \mathrm{~nm}$ referente ao monômero diprotonado acompanhada de outra banda de menor intensidade por volta de $680 \mathrm{~nm}$ [7].

Os comprimentos de onda de absorção $(\lambda)$ das formas monomérica (protonada ou diprotonada) e dimérica dos corantes catiônicos estudados são apresentados na Tabela 1.

Tabela 1. Comprimento de onda de absorção experimental em solução aquosa para os monômeros mono $\left(\lambda_{\text {exp }+1} \mathrm{em} \mathrm{nm}\right)$ e diprotonados $\left(\lambda_{\text {exp }+2} \mathrm{em} \mathrm{nm}\right)$ e para os dímeros $\left(\lambda_{\text {exp,dim }} \mathrm{em}\right.$ $\mathrm{nm})$ dos corantes catiônicos estudados

\begin{tabular}{|lccc|}
\hline \multicolumn{1}{|c}{ Corante } & $\boldsymbol{\lambda}_{\text {exp+1 }}[\mathbf{6 , 7 ]}$ & $\boldsymbol{\lambda}_{\text {exp+2 }}$ & $\boldsymbol{\lambda}_{\text {exp,dim }}$ \\
\hline Azul de metileno & 665 & $750[7]$ & $605[7]$ \\
Tionina & 600 & $673[20]$ & $557[20]$ \\
Laranja de acridina & 492 & $490[21]$ & $470[21]$ \\
Proflavina & 445 & --- $^{*}$ & --- $^{*}$ \\
Vermelho neutro & 540 & $606[22]$ & $505[23]$ \\
Safranina & 520 & $580[24]$ & $500[6,7]$ \\
\hline
\end{tabular}

* Valor ainda não bem estabelecido. 


\subsection{Argilas $[5,25,29-36,39-41]$}

As argilas são constituídas por partículas cristalinas de um número restrito de minerais conhecidos como argilominerais, que são silicatos de alumínio hidratados (contendo, em certos tipos, elementos como magnésio, ferro, cálcio, sódio, potássio, lítio e outros) e podem ser classificados segundo três características: a estrutura da camada (minerais 1:1 ou 2:1), a ocupação da folha octaédrica (dioctaédrica e trioctaédrica) e a natureza dos espaços interlamelares (expansível e não expansível).

Nos minerais $1: 1$, as lamelas são formadas por uma folha tetraédrica e outra octaédrica; enquanto nos minerais 2:1, as lamelas são formadas por duas folhas tetraédricas e uma folha octaédrica central (Figura 2).

A segunda característica importante nos argilominerais se refere ao grau de ocupação da folha octaédrica. Quando as folhas octaédricas são formadas por átomos de Al(III), somente dois terços das posições do octaedro podem estar preenchidas para manter a neutralidade elétrica da camada. Por esta razão, a montmorilonita, por exemplo, que contém principalmente alumínio trivalente em sua folha octaédrica, é denominada de dioctaédrica. Por outro lado, minerais que contêm $\mathrm{Mg}$ (II) na folha octaédrica apresentam todas as posições preenchidas para manter a neutralidade da camada, fazendo parte do grupo dos trioctaédricos, como é o caso das hectoritas. 


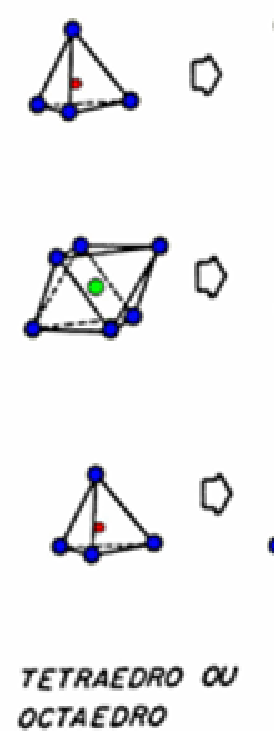

O oxigenio OCTAEDRO
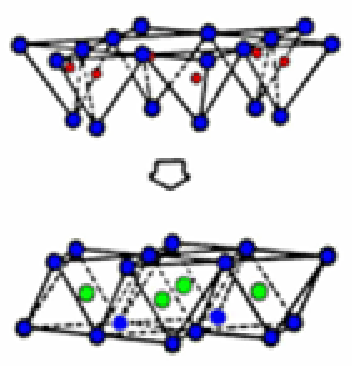

○

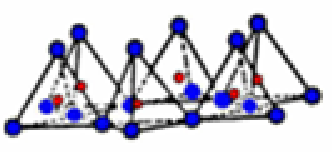

FOLHA TETRAÉOAICA $\propto$ FOLHA OCTAEORICA

Hidroxile
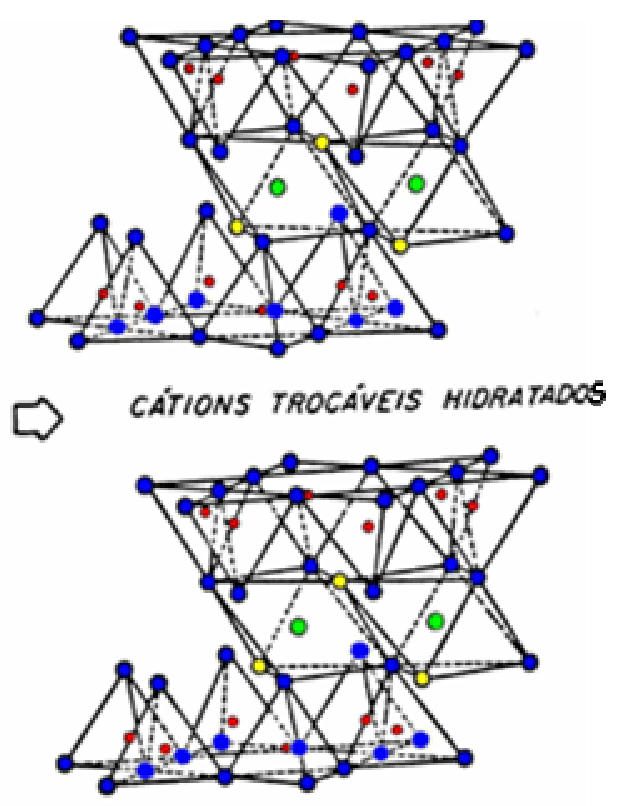

ESTRUTURA OA CAMAOA

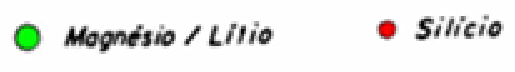

Figura 2. Representação das folhas de um argilomineral [7].

Uma das propriedades mais importantes dos argilominerais é a existência de uma carga líquida negativa em suas camadas. As montmorilonitas derivam da pirofilita pela substituição de alguns átomos de $\mathrm{Si}(\mathrm{IV})$ na folha tetraédrica por átomos de $\mathrm{Al}(\mathrm{III})$. Podem acontecer também substituições na folha octaédrica, onde átomos de $\mathrm{Al}(\mathrm{III})$ são substituídos por $\operatorname{Mg}(\mathrm{II})$. Estas substituições por átomos de valência menor causam uma deficiência de cargas positivas, resultando numa lamela carregada negativamente. Uma vez que esses átomos possuem tamanhos similares, estas substituições não causam distorção na estrutura da lamela. As cargas negativas das camadas do argilomineral são contrabalanceadas por cátions adsorvidos ou intercalados, geralmente alcalinos e alcalinos terrosos, que estão fixos eletrostaticamente ao longo das faces e entre as camadas das partículas da argila, possuindo uma baixa mobilidade. 
Os argilominerais que apresentam carga negativa em suas lamelas, quando dispersos em água ou mesmo quando colocados em uma atmosfera úmida, podem inchar (processo conhecido por "swelling") pela entrada de uma a quatro camadas de moléculas de água nesse espaço interlamelar, dependendo do cátion que se encontra nesse espaço. Estes argilominerais são classificados como expansíveis e a conseqüência mais interessante é a possibilidade de intercalar cátions volumosos e mesmo moléculas polares na região interlamelar.

\subsection{A interação de corantes catiônicos e argilas $[6,7,25,26]$}

Os corantes têm sido usados freqüentemente como sondas na análise de vários sistemas. Existe um grande número de estudos sobre sistemas de corantes catiônicos adsorvidos em argilas que se baseiam, principalmente, em medidas espectrofotométricas (embora medidas de emissão de fluorescência também tenham sido utilizadas) [27-37]. Quando o corante é adsorvido na partícula de argila, o seu comportamento espectral é modificado. Este fato é que faz do corante uma sonda.

As forças de atração responsáveis pelas interações entre corantes e substratos são também capazes de provocar interações entre as moléculas do próprio corante, resultando em espécies que podem ser desde simples dímeros até agregados contendo centenas de moléculas. Observa-se, entretanto, que a formação de agregados ocorre em concentrações de corante muito menores do que em solução homogênea.

Uma das linhas de pesquisa desenvolvidas pelo Grupo de Fotoquímica (IQSC-USP) é o estudo da interação de corantes catiônicos em partículas de argila [6,7,19-22,24-27,37,38]. Como exemplo, apresentamos um dos espectros de absorção obtidos pelo grupo, em função do tempo (Figura 3), do corante azul de metileno numa suspensão de argila montmorilonita SWy-1 [6,7,37]. No início $\left(\mathrm{t}_{0}\right)$ observa-se uma banda intensa em torno de 570nm, 
correspondente aos agregados do corante adsorvidos na superfície externa das partículas de argila, e uma banda em torno de 670nm que corresponde à forma monomérica do corante. Com o passar do tempo, observa-se uma diminuição da banda referente aos agregados (570nm) enquanto a banda referente aos monômeros (670nm) aumenta. Além disso, observase o aparecimento da banda em $765 \mathrm{~nm}$, que é atribuída a monômeros protonados.

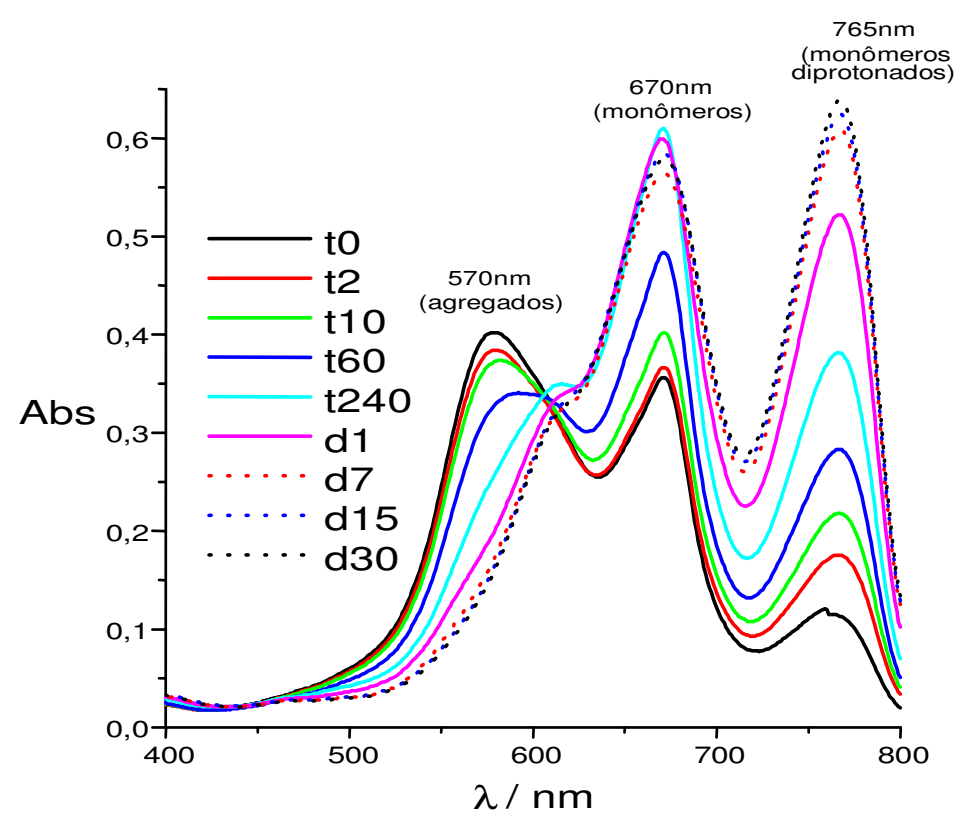

Figura 3. Espectro de absorção do Azul de Metileno $\left(1,2 \times 10^{-5}\right.$ mol. $\left.\mathrm{L}^{-1}\right)$ em suspensão aquosa de argila do tipo montmorilonita $\mathrm{SWy}-1\left(0,11 \mathrm{~g} . \mathrm{L}^{-1}\right)$ em função do tempo em minutos $(0$ a 240) e em dias (1 a 30) [6,7,37].

Os corantes apresentam uma grande tendência de se adsorverem nas superfícies externas das partículas de argila, aumentando a concentração local e induzindo a agregação das moléculas do corante. Com o passar do tempo ocorre uma reorganização do corante nas partículas da argila, com os monômeros indo ocupar os espaços interlamelares, onde podem ser protonados. 


\subsection{Revisão da Literatura}

Nos últimos 50 anos, o método Pariser-Parr-Pople (PPP) [42,43] e os métodos semiempíricos CNDO/S [44] e ZINDO [45-49] têm sido empregados para prever o comportamento espectral de diversos corantes [50-54]. Mais recentemente, Guillaumont e Nakamura [55] utilizaram a teoria do funcional de densidade dependente do tempo (TD-DFT) para calcular as energias de excitação e as respectivas forças do oscilador de alguns corantes, dentre eles dois catiônicos (estrutura apresentada na Figura 4). Neste estudo, os autores observaram que o método TD-DFT reproduz corretamente os valores experimentais das moléculas estudadas, mas para os corantes catiônicos a diferença entre os valores experimental e teórico é maior. Essa diferença foi atribuída à flexibilidade da estrutura dos corantes, que poderiam apresentar várias conformações em solução.

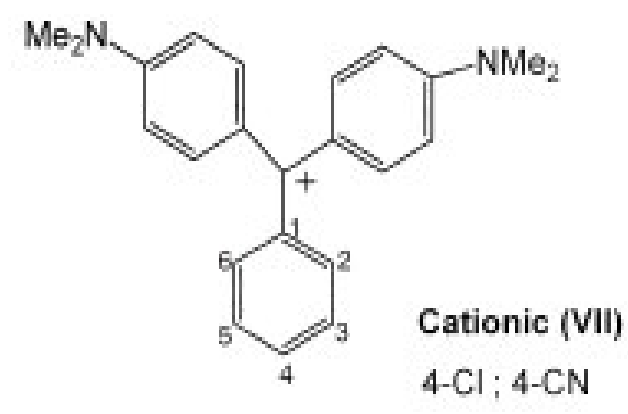

Figura 4. Estrutura do corante catiônico estudado por Guillaumont e Nakamura [55].

Yates e Patel [53] utilizaram o método MNDO para estudar alguns corantes catiônicos, dentre eles o azul de metileno, a tionina, o vermelho neutro, a laranja de acridina e a proflavina. Apenas os dois primeiros corantes foram considerados em sua forma carregada, enquanto os demais foram tratados como sendo neutros. Neste trabalho são analisadas as variações na geometria, no calor de formação, no potencial de ionização, no momento de dipolo e nas cargas atômicas em função das diferenças estruturais dos corantes. As principais conclusões foram: o momento de dipolo não apresenta variação sistemática entre corantes 
neutros ou carregados; o átomo de enxofre é responsável pelas diferenças geométricas do anel central, mas os corantes são todos planares; e, finalmente, a carga dos corantes tiazínicos se concentra sobre o átomo de enxofre.

Lupan [54] estudou quatro corantes catiônicos, dentre eles, o azul de metileno, a laranja de acridina e a proflavina utilizando os métodos PPP e PM3, procurando explicar a interação desses corantes com surfactantes aniônicos com base nas propriedades calculadas (energia dos orbitais HOMO e LUMO e cargas atômicas).

Quintão e colaboradores [56] utilizaram alguns métodos $a b$ initio para estudar três diferentes clusters de azul de metileno com uma molécula de água com o objetivo de esclarecer a influência das ligações hidrogênio nas propriedades espectroscópicas do corante. Os autores concluíram que o corante faz múltiplas ligações de hidrogênio com a água atuando como aceitadora de prótons. Porém, essa interação pouco influencia nos espectros de infravermelho e de absorção indicando a estabilidade do corante (muito desejável para que o corante seja utilizado em terapias fotodinâmicas).

Dentre as primeiras simulações de argilas estão os trabalhos de Skipper e colaboradores [57,58]. Nesses trabalhos, os autores simulam a água do espaço interlamelar de argilas do tipo 2:1 utilizando MC (Monte Carlo) no ensemble NPT. Foram estudados os cátions interlamelares mais comumente encontrados em argilas: $\mathrm{Na}^{+}$e $\mathrm{Mg}^{2+}$ e consideraram a unidade de argila como sendo $\mathrm{Al}_{4} \mathrm{Si}_{8} \mathrm{O}_{20}(\mathrm{OH})_{4}$, contendo 28 sítios de interação. Para dar à argila uma carga negativa, foram colocadas cargas -1 em um dos seis sítios possíveis. Em trabalhos posteriores, os autores utilizaram essa estrutura em simulações de MC e de DM (Dinâmica Molecular) para estudar diferentes cátions intercalados (Na, Li, K, Cs) [59-64].

Outros potenciais foram obtidos por Teppen e colaboradores [65] para as argilas gibbsita, caolinita, pirofilita e beidelita para descrever melhor, particularmente, o ângulo OAl-O e as cargas atômicas. Com isso, chegaram a reproduzir a maior parte dos parâmetros 
estruturais desses minerais, com um erro aproximado de apenas 1\%. Esses potenciais foram testados para simular a interação de uma molécula orgânica (tricloroetano) com o sistema argila-água [66]. A simulação indicou que coexistem três mecanismos de interação distintos. O mecanismo mais estável é o contato completo da molécula com a superfície da argila. $\mathrm{O}$ segundo menos estável envolve a interação de um único átomo $(\mathrm{Cl}$ com a superfície da argila). No terceiro mecanismo, a molécula $\mathrm{C}_{2} \mathrm{HCl}_{3}$ nunca entra em contato direto com a superfície da argila, mas é adsorvida sobre a primeira camada de água.

Chatterjee e colaboradores realizaram uma série de estudos químico-quânticos de argilas do tipo montmorilonita, partindo da estrutura da pirofilita $\left(\mathrm{Si}_{8} \mathrm{Al}_{4} \mathrm{O}_{20}(\mathrm{OH})_{4}\right)$. Os autores realizaram um estudo das propriedades eletrônicas e estruturais da montmorilonita utilizando os métodos MNDO e DFT para um cluster contendo dois átomos de Al. Verificaram que os dois átomos de Al são distinguíveis e essa distinção se dá pela diferente conformação dos grupos hidroxila a eles ligados [67]. Estudaram ainda a substituição isomórfica [68] de um átomo de $\mathrm{Al}^{+3}$ por $\mathrm{Na}^{+}, \mathrm{K}^{+}, \mathrm{Mg}^{+2}, \mathrm{Fe}^{+2}$ e $\mathrm{Fe}^{+3}$. A ordem de preferência na substituição calculada foi $\mathrm{Fe}^{+3}>\mathrm{Mg}^{+2}>\mathrm{Fe}^{+2}>\mathrm{Na}^{+}>\mathrm{K}^{+}$.

Gorb et al. [69] estudaram, em particular, a substituição isomórfica de $\mathrm{Al}^{+3}$ por $\mathrm{Mg}^{+2}$ e de $\mathrm{Si}^{+4}$ por $\mathrm{Al}^{+3}$ em montmorilonita usando o método semi-empírico PM3. Para compensar a carga negativa gerada (-2), foi colocado um cátion $\mathrm{Mg}^{+2}$ na cavidade ditrigonal, resultando na estrutura de fórmula $\mathrm{Mg}\left(\mathrm{Si}_{5} \mathrm{AlMgAlO}_{24} \mathrm{H}_{18}\right)$. Os autores concluíram que as vizinhanças do tetraedro $\mathrm{AlO}_{4}$ é a região mais favorável para o cátion $\mathrm{Mg}^{+2}$.

O grupo de Chatterjee realizou, ainda, cálculos químico-quânticos do sistema argilaágua e do sistema argila-água-cátion [70,71]. Cálculos semi-empíricos foram realizados para o cluster $\mathrm{Al}_{2} \mathrm{Si}_{6} \mathrm{O}_{24} \mathrm{H}_{18}$ e cálculos utilizando DFT para um cluster menor, $\mathrm{AlSi}_{4} \mathrm{O}_{16} \mathrm{H}_{10}$. A carga negativa que a argila apresenta naturalmente foi inserida substituindo um $\mathrm{Si}^{+4}$ por um $\mathrm{Al}^{+3}$. Os cálculos consideraram apenas uma molécula de água nas vizinhanças deste modelo 
de esmectita (grupo que inclui a montmorilonita). Observou-se que dentre todas as orientações possíveis para a molécula de água, a de menor energia é aquela em que os dois átomos de $\mathrm{H}$ apontam para a superfície da argila. Já para o estudo que envolve a interação com o cátion $\left(\mathrm{Na}^{+}\right)$, verificou-se que este se encontra rodeado por cinco moléculas de água e foi demonstrada a dependência da localização desse cátion com a carga das camadas octaédrica e tetraédrica. Estudos mais recentes do grupo [72] conseguiram correlacionar a carga da lamela com a atividade catalítica de esmectitas dioctaédricas utilizando DFT.

Young e Smith [73] demonstraram como o swelling ("inchamento") da argila depende do tamanho e da carga do íon interlamelar. Marry e colaboradores [74] estudaram a montmorilonita intercalada com $\mathrm{Na}^{+}$e $\mathrm{Cs}^{+}$utilizando $\mathrm{MC}$ e DM. Observaram que o $\mathrm{Cs}^{+}$ difunde mais rapidamente do que $\mathrm{Na}^{+}$e o arranjo espacial das superfícies da argila desempenham um papel fundamental na escolha dos sítios a serem ocupados e na mobilidade dos cátions.

A interação entre uma molécula orgânica (um tipo de pesticida, o flutriafol) e argilas do tipo montmorilonita e caolinita foi estudada por Zhmud e colaboradores [75]. No caso da montmorilonita, inicialmente foi simulada uma estrutura com fórmula $\mathrm{Si}_{102} \mathrm{O}_{318} \mathrm{Al}_{57} \mathrm{H}_{83}$, utilizando o campo de força MM2. Para os cálculos semi-empíricos (AM1 e PM3), porém, foram isolados clusters com fórmula $\mathrm{Si}_{12} \mathrm{O}_{34} \mathrm{Al}_{4} \mathrm{H}_{14}$. Deste estudo, foram estimadas as energias das ligações hidrogênio entre água, flutriafol e argila. Verificou-se também que o flutriafol poderia ser protonado ao interagir com os grupos hidroxila presentes nas extremidades das argilas. Outros exemplos do estudo da interação de moléculas orgânicas com argila são o trabalho de Titiloye e Skipper [76], que utilizaram MC e DM para estudar a estrutura e a difusão de metano em montmorilonita intercalada com $\mathrm{Na}^{+}$, e o trabalho de Pospíšil e colaboradores [77,78], que estudaram, via DM e difração de raios-X, a estrutura de montmorilonita intercalada com cetilpiridinio, cetiltrimetilamonio e octadecilamina. 
Teppen e colaboradores [79] estudaram a adsorção de azul de metileno em beidelita, montmorilonita e muscovita utilizando o campo de força empírico desenvolvido por eles [65]. Os resultados indicaram que a adsorção desse corante pode resultar numa ampla variedade de configurações e, portanto, os experimentos que se baseiam no método do íon de azul de metileno para determinar áreas superficiais devem ser interpretados com cautela.

\subsection{Objetivos}

A interação entre o Grupo de Química Quântica e o Grupo de Fotoquímica já produziu duas dissertações [1,2]. Os objetivos deste trabalho foram aprofundar esses estudos anteriores, comparando diferentes métodos de química quântica para obtenção de geometrias, propriedades eletrônicas e espectros de absorção dos corantes catiônicos nas suas diversas formas e estudar alguns modelos para a interação dos corantes com a argila. Foi dada especial atenção à inclusão do solvente (água) nos cálculos: além do método contínuo de solvatação, foi utilizado o método de Monte Carlo, dado o tamanho que o sistema pode adquirir ao incluir moléculas de solvente. 
2. Métodos 
A inclusão de efeitos do solvente na descrição teórica de sistemas químicos pode ser feita utilizando métodos que consideram o solvente de maneira discreta ou contínua. A primeira satisfaz a intuição química, mas necessita de um esforço computacional muito grande até mesmo para sistemas simples, tornando-a impossível para a aplicação em sistemas de alto nível de teoria de Mecânica Quântica. Por outro lado, os métodos contínuos são atualmente acoplados, com sucesso, à maioria dos métodos de Química Quântica.

Em 1994, numa revisão minuciosa a respeito dos modelos contínuos de solvatação, Tomasi e Persico [80] dividem as possíveis abordagens para o tratamento do efeito solvente em quatro categorias:

a. métodos baseados na elaboração de funções físicas (como a expansão de virial das equações de estado);

b. métodos baseados em simulação computacional de líquidos ( $\mathrm{MC}$ ou dinâmica molecular);

c. métodos baseados no modelo contínuo (eletrostático); e

d. métodos baseados na descrição supermolecular de soluções.

Neste capítulo, será apresentada uma breve descrição dos dois métodos utilizados para o estudo dos efeitos do solvente: o PCM (Polarizable Continuum Model), baseado no modelo contínuo, e o método de simulação computacional MC (Monte Carlo). Devido à existência de uma rica literatura específica voltada aos conceitos relacionados a esses temas (vide, por exemplo, 80-90,92-113), essa introdução visa apenas discutir alguns conceitos básicos 


\subsection{Métodos baseados no Modelo Contínuo [80]}

Os métodos SCRF (Self-Consistent Reaction Field) permitem incorporar os efeitos do solvente diretamente na química quântica, mas negligenciam a estrutura de solvatação microscópica na vizinhança do soluto. Nesses métodos, é construída uma cavidade ao redor do soluto e este é tratado quanticamente, enquanto o solvente é representado por um dielétrico contínuo. A distribuição de carga do soluto, dentro da cavidade, polariza o contínuo dielétrico, o qual, por sua vez, polariza a distribuição de carga do soluto. Esta definição da interação soluto-solvente corresponde a um processo auto-consistente, que é numericamente solucionado seguindo um procedimento iterativo.

Nos modelos contínuos, o Hamiltoniano pode ser reduzido a um Hamiltoniano que leva em consideração explicitamente apenas o soluto $\left(\hat{H}_{0}\right)$, enquanto o restante do sistema é descrito por um campo de reação $\left(V_{R}\right)$ gerado pela interação soluto-solvente, ou seja, pela reação do solvente contra a distribuição de carga do soluto.

$$
\left(\hat{H}_{0}+\hat{V}_{R}\right) \Psi=E \Psi
$$

O operador do campo de reação é descrito em termos de um conjunto aparente de pontos de carga dispersos sobre a interface soluto-solvente $\left(S_{i}\right)$, isto é, a cavidade do soluto (Equação 2). As contribuições do soluto $\left(V_{\rho}\right)$ e do solvente $\left(V_{\sigma}\right)$ ao potencial eletrostático são consideradas na densidade de carga $\left(\sigma\left(s_{i}\right)\right)$.

$$
V_{R}=\frac{\sum_{i} \sigma\left(s_{i}\right) S_{i}}{\left|r-r_{0}\right|}=\frac{\sum_{i} q_{i}}{\left|r-r_{0}\right|}, \operatorname{sendo} \sigma\left(s_{i}\right)=-\left\{\varepsilon-\frac{1}{4} \pi \varepsilon\left[\frac{\partial\left(V_{\rho}(r)+V_{\sigma}(r)\right)}{\partial n}\right]\right\}
$$


Em 1934, as expressões de Born e Bell para a energia de interação clássica de um simples "soluto" com o meio (representado por um contínuo dielétrico) foram utilizadas por Kirkwood para propor um modelo contínuo, mas em que o "soluto" era descrito quanticamente [97]. Mas foi a partir das contribuições de Onsager [98] que o modelo começou a ser utilizado para simular uma série de efeitos do solvente (influência do solvente nos espectros vibracionais e eletrônicos, conformações moleculares, reatividade, dentre outros). O modelo de Onsager normalmente usa uma cavidade idealizada (esférica ou elipsoidal) permitindo uma solução analítica para a energia de interação entre o multipolo do soluto e o multipolo que este induz no contínuo. Porém essa cavidade pode não corresponder à forma real do soluto, que nem sempre pode ser aproximado a uma esfera ou a uma elipse. $\mathrm{O}$ método é muito sensível para a escolha do raio do soluto, mas não muito sensível para a constante dielétrica de solventes polares.

O método PCM, diferentemente do modelo de Onsager, coloca um soluto em uma cavidade formada pela união de esferas centradas em cada átomo da molécula. O PCM inclui também um tratamento mais exato, em relação ao modelo de Onsager, da interação eletrostática com o meio circundante, pois o potencial eletrostático do soluto gera uma superfície de carga aparente na superfície da cavidade.

Neste método, a interação soluto-solvente é dividida nas seguintes contribuições:

- Interações estéricas - contribuição mais importante para a energia, pois representa o trabalho feito para o sistema criar uma cavidade no solvente;

- Interações de dispersão-repulsão - são interações de curto alcance. O modelo para este sistema pode se basear num simples esquema átomo-átomo ou pode envolver funções de onda moleculares; 
- Interação eletrostática - é o trabalho feito sobre o sistema quando um soluto que se encontra dentro de uma cavidade é carregado. No PCM todos os efeitos devidos à interação eletrostática entre soluto e solvente são modelados substituindo o solvente por um contínuo caracterizado pela constante dielétrica experimental.

A energia livre de hidratação $\left(\Delta G_{\text {solv }}\right)$ é determinada como uma adição das contribuições eletrostáticas $\left(\Delta G_{\text {ele }}\right.$ ) e estéricas (Equação 3). A energia estérica é expressa pela soma dos termos das contribuições de cavitação $\left(\Delta G_{c a v}\right)$ e de van der Waals $\left(\Delta G_{v d W}\right)$, que considera os efeitos de dispersão-repulsão e de volume [88].

$$
\Delta G_{\text {solv }}=\Delta G_{\text {ele }}+\Delta G_{c a v}+\Delta G_{v d W}
$$

O primeiro artigo sobre o PCM (que ainda não recebia esse nome) foi publicado em 1981 pelo Prof. Jacopo Tomasi e colaboradores [84]. Desde então, foram publicados mais de 180 documentos pelos grupos de Pisa, Nápoles e Parma e mais de 1000 publicações com aplicações e contribuições de outros grupos, demonstrando que o PCM vem sendo considerado o modelo contínuo mais refinado e acurado disponível [89].

Além da versão mais antiga do PCM, que é atualmente chamada de DPCM (o D significa dielectric), outras duas formulações foram desenvolvidas: o CPCM [90], proposto por Cossi e Barone, baseado no modelo COSMO (Conductor-like Screening Model) [91] e o IEFPCM (Integral Equation Formalism version of PCM), proposto por Cancès e Mennucci [92-94]. Neste trabalho, utilizou-se a formulação IEFPCM que tem aplicabilidade mais ampla, pois pode ser utilizada para dielétricos isotrópicos e anisotrópicos, soluções iônicas e interfaces líquido-gás, líquido-líquido e líquido-metal [95], e é a versão default do PCM adotada pelo programa Gaussian 03 [96,125]. 


\title{
2.2. Simulação computacional de líquidos
}

\author{
K. Coutinho, na referência 101 faz uma descrição dos métodos de simulação de
}

líquidos, dando especial atenção ao Método Monte Carlo, que é o método escolhido para a

realização das simulações neste trabalho. Essa descrição é parcialmente reproduzida aqui,

dada a sua clareza e objetividade:

Numa simulação computacional de líquidos, o sistema é representado por $\mathrm{N}$ átomos, ou moléculas, que interagem através do potencial U. Os átomos são confinados numa caixa e o conjunto de posições atômicas $\mathrm{r}=\left(\mathrm{r} 1 ; \mathrm{r} 2 ; \ldots ; \mathrm{r}_{\mathrm{N}}\right)$ definem uma configuração i, denotada por $\Gamma_{\mathrm{i}}(\mathrm{r})$. De acordo com o método de simulação, regras que definem os movimentos atômicos são estabelecidas. A cada novo conjunto de posições atômicas, r, uma nova configuração $\Gamma_{\mathrm{i}}(\mathrm{r})$ é gerada e a evolução da simulação se dá através do movimento sucessivo dos átomos, ou seja, da geração sucessiva de configurações. Todas as configurações geradas através da simulação pertencem ao espaço de configurações $\left\{\Gamma_{\mathrm{i}}\right\}$. [...]

Existem dois processos para gerar as configurações $\Gamma_{\mathrm{i}}(\mathrm{r})$, o determinístico e o estocástico. O processo determinístico é implementado no método de simulação conhecido como Dinâmica Molecular. Neste método, a partir do potencial de interação $\mathrm{U}(\mathrm{r})$, as forças que atuam sobre os átomos são calculadas, $\mathrm{F}=-\mathrm{dU} / \mathrm{dr}$, e as equações de movimento são resolvidas para um intervalo de tempo $\delta$ t. Neste processo, as posições atômicas sucessivas são calculadas e novas configurações são geradas. Na Dinâmica Molecular, os átomos se movem em trajetórias geradas a partir da integração das equações de movimento e as propriedades observáveis são obtidas através de médias temporais sobre as trajetórias dos átomos.

O processo estocástico para gerar configurações, é implementado no método de simulação conhecido como método de Monte Carlo. Neste método, posições atômicas sucessivas são selecionadas aleatoriamente e novas configurações são geradas, de tal forma a satisfazerem a distribuição de probabilidades de Gibbs.

Todo desenvolvimento teórico feito sobre simulações computacionais é baseado na hipótese de que tanto o processo determinístico quanto o estocástico para gerar configurações são ergódicos. Isto significa que em simulações infinitamente longas, todo o espaço de configurações é visitado, ou seja, todas as configurações acessíveis pertencentes ao espaço de configurações são geradas pela simulação. Portanto, existe equivalência entre os processos, ou os dois métodos de simulação, Dinâmica Molecular e Monte Carlo. Entretanto, em simulações finitas não existe garantia de equivalência entre eles. Porém, é esperado que em simulações suficientemente longas, exista uma certa semelhança na distribuição de configurações geradas pelos dois métodos, pois regiões do espaço de configurações mais densas com trajetórias (geradas com Dinâmica Molecular) são regiões mais prováveis e, portanto, mais acessíveis na simulação com Monte Carlo.[...]

Para gerar uma boa descrição do sistema molecular, é muito importante ter um bom modelo para o potencial de interação U. (...) o potencial de interações moleculares pode ser escrito como:

$$
U(r)=\sum_{i} u_{1}\left(\vec{r}_{i}\right)+\sum_{i} \sum_{j>i} u_{2}\left(\vec{r}_{i}, \vec{r}_{j}\right)+\sum_{i} \sum_{j>i} \sum_{k>j} u_{3}\left(\vec{r}_{i}, \vec{r}_{j}, \vec{r}_{k}\right)+\ldots
$$

onde o primeiro termo do lado direito $\mathrm{u}_{1}$, é o potencial que atua em um corpo e representa o efeito de forças externas no sistema; o segundo termo, $u_{2}$, é o potencial de pares que representa a interação entre dois corpos (...) $u_{3}$ é o potencial que representa a interação entre três corpos; o termo seguinte, $u_{4}$, representa a interação entre quatro corpos e assim sucessivamente. A contribuição do potencial de quatro corpos e ordens superiores é supostamente pequena quando comparada a $u_{2} \mathrm{e}_{3}$. Portanto, em geral, os potenciais de interação são truncados em $u_{3}$. $\mathrm{O}$ termo $\mathrm{u}_{3}$ é 
indubitavelmente significante em sistemas densos; entretanto, as aproximações com potencial de pares são indiscutivelmente boas para descrever propriedades de líquidos, pois os efeitos médios de três corpos, ou muitos, podem ser parcialmente incluídos através da definição de um potencial efetivo de pares:

$$
U(r)=\sum_{i} u_{1}\left(\vec{r}_{i}\right)+\sum_{i} \sum_{j>i} u_{2}^{e f}\left(r_{i, j}\right)
$$

onde o potencial efetivo de pares representa todos os efeitos de muitos corpos. [...] Convenientemente, o potencial de pares é dividido em duas partes: intramolecular e intermolecular.[...] $\mathrm{O}$ potencial intermolecular $\mathrm{U}\left(r_{i j}\right)$ mais usado na descrição de sistemas em fase líquida é o potencial Lennard-Jones (LJ) com o potencial de Coulomb:

$$
U\left(r_{i j}\right)=4 \varepsilon_{i j}\left[\left(\frac{\sigma_{i j}}{r_{i j}}\right)^{12}-\left(\frac{\sigma_{i j}}{r_{i j}}\right)^{6}\right]+\frac{q_{i} q_{j}}{r_{i j}}
$$

onde $\varepsilon_{i j}=\sqrt{\varepsilon_{i} \varepsilon_{j}} ; \sigma_{i j}=\sqrt{\sigma_{i} \sigma_{j}}$ ou $\sigma_{i j}=\left(\sigma_{i}+\sigma_{j}\right) / 2, \varepsilon_{\mathrm{i}}$ e $\sigma_{\mathrm{i}}$ são os parâmetros LJ e q $\mathrm{q}_{\mathrm{i}}$ é a carga do sítio $i$.[...]

As propriedades termodinâmicas são obtidas conforme o ensemble escolhido. A denominação e propriedades dos ensembles dependem das grandezas macroscópicas escolhidas como invariantes, sendo que alguns exemplos são [107]:

- Microcanônico: são mantidos constantes o número de partículas, o volume e a energia dos microestados, também conhecido como NVE;

- Canônico: o número de moléculas que compõem o sistema, o volume e a temperatura são mantidos fixos. Neste ensemble, também denominado NVT, cada microestado pode trocar energia com os outros, como num banho termostático;

- Grã-canônico: cada microestado funciona como um sistema aberto, sendo que podem haver flutuações na quantidade de matéria. $\mathrm{O}$ volume, a temperatura e o potencial químico de cada microestado são invariantes, de modo que também é conhecido como ensemble $\mu V T$, ou ainda ensemble de Gibbs;

- Isotérmico e Isobárico: o número de partículas, a temperatura e a pressão são fixos, sendo que é permitido a cada microestado flutuações em seu volume, também chamado NPT.

No limite termodinâmico ( $\mathrm{N} \rightarrow \infty$ ) todos os ensembles são equivalentes, porém as simulações são feitas com sistemas finitos e por isto, para estudar certo tipo de propriedade, um ensemble pode ser vantajoso em relação a outro. Para calcular as propriedades 
termodinâmicas (observáveis) são usadas médias e flutuações das grandezas obtidas durante a simulação [107].

Os ensembles NVT e NPT são muito usados no estudo de propriedades termodinâmicas e estruturais de sistemas líquidos. A diferença da simulação do ensemble NPT em relação ao NVT, está na variação do volume, possível graças ao fato de a pressão ser constante. Durante a evolução da simulação, as moléculas são movidas e o volume é mudado aleatoriamente. A simulação feita no ensemble NPT é computacionalmente mais cara que a no NVT, pois a quantidade de números aleatórios e testes de aceitação são maiores [101]. 
3. METODOLOGIA 
As estruturas dos corantes catiônicos estudados foram otimizadas no vácuo e em meio aquoso (IEFPCM) com os métodos AM1 [114] e DFT [115-117], o que forneceu, conseqüentemente, quatro diferentes estruturas para cada corante. A seguir, foram escolhidas duas moléculas, AM e LA, para avaliar a melhor metodologia para obter os espectros de todos os corantes estudados. Para isso foram utilizados os métodos ZINDO [45-49], time-dependent Hartree-Fock (TD-HF) e time-dependent Density Functional Theory (TD-DFT) [118-120], no vácuo e em meio aquoso (IEFPCM). No caso do corante SF, foi realizado também um estudo da rotação do anel fenílico utilizando os métodos AM1 e ZINDO.

O estudo da diprotonação dos corantes catiônicos foi realizado seguindo a melhor metodologia definida no estudo dos corantes monoprotonados: foi utilizado o método DFT para a otimização das geometrias em meio aquoso (com o método IEFPCM) e o espectro de absorção foi calculado com o método ZINDO. Para este estudo, inicialmente, foram calculados os mapas de potencial eletrostático (MEP) para os corantes monoprotonados, com o programa Spartan [123]. A seguir, foram propostas estruturas que correspondem à estrutura monoprotonada com um átomo de $\mathrm{H}$ ligado a um dos átomos de N. Por exemplo, uma das estruturas propostas para a diprotonação do $\mathrm{AM}$ é resultado da ligação de um $\mathrm{H}$ a um N alifático ( $\mathrm{N}$ da amina terciária, $\mathrm{N}_{\mathrm{t}}$ ) e a outra estrutura é resultante da ligação do $\mathrm{H}$ com o $\mathrm{N}$ do anel central ( $\mathrm{N}$ do anel central, $\mathrm{N}_{\mathrm{a}}$ ). As mesmas estruturas podem ser propostas para a $\mathrm{TN}$, porém, o $\mathrm{N}$ alifático não é uma amina terciária, mas uma primária $\left(\mathrm{N}_{\mathrm{p}}\right)$. A LA e a PF apresentam apenas um átomo de $\mathrm{N}$ que poderia ser protonado, um $\mathrm{N}$ alifático $\left(\mathrm{N}_{\mathrm{t}}\right.$ para a LA e $\mathrm{N}_{\mathrm{p}}$ para a $\mathrm{PF}$ ) pois o $\mathrm{N}$ do anel já se encontra protonado quando o corante se encontra na forma monoprotonada. No caso do $\mathrm{VN}$, são propostas três estruturas, pois este corante 
apresenta três nitrogênios distintos: $N_{t}, N_{p}$ e $N_{a}$, enquanto para a SF tem um $N_{p}$ e um $N_{a}$ que podem ser protonados.

Para o estudo dos dímeros, foram avaliadas as estruturas cristalográficas encontradas no Cambridge Structural Database [124] para AM, LA e PF, uma vez que não foi possível obter estruturas para os dímeros pela otimização direta (o método AM1 distancia os monômeros e os cálculos DFT/B3LYP não convergiram; como a energia de interação entre os monômeros para formar o dímero é muito pequena, seria necessário testar se os métodos com alto grau de correlação eletrônica, mas computacionalmente mais custosos, conseguiriam fornecer estruturas para os dímeros). Dos cristais, foram retirados dímeros dos tipos sanduíche e co-planar e então calculada a energia total com o método DFT e o espectro de absorção com o método ZINDO no vácuo e em meio aquoso (simulada com o método IEFPCM).

No método IEFPCM a cavidade é obtida pela sobreposição de esferas centradas nos átomos (ou grupo de átomos no caso de $\mathrm{CH}, \mathrm{CH}_{2}$ e $\mathrm{CH}_{3}$ ) e definida em termos do raio de van der Waals [121] multiplicado por um fator $=1,2$, que demonstrou reproduzir adequadamente as interações para uma série de solutos com água [122]. Os raios utilizados são apresentados na Tabela 2.

Tabela 2. Raios (em $\AA$ ) das esferas utilizadas na construção das cavidades dos corantes catiônicos estudados

\begin{tabular}{|l|c|c|c|c|c|c|}
\hline Átomo/grupo & $\mathrm{CH}_{3}$ & $\mathrm{CH}$ & $\mathrm{C}$ & $\mathrm{N}$ & $\mathrm{S}$ & $\mathrm{H}$ (ligado a N) \\
\hline Raio & 2,40 & 2,28 & 2,04 & 1,92 & 2,16 & 1,44 \\
\hline
\end{tabular}

Foram calculadas as cargas atômicas de Mulliken num cálculo single point com o método AM1 para dois tipos de clusters da argila montmorilonita: $\mathrm{Si}_{16} \mathrm{Al}_{6} \mathrm{Mg}_{2} \mathrm{O}_{48} \mathrm{H}_{16}$ e $\mathrm{Si}_{30} \mathrm{O}_{47} \mathrm{H}_{44}$. A seguir, foram otimizados clusters formados pela argila montmorilonita (com a estrutura $\mathrm{Si}_{30} \mathrm{O}_{47} \mathrm{H}_{44}$ ) e cada um dos corantes. Foram utilizadas as estruturas dos corantes 
previamente otimizadas com DFT/IEFPCM. Para a SF foram utilizadas duas estruturas diferentes: uma obtida pela otimização sem restrições com DFT/IEFPCM e outra obtida com o ângulo entre o anel e o plano dos três anéis fundidos fixo em $20^{\circ}$. Os sete clusters foram, então, otimizados utilizando o método AM1.

Os cálculos de química quântica foram realizados utilizando o pacote computacional Gaussian 03 [125], mas os cálculos semi-empíricos (AM1 e ZINDO) só puderam ser realizados em conjunto com o método IEFPCM utilizando a versão do Gaussian 03 de desenvolvimento do grupo do Prof. J. Tomasi [126], uma vez que esta combinação (métodos semi-empíricos + IEFPCM [127]) ainda não estava disponível comercialmente. Os cálculos HF foram realizados com a base 6-31+G(d) e os cálculos DFT com o funcional B3LYP [128130] e a base $6-31+\mathrm{G}(\mathrm{d})$.

Foram realizadas simulações de MC no ensemble NVT para os monômeros de AM, TN e LA, e para algumas conformações de dímeros de AM em água, com o programa desenvolvido por R. S. Neves [para maiores detalhes sobre o programa vide referência 107]. Foi utilizado o potencial Lennard-Jones (LJ) com os parâmetros de van der Waals retirados do artigo "A Second Generation Force Field for the Simulation of Proteins, Nucleic Acids, and Organic Molecules” [131] e o modelo TIP4P [132] para as moléculas de água.

Foram construídos dois potenciais para o corante AM com base nas posições e nas cargas atômicas (derivadas do potencial eletrostático [133]) obtidas por duas metodologias: com o método AM1 no vácuo e com DFT em meio aquoso (IEFPCM-DFT). Em ambos os casos, a simulação foi realizada para uma molécula de soluto e 1000 de água; a termalização foi realizada em 10 mil ciclos (cada ciclo corresponde à movimentação de todas as moléculas do sistema), a produção em 55 mil ciclos e foi aplicado um raio de corte esférico de $15 \AA$ ao potencial de interação. O espectro do soluto (monômero) e da primeira camada de solvatação 
das configurações com baixo grau de correlação estatística foi obtido com o programa ZINDO e, então, calculado o máximo de absorção médio.

Tendo em vista os resultados obtidos com os dois potenciais construídos para o AM, foram construídos os potenciais para os corantes TN e LA com base nas geometrias obtidas com DFT em meio aquoso (IEFPCM). As simulações para esses monômeros foram realizadas com 1000 moléculas de água; a termalização foi realizada em 10 mil ciclos, a produção em 60 mil ciclos e foi aplicado um raio de corte esférico de $15 \AA$ ao potencial de interação. O espectro do soluto (monômero) e da primeira camada de solvatação das configurações com baixo grau de correlação estatística foi obtido com o método ZINDO para obter o máximo de absorção médio para cada corante.

Já no caso do dímero de AM, foram realizadas duas simulações chamadas de:

(a) "caixa pequena", ou seja, duas moléculas de soluto com 1000 moléculas de água, a termalização realizada em 20 mil ciclos e a produção em 100 mil ciclos.

(b) “caixa grande”, em que foram incluídas 2000 moléculas de água para evitar que o tamanho da caixa estivesse restringindo o movimento de um monômero em relação ao outro. Nesse caso, a termalização foi realizada em 50 mil ciclos e a produção em 200 mil ciclos. 
4. RESULTADOS E DISCUSSÃO 


\subsection{Estudo dos monômeros dos corantes catiônicos}

\subsubsection{Efeito do solvente na geometria e no espectro dos corantes catiônicos utilizando o modelo contínuo (IEFPCM)}

O estudo das moléculas monoprotonadas, iniciado no mestrado [2], foi ampliado no estágio realizado no grupo do Prof. Tomasi e da Prof ${ }^{\mathrm{a}}$. Mennucci [134].

As otimizações realizadas com AM1 e DFT forneceram estruturas planares para todos os corantes estudados, com exceção da SF, cujo anel fenílico se encontra perpendicular ao plano do restante da molécula (o plano xy na Figura 1 foi adotado como plano molecular). Na Seção 4.1.2 é apresentado um estudo mais detalhado sobre a rotação deste anel fenílico.

Os diferentes métodos forneceram geometrias muito semelhantes, com apenas pequenas diferenças, que aparecem principalmente ao redor do heteroátomo do anel central. A Tabela 3 apresenta alguns parâmetros geométricos para essa região dos corantes: o comprimento de ligação entre o heteroátomo $(\mathrm{X})$ e um átomo de carbono $(\mathrm{X}=\mathrm{S}$ para $\mathrm{AM}$ e $\mathrm{TN}, \mathrm{X}=\mathrm{N}$ para os demais corantes), a distância entre os dois carbonos ligados ao heteroátomo e o ângulo formado entre esses dois carbonos e o heteroátomo (C-X-C).

As estruturas obtidas em meio aquoso têm ângulo C-X-C menor do que as respectivas estruturas obtidas no vácuo, com exceção da SF cujo ângulo se torna maior quando otimizada em meio aquoso. Quando o ângulo C-X-C se torna menor, o heteroátomo fica mais exposto ao solvente, o que aumenta a interação heteroátomo-solvente e a estabilização do soluto. A SF é 
a única exceção porque, neste caso, um anel fenílico está ligado ao heteroátomo, o que torna esta região da molécula mais hidrofóbica.

Tabela 3. Parâmetros geométricos para os corantes catiônicos estudados obtidos no vácuo (v) e em meio aquoso (s)

\begin{tabular}{|c|c|c|c|c|}
\hline Corante & Geometria & $\mathbf{C}-\mathbf{X} *(\AA)$ & C--C (̊) & $\mathrm{C}-\mathrm{X}-\mathrm{C}\left(^{0}\right)$ \\
\hline \multirow[t]{4}{*}{$\mathrm{AM}$} & AM1 & 1,66 & 2,63 & 104,9 \\
\hline & AM1 (s) & 1,65 & 2,61 & 104,8 \\
\hline & DFT & 1,82 & 2,82 & 103,2 \\
\hline & DFT & 1,75 & 2,77 & 102,1 \\
\hline \multirow[t]{4}{*}{ LA } & AM1 (v) & 1,39 & 2,43 & 122,3 \\
\hline & AM1 (s) & 1,38 & 2,42 & 122,0 \\
\hline & DFT $\quad(v)$ & 1,38 & 2,44 & 125,1 \\
\hline & DFT $\quad(s)$ & 1,37 & 2,44 & 124,9 \\
\hline \multirow[t]{4}{*}{$\mathrm{TN}$} & AM1 (v) & 1,66 & 2,63 & 104,9 \\
\hline & AM1 (s) & 1,65 & 2,62 & 104,8 \\
\hline & DFT & 1,75 & 2,74 & 103,3 \\
\hline & DFT & 1,75 & 2,74 & 103,2 \\
\hline \multirow[t]{4}{*}{$\mathrm{PF}$} & AM1 (v) & 1,38 & 2,42 & 122,2 \\
\hline & AM1 (s) & 1,38 & 2,42 & 122,0 \\
\hline & DFT $\quad(v)$ & 1,38 & 2,44 & 125,1 \\
\hline & DFT & 1,37 & 2,44 & 124,9 \\
\hline \multirow[t]{4}{*}{ VN } & AM1 (v) & 1,38 & 2,41 & 121,0 \\
\hline & AM1 (s) & 1,38 & 2,40 & 120,9 \\
\hline & DFT & 1,37 & 2,42 & 123,4 \\
\hline & DFT & 1,37 & 2,41 & 123,3 \\
\hline \multirow[t]{4}{*}{ SF } & AM1 & 1,39 & 2,41 & 120,2 \\
\hline & AM1 (s) & 1,39 & 2,41 & 120,4 \\
\hline & DFT & 1,38 & 2,41 & 121,1 \\
\hline & DFT & 1,38 & 2,41 & 121,2 \\
\hline
\end{tabular}


Foram realizados cálculos das energias de excitação com três diferentes métodos, TDHF, TD-DFT e ZINDO para AM e LA com o intuito de escolher a melhor metodologia a ser aplicada a todos os corantes estudados. Foram calculadas as energias de excitação no vácuo e em meio aquoso para cada uma das quatro estruturas obtidas anteriormente. Na Tabela 4 são apresentados os comprimentos de onda $(\lambda)$ obtidos e o erro (\%) em relação aos valores experimentais medidos em meio aquoso.

Os $\lambda$ calculados apresentam erro de aproximadamente $35 \%$ para AM e LA quando calculados com TD-HF, 20\% para AM e 10\% para LA com TD-DFT e inferior a $10 \%$ para os dois corantes com ZINDO. Incluindo o solvente nos cálculos, o erro no $\lambda$ calculado diminui em 5\% para o TD-HF e ZINDO e em 2\% para o TD-DFT. Para os dois corantes, o melhor resultado foi obtido com o IEFPCM-ZINDO utilizando as geometrias obtidas em meio aquoso com DFT. Dessa forma, foram escolhidos o ZINDO e as geometrias DFT como metodologia para estudar o espectro dos outros corantes no vácuo e em meio aquoso (Tabela 5).

Como observado para o AM e a LA, os resultados obtidos com IEFPCM-ZINDO apresentam erro em relação aos resultados experimentais menor do que o erro do espectro calculado no vácuo; somente para o VN o erro cresce ligeiramente quando calculado em meio aquoso. Um resumo dos resultados obtidos com ZINDO para todos os corantes é apresentado na forma de gráfico na Figura 5, junto com os valores experimentais correspondentes. 
Tabela 4. Comprimento de onda de absorção $(\lambda$, em $\mathrm{nm}$ ) para o AM e para a LA calculado com TD-HF, TD-DFT e ZINDO no vácuo (v) e em meio aquoso (s) para quatro diferentes geometrias

\begin{tabular}{|c|c|c|c|c|c|}
\hline \multirow[b]{2}{*}{ Geometria } & \multirow[b]{2}{*}{ Espectro } & \multicolumn{2}{|c|}{$\mathbf{A M}$} & \multicolumn{2}{|c|}{ LA } \\
\hline & & $\lambda(\mathbf{n m})$ & erro* $(\%)$ & $\lambda(\mathbf{n m})$ & erro* $(\%)$ \\
\hline \multirow[t]{6}{*}{ AM1(v) } & ZINDO (v) & 581 & 13 & 455 & 7 \\
\hline & ZINDO (s) & 640 & 4 & 457 & 7 \\
\hline & TD-HF (v) & 424 & 36 & 335 & 32 \\
\hline & TD-HF (s) & 448 & 33 & 338 & 31 \\
\hline & TD-DFT (v) & 512 & 23 & 441 & 10 \\
\hline & TD-DFT (s) & 541 & 19 & 451 & 8 \\
\hline \multirow[t]{6}{*}{ AM1 (s) } & ZINDO (v) & 579 & 13 & 454 & 7 \\
\hline & ZINDO (s) & 636 & 4 & 454 & 7 \\
\hline & TD-HF (v) & 421 & 37 & 334 & 32 \\
\hline & TD-HF (s) & 444 & 33 & 336 & 31 \\
\hline & TD-DFT (v) & 514 & 23 & 442 & 10 \\
\hline & TD-DFT (s) & 542 & 18 & 452 & 8 \\
\hline \multirow[t]{6}{*}{ DFT (v) } & ZINDO (v) & 590 & 11 & 453 & 8 \\
\hline & ZINDO (s) & 663 & 0,3 & 456 & 7 \\
\hline & TD-HF (v) & 443 & 33 & 333 & 32 \\
\hline & TD-HF (s) & 476 & 28 & 337 & 31 \\
\hline & TD-DFT (v) & 504 & 24 & 432 & 12 \\
\hline & TD-DFT (s) & 537 & 19 & 444 & 9 \\
\hline \multirow[t]{6}{*}{ DFT (s) } & ZINDO (v) & 583 & 12 & 452 & 8 \\
\hline & ZINDO (s) & 651 & 2 & 455 & 7 \\
\hline & TD-HF (v) & 433 & 35 & 332 & 32 \\
\hline & TD-HF (s) & 463 & 30 & 336 & 31 \\
\hline & TD-DFT (v) & 501 & 25 & 433 & 12 \\
\hline & TD-DFT (s) & 532 & 20 & 444 & 9 \\
\hline
\end{tabular}

* Diferença entre o $\lambda$ calculado e experimental (665 nm para AM e 490nm para LA). 
Tabela 5. Comprimento de onda de absorção ( $\lambda$, em nm, obtido com o ZINDO) para PF, TN, VN e SF calculado no vácuo (v) e em meio aquoso (s) para as duas diferentes geometrias obtidas com DFT

\begin{tabular}{|c|c|c|c|c|c|}
\hline Corante & Geometria & Espectro & $\lambda(\mathrm{nm})$ & erro* $(\%)$ & $\lambda_{\exp }(\mathrm{nm})$ \\
\hline \multirow[t]{4}{*}{$\mathrm{PF}$} & $\mathrm{V}$ & $\mathrm{v}$ & 429 & 4 & 445 \\
\hline & $\mathrm{v}$ & $\mathrm{s}$ & 442 & 1 & \\
\hline & $\mathrm{s}$ & $\mathrm{v}$ & 429 & 4 & \\
\hline & $\mathrm{s}$ & $\mathrm{s}$ & 442 & 1 & \\
\hline \multirow[t]{4}{*}{$\mathrm{TN}$} & $\mathrm{V}$ & $\mathrm{v}$ & 550 & 8 & 600 \\
\hline & $\mathrm{v}$ & $\mathrm{s}$ & 628 & 5 & \\
\hline & $\mathrm{s}$ & $\mathrm{v}$ & 552 & 8 & \\
\hline & $\mathrm{s}$ & $\mathrm{s}$ & 631 & 5 & \\
\hline \multirow[t]{4}{*}{ VN } & $\mathrm{v}$ & $\mathrm{v}$ & 520 & 3 & 535 \\
\hline & $\mathrm{v}$ & $\mathrm{s}$ & 555 & 4 & \\
\hline & $\mathrm{s}$ & $\mathrm{v}$ & 520 & 3 & \\
\hline & $\mathrm{S}$ & $\mathrm{s}$ & 555 & 4 & \\
\hline \multirow[t]{4}{*}{$\mathrm{SF}$} & $\mathrm{v}$ & $\mathrm{v}$ & 504 & 5 & 530 \\
\hline & $\mathrm{v}$ & $\mathrm{s}$ & 551 & 4 & \\
\hline & $\mathrm{s}$ & $\mathrm{v}$ & 505 & 5 & \\
\hline & $\mathrm{s}$ & $\mathrm{s}$ & 554 & 5 & \\
\hline
\end{tabular}

* Diferença entre o $\lambda$ calculado e experimental (vide Tabela 1).

As duas diazinas (VN e SF) têm máximos de absorção experimentais em comprimentos de onda muito próximos, enquanto nas outras duas classes de corantes, os corantes menores (TN e PF) têm máximos de absorção experimentais deslocados em cerca de $50 \mathrm{~nm}$ em relação aos outros membros da classe (AM e LA, respectivamente). A principal diferença entre os membros dessas duas classes é a substituição dos grupos $\mathrm{CH}_{3}$ no $\mathrm{AM}$ e na LA por átomos $\mathrm{H}$ na $\mathrm{TN}$ e na $\mathrm{PF}$, respectivamente. Os dados apresentados na Figura 5 demonstram que essa substituição tem efeito muito menor nos comprimentos de absorção 
calculados do que nos experimentais. Para procurar explicar essa diferença de comportamento, foram analisados os orbitais moleculares que mais contribuem para a transição eletrônica, ou seja, o HOMO e o LUMO. A representação gráfica desses orbitais (Figura 6) mostra que os grupos metila do AM e da LA têm uma pequena contribuição tanto ao HOMO quanto ao LUMO. Provavelmente, a diferença observada experimentalmente é devida à diferente solvatação dos grupos metila nas moléculas maiores em relação àquela dos átomos de hidrogênio nas moléculas menores.

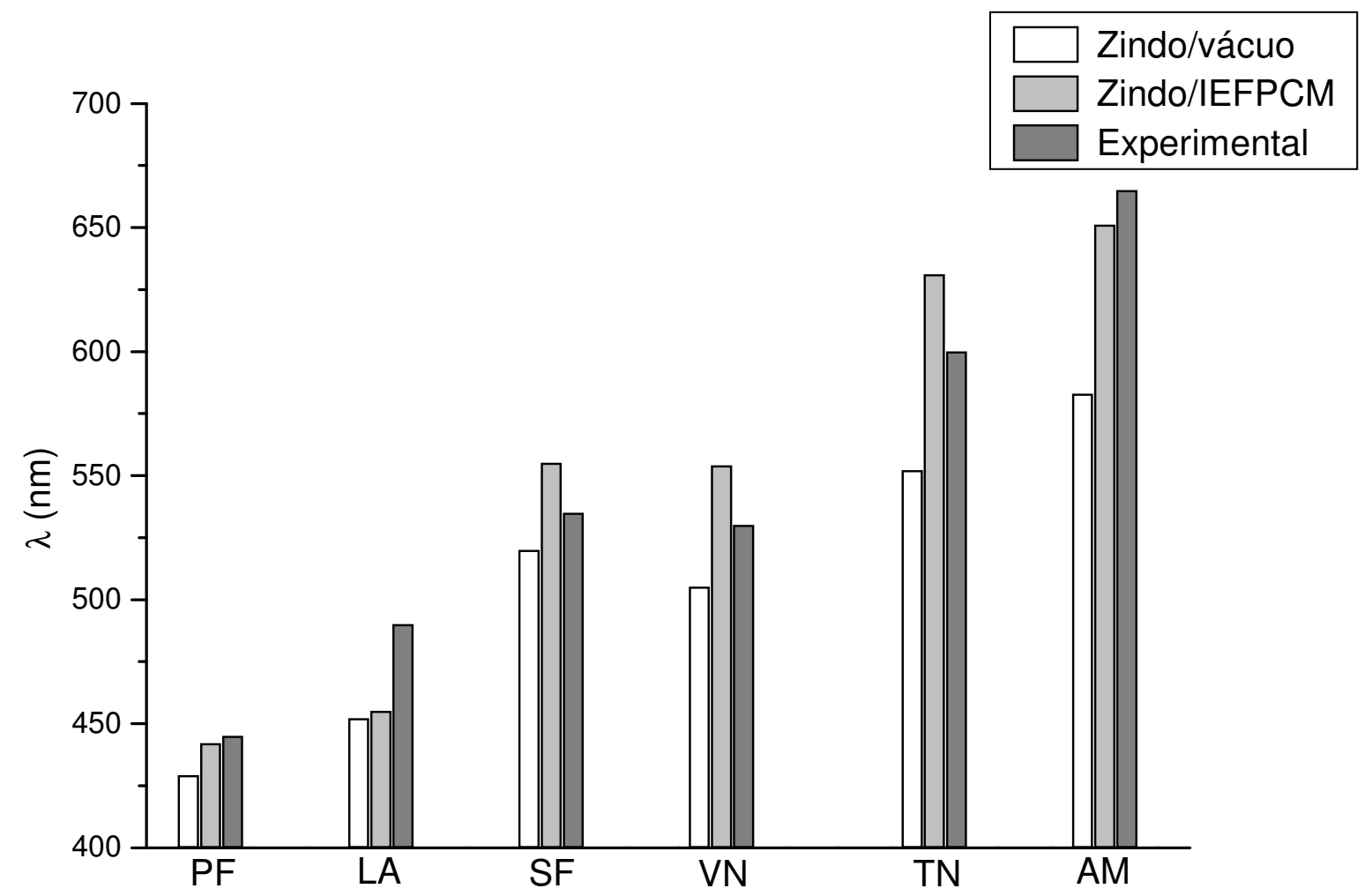

Figura 5. Máximos de absorção experimental e teórico (em $\mathrm{nm}$ ) para os corantes catiônicos estudados. 

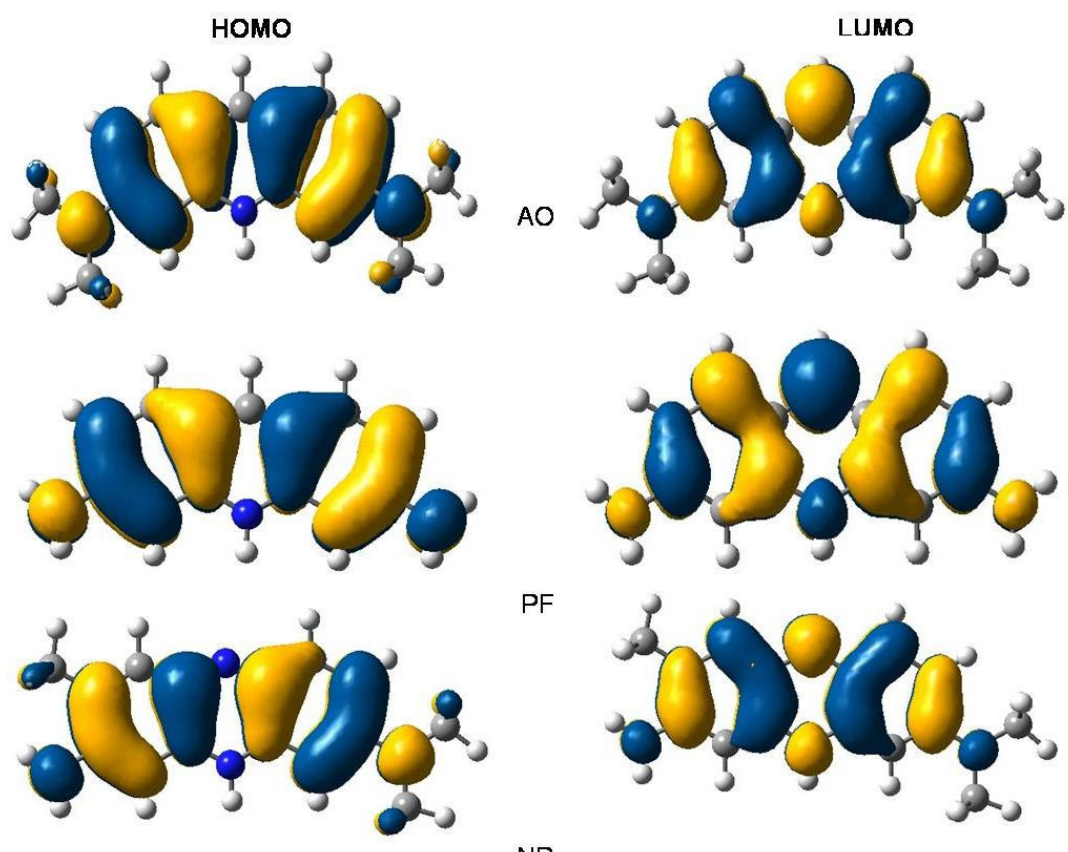

$\mathrm{PF}$
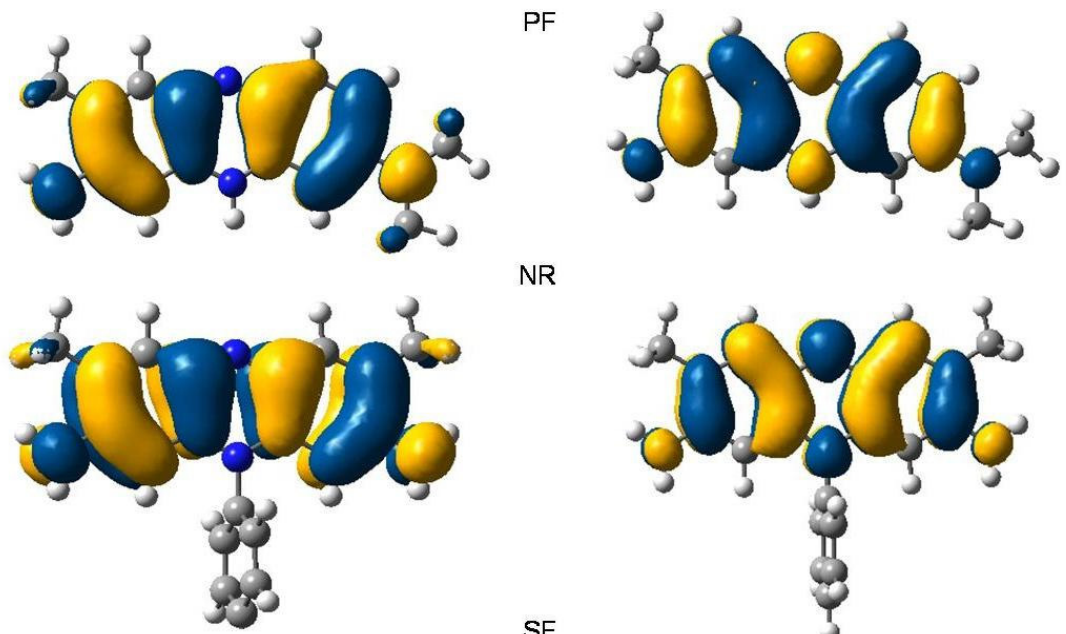

$N R$
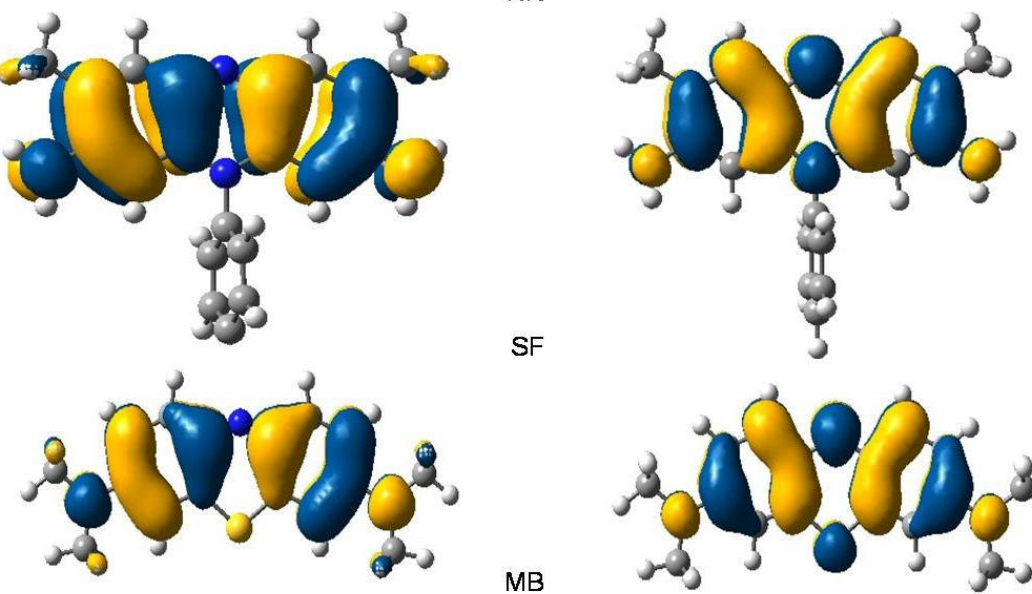

SF
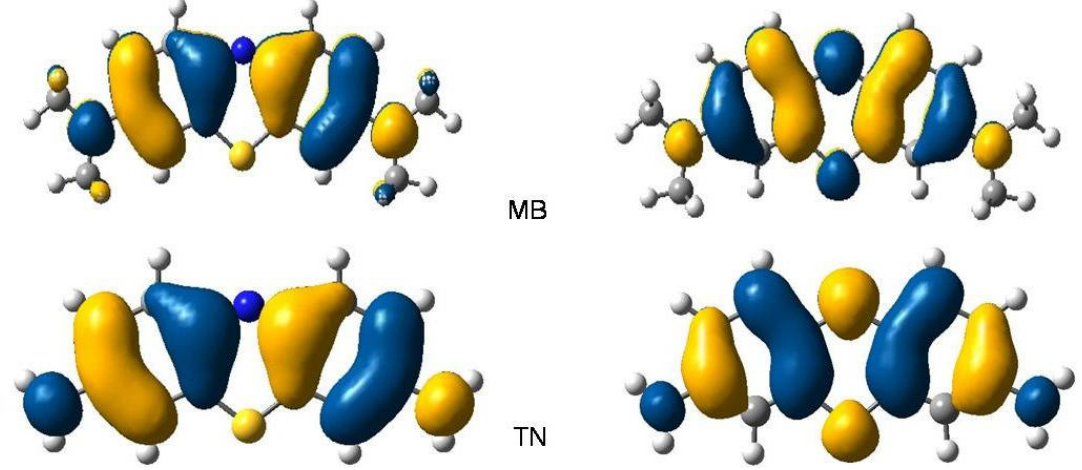

Figura 6. Representação gráfica dos orbitais moleculares HOMO e LUMO para os corantes catiônicos estudados.

Foram realizados, então, cálculos considerando duas moléculas de água de forma discreta para dois corantes, AM e TN, respectivamente o membro maior e o menor da família dos corantes tiazínicos. A Figura 7 apresenta as estruturas propostas para esses clusters dos corantes com duas moléculas de solvente (água). As moléculas de água foram colocadas 
próximas aos grupos alifáticos de cada corante, pois é esta a região que os diferencia. Os clusters foram otimizados no vácuo com o funcional B3LYP e a base 6-31+G(d). Foram, então, calculados os espectros com o método ZINDO no vácuo e em meio aquoso utilizando o método IEFPCM.

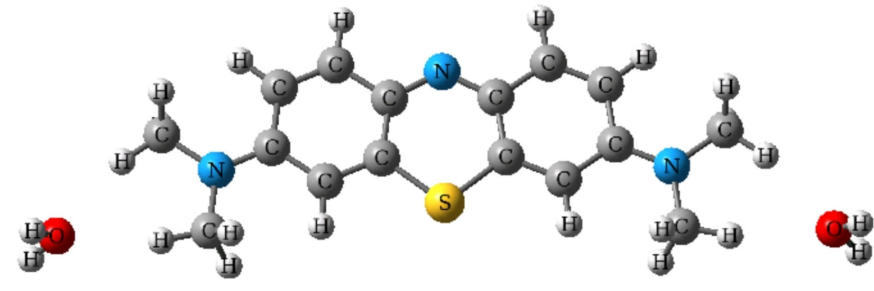

(a)

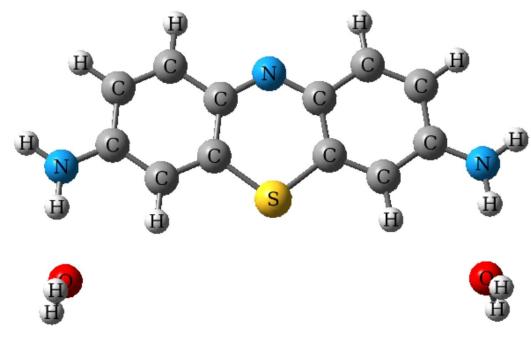

(b)

Figura 7. Estruturas dos clusters (a) $\mathrm{MB}+2 \mathrm{H}_{2} \mathrm{O}$ e (b) $\mathrm{TN}+2 \mathrm{H}_{2} \mathrm{O}$.

A distância entre o átomo de oxigênio da água e o átomo de hidrogênio do corante mais próximo à molécula de água é de 2,31 Å para o AM e de 1,87 para a TN, indicando que há uma maior interação entre o solvente e o corante no segundo caso. Na Tabela 6 são comparados os valores obtidos com o ZINDO no vácuo e em meio aquoso (simulada com IEFPCM) para os corantes AM e TN otimizados em solvente considerado de forma contínua $\left(\mathrm{AM}+\mathrm{IEFPCM}\right.$ e TN + IEFPCM) e no vácuo com duas moléculas de água $\left(\mathrm{AM}+2 \mathrm{H}_{2} \mathrm{O}\right.$ e $\left.\mathrm{TN}+2 \mathrm{H}_{2} \mathrm{O}\right)$

Observa-se que há uma maior aproximação das moléculas de água à TN do que ao AM, porém os comprimentos de onda obtidos para os clusters propostos, quando comparados aos valores obtidos sem as moléculas de água, indicam que os efeitos das ligações hidrogênio não explicam as diferenças entre os dois membros da família. Pelo contrário, essa interação torna os sistemas ainda mais similares. 
Tabela 6. Comprimento de onda do máximo $(\lambda$, em nm) teórico obtido para os corantes AM e TN

\begin{tabular}{lcc}
\hline \multicolumn{1}{c}{ Geometria } & Espectro & $\lambda(\mathbf{n m})$ \\
\hline $\mathrm{AM}+\mathrm{IEFPCM}$ & ZINDO (vácuo) & 583 \\
& ZINDO (IEFPCM) & 651 \\
$\mathrm{AM}+2 \mathrm{H}_{2} \mathrm{O}$ & ZINDO (vácuo) & 585 \\
& ZINDO (IEFPCM) & 654 \\
$\mathrm{TN}+\mathrm{IEFPCM}$ & ZINDO (vácuo) & 552 \\
$\mathrm{TN}+2 \mathrm{H}_{2} \mathrm{O}$ & ZINDO (IEFPCM) & 631 \\
& ZINDO (vácuo) & 556 \\
& ZINDO (IEFPCM) & 632 \\
\hline
\end{tabular}

$\mathrm{Na}$ Tabela 7 , são apresentados o deslocamento das energias de excitação $\left(\Delta \varepsilon_{\text {solv }}\right)$ calculadas em meio aquoso em relação às calculadas no vácuo e os momentos de transição calculados no vácuo e em meio aquoso. Todos os valores apresentados nessa tabela foram calculados com ZINDO para as geometrias obtidas com DFT.

O maior deslocamento foi encontrado para as tiazinas $\left(\Delta \varepsilon_{\mathrm{solv}}=0,29 \mathrm{eV}\right.$ para a TN e 0,20 eV para o AM), enquanto as acridinas apresentaram menor variação (menor que 0,10 eV); as diazinas, VN e SF, apresentaram um deslocamento intermediário, 0,15 e 0,22 eV, respectivamente.

O efeito do solvente nos espectros de absorção pode ainda ser avaliado em termos dos momentos de transição. Devido à natureza das transições eletrônicas consideradas aqui, os momentos de transição se posicionam ao longo do eixo $\mathrm{x}\left(\mu_{\mathrm{x}}\right.$ na Tabela 7), exceto para o VN que apresenta uma pequena contribuição ao longo do eixo y (em torno de -0,6 u.a.). A direção do momento de transição aliada à análise da representação gráfica do HOMO e do LUMO (Figura 6) indica que a transição eletrônica ocorre ao longo do eixo x. A assimetria do VN em 
relação ao eixo y explica a presença de uma pequena componente do momento de transição nesta direção.

Tabela 7. Diferença entre as energias de excitação $\left(\Delta \varepsilon_{\text {solv }}\right.$, em eV) e momentos de dipolo $\left(\mu_{\mathrm{x}}\right.$, em u.a.) calculados com ZINDO no vácuo (v) e em meio aquoso (s). As geometrias utilizadas foram obtidas com DFT

\begin{tabular}{|c|c|c|c|}
\hline Corante & Fase & $\Delta \varepsilon_{\text {solv }}$ & $\mu_{\mathrm{x}}$ \\
\hline \multirow[t]{2}{*}{$\mathrm{AM}$} & $\mathrm{V}$ & --- & 5,09 \\
\hline & $\mathrm{s}$ & 0,20 & 5,17 \\
\hline \multirow[t]{2}{*}{ LA } & $\mathrm{v}$ & --- & 3,89 \\
\hline & $\mathrm{s}$ & 0,01 & 3,97 \\
\hline \multirow[t]{2}{*}{$\mathrm{PF}$} & $\mathrm{v}$ & --- & 3,59 \\
\hline & $\mathrm{s}$ & 0,08 & 3,80 \\
\hline \multirow[t]{2}{*}{$\mathrm{TN}$} & $\mathrm{v}$ & --- & 4,65 \\
\hline & $\mathrm{s}$ & 0,29 & 4,95 \\
\hline \multirow[t]{2}{*}{ VN } & $\mathrm{v}$ & --- & 4,17 \\
\hline & $\mathrm{s}$ & 0,15 & 4,37 \\
\hline \multirow[t]{2}{*}{ SF } & $\mathrm{v}$ & --- & 4,03 \\
\hline & s & 0,22 & 4,38 \\
\hline
\end{tabular}

Comparando os valores obtidos no vácuo e em meio aquoso, $\mu_{\mathrm{x}}$ apresenta um aumento de 0,1 para LA, 0,15 para AM, 0,2 para PF e VN, 0,30 para TN e 0,35 para SF. Os membros das classes que apresentam $-\mathrm{NH}_{2}$ ligados aos anéis no lugar de $\mathrm{N}\left(\mathrm{CH}_{3}\right)_{2}$, sofrem maior influência do solvente sobre os momentos de transição. Este efeito é devido à maior hidrofilicidade do $\mathrm{NH}_{2}$ em relação ao $\mathrm{N}\left(\mathrm{CH}_{3}\right)_{2}$, o que se reflete numa maior interação com o solvente. Entretanto, as variações encontradas nos momentos de dipolo não reproduzem exatamente o comportamento do deslocamento das energias de excitação: enquanto o maior $\Delta \mu$ é encontrado para a SF, o maior $\Delta \varepsilon_{\text {solv }}$ encontrado para a TN. 


\subsubsection{Rotação do anel fenílico da SF}

Na seção anterior, foram utilizados diversos métodos para a otimização da geometria dos corantes e, no caso da SF, verificou-se que o ângulo formado entre o plano do anel fenílico e o plano que abrange o restante da molécula é de cerca de $90^{\circ}$ para todos os métodos utilizados. Entretanto, Sakata e Hara [135] realizaram um estudo sobre a torsão do 9fenilantraceno (que é uma molécula muito semelhante à safranina mas sem heteroátomos) propriedade essa que pode ser importante nas reações com essa molécula. Os autores utilizaram o método de HF para obter a geometria do estado fundamental e CASSCF/MCQDPT para obter os potenciais de torsão entre o grupo fenílico e o antraceno (ângulo $\alpha$, formado entre o Ca, C9, C1' e C2', na Figura 8) para o estado fundamental e excitado. Para o estado fundamental, encontraram o mínimo de energia em que o ângulo $\alpha$ é de $90^{\circ}$, enquanto para o estado excitado foram encontrados dois mínimos, em $60^{\circ}$ e $120^{\circ}$ (que são equivalentes, uma vez que a molécula é simétrica).

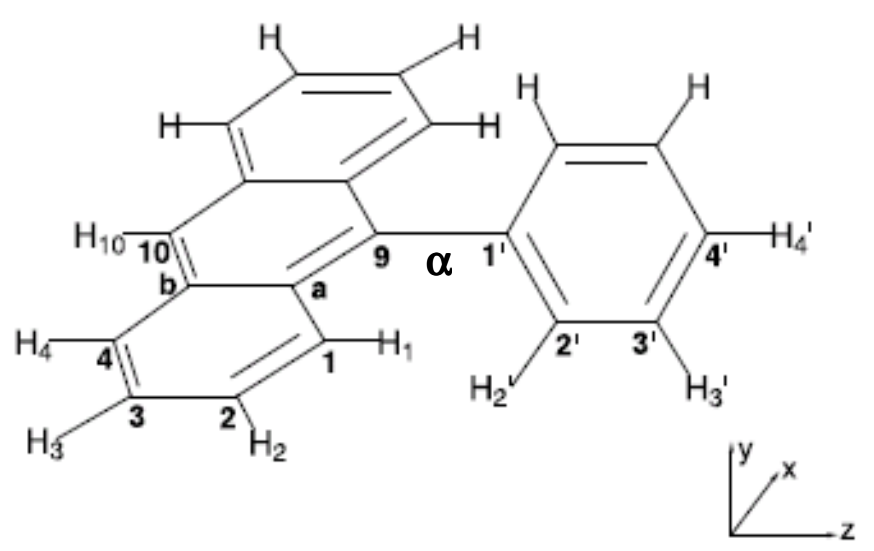

Figura 8. Estrutura e numeração adotada para o 9-fenilantraceno [135]. 
Tendo em vista a importância deste ângulo diedro, foram realizados cálculos para diversas conformações da safranina, com os métodos já utilizados nos cálculos anteriores, AM1 e ZINDO.

A geometria da SF foi reotimizada com o método AM1, mantendo-se fixo o ângulo diedro formado entre o plano do anel fenílico e o plano que compreende o restante da molécula (que também será chamado de $\alpha$ ) para os seguintes valores: $10^{\circ}, 20^{\circ}, 30^{\circ}, 40^{\circ}, 50^{\circ}$, $60^{\circ}, 70^{\circ}, 80^{\circ}$ e $90^{\circ}$. Como a molécula é simétrica em relação ao eixo y, não é necessário realizar o cálculo para ângulos maiores que $90^{\circ}$ (vide Figura 1). A seguir, para cada geometria obtida, foi calculado o espectro com o método ZINDO.

A Tabela 8 apresenta os valores de energia total para as moléculas otimizadas $\left(\mathrm{E}_{\mathrm{T}}\right.$ AM1) os resultados dos cálculos com o método ZINDO: os comprimentos de onda de absorção, as forças do oscilador correspondentes e a energia do estado excitado para cada conformação.

Embora as diferenças de energia sejam pequenas, no estado fundamental, a geometria de menor valor $\mathrm{E}_{\mathrm{T}}$, sendo assim a mais estável, é a conformação com $\alpha=80^{\circ}$ e, nesta conformação, os três anéis fundidos são planares. Já no estado excitado, é a conformação com $\alpha=10^{\circ}$, que apresenta a menor $\mathrm{E}_{\mathrm{T}}$, mas o primeiro estado excitado apresenta força do oscilador muito pequena. Dentre as conformações que apresentam o $1^{\circ}$ estado excitado como a transição mais intensa, é a conformação com $\alpha=70^{\circ}$ que apresenta a menor $\mathrm{E}_{\mathrm{T}}$. Com exceção do ângulo $\alpha$, há poucas diferenças estruturais entre as conformações com $\alpha=50^{\circ}$ a $90^{\circ}$, sendo que os anéis fundidos são planares. Porém, nas outras conformações, em que $10^{\circ} \leq \alpha \leq 40^{\circ}$, os anéis fundidos estão ligeiramente torcidos. Na Figura 9 é possível visualizar essa deformação na estrutura $\operatorname{com} \alpha=30^{\circ}$. 
Tabela 8. Comprimento de absorção $(\lambda$, em $\mathrm{nm}$ ), força do oscilador (f) e energia total do estado excitado ( $\mathrm{E}_{\mathrm{T}}$ ZINDO, em u.a.) obtidos com o método ZINDO para as várias conformações da SF

\begin{tabular}{ccccccc}
\hline $\boldsymbol{\alpha}$ & $\begin{array}{c}\mathbf{E}_{\mathbf{T}} \mathbf{A M 1} \\
(\mathbf{u . a .})\end{array}$ & $\begin{array}{c}\Delta \mathbf{E}_{\mathbf{T}} \mathbf{A M 1} \\
\left(\mathbf{k c a l . m o l} \mathbf{- 1}^{*}\right)^{*}\end{array}$ & $\begin{array}{c}\mathbf{E}_{\mathbf{T}} \mathbf{Z I N D O} \\
(\mathbf{u . a .})\end{array}$ & $\begin{array}{c}\Delta \mathbf{E}_{\mathbf{T}} \mathbf{Z I N D O} \\
\left(\mathbf{k c a l . m o l}^{-\mathbf{1}}\right)^{*}\end{array}$ & $\boldsymbol{\lambda}(\mathbf{n m})$ & $\mathbf{f}$ \\
\hline $10^{\circ}$ & 0,6185 & 145,17 & $-160,8310$ & $-128,99$ & 566 & 0,05 \\
& & & & & $535^{* *}$ & $0,76^{* * *}$ \\
$20^{\circ}$ & 0,4034 & 10,28 & $-160,6026$ & 14,23 & 542 & 0,86 \\
$30^{\circ}$ & 0,3971 & 6,33 & $-160,6102$ & 9,47 & 532 & 0,88 \\
$40^{\circ}$ & 0,3925 & 3,45 & $-160,6164$ & 5,58 & 524 & 0,90 \\
$50^{\circ}$ & 0,3897 & 1,69 & $-160,6200$ & 3,32 & 519 & 0,92 \\
$60^{\circ}$ & 0,3881 & 0,69 & $-160,6216$ & 2,32 & 515 & 0,94 \\
$70^{\circ}$ & 0,3874 & 0,25 & $-160,6253$ & 0,00 & 513 & 0,94 \\
$80^{\circ}$ & 0,3870 & 0,00 & $-160,6222$ & 1,94 & 512 & 0,96 \\
$90^{\circ}$ & 0,3879 & 0,56 & $-160,6227$ & 1,63 & 512 & 0,97 \\
\hline
\end{tabular}

* Diferença calculada em relação à estrutura de menor energia (no caso de $\Delta \mathrm{E}_{\mathrm{T}} \mathrm{AM} 1$, em relação à estrutura com $\alpha=80^{\circ}$ e para $\Delta \mathrm{E}_{\mathrm{T}} \mathrm{ZINDO}$, em relação à estrutura com $\alpha=70^{\circ}$ )

** $2^{\circ}$ estado excitado; nos outros casos o $1^{\circ}$ estado excitado sempre tem a maior força de oscilador.

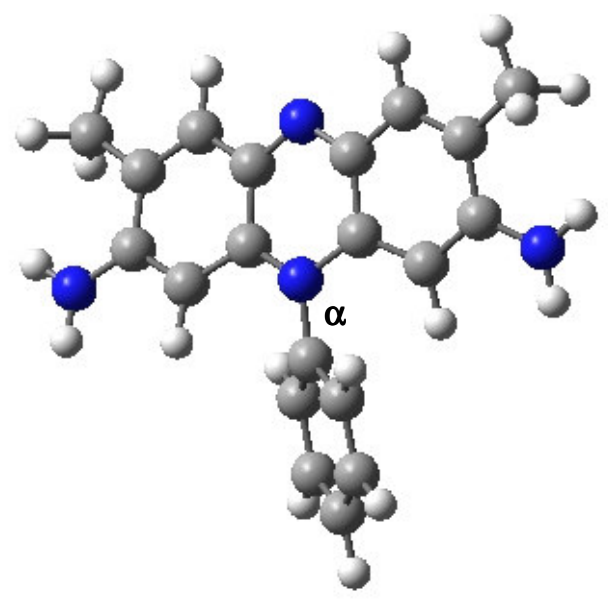

Figura 9. Geometria obtida para a SF pela otimização com o método AM1 mantendo-se $\alpha=30^{\circ}$.

Os valores obtidos para o comprimento de onda de absorção são muito próximos do valor experimental $(530 \mathrm{~nm})$ para todas as conformações, entretanto, a conformação com $\alpha=30^{\circ}$ é aquela que apresenta o espectro mais próximo. Todos os comprimentos de onda 
apresentados na Tabela 8 correspondem à transição HOMO $\rightarrow$ LUMO e são as transições mais intensas obtidas. As representações gráficas dos orbitais moleculares envolvidos nas transições para as estruturas com $\alpha=30^{\circ}$ (que apresenta espectro mais próximo do experimental) e $70^{\circ}$ (conformação com menor $\mathrm{E}_{\mathrm{T}}$ no estado excitado) são apresentadas na Figura 10.

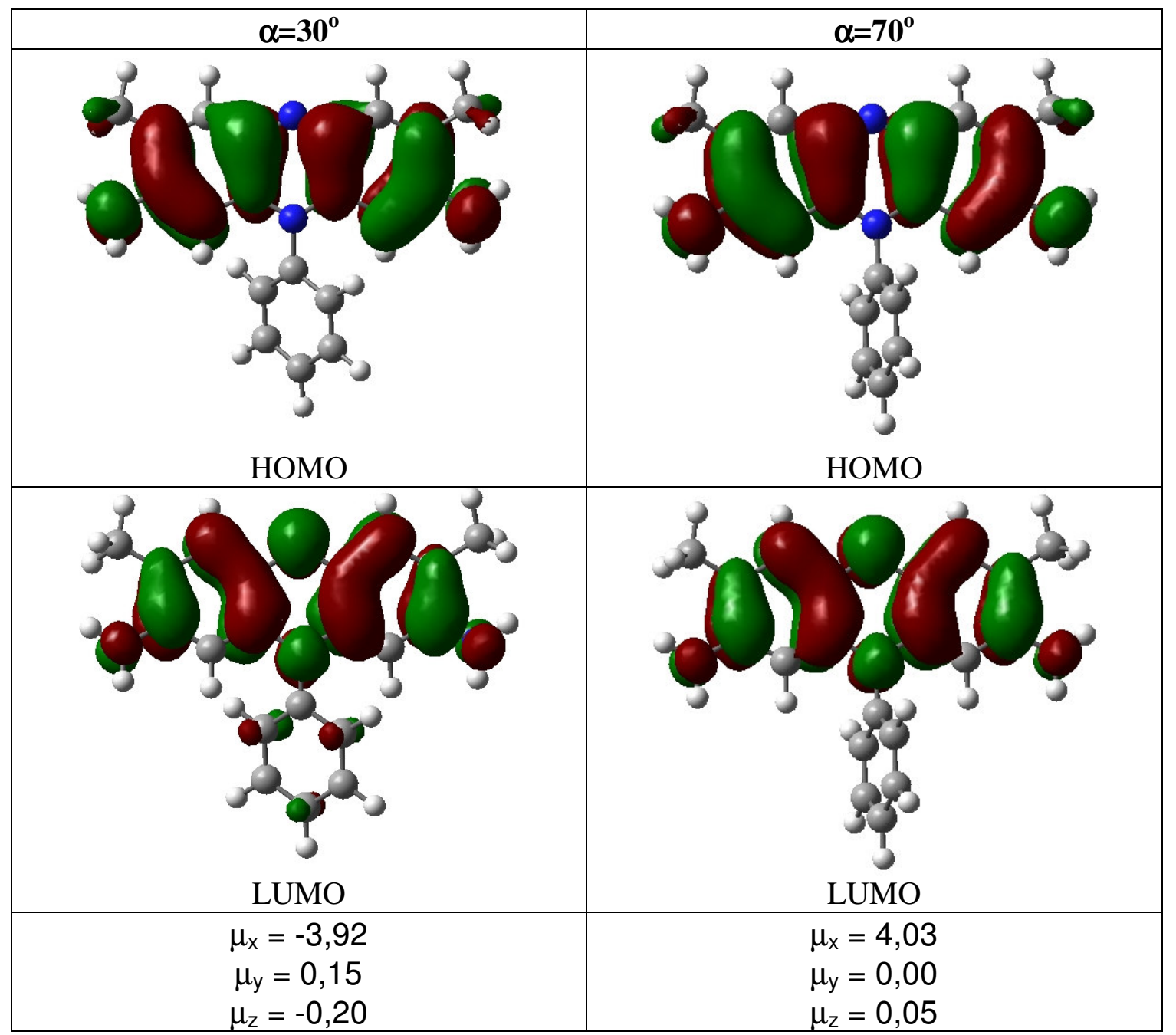

Figura 10. Representações gráficas dos orbitais moleculares envolvidos na transição principal do espectro de absorção do corante SF e contribuições para o dipolo de transição $(\mu)$ para as conformações $\operatorname{com} \alpha=30^{\circ}$ e $70^{\circ}$.

A representação gráfica dos orbitais moleculares HOMO e LUMO para a conformação com $\alpha=70^{\circ}$ é semelhante às representações para as conformações com $50^{\circ} \leq \alpha \leq 90^{\circ}$ e a representação para a conformação $\operatorname{com} \alpha=30^{\circ}$ é semelhante para todas as conformações em 
que os anéis fundidos estão torcidos (ou seja, com $10^{\circ} \leq \alpha \leq 40^{\circ}$ ). O HOMO apresenta as mesmas contribuições atômicas para todas as conformações, porém o LUMO tem contribuições atômicas do anel fenílico quando este apresenta $\alpha \leq 40^{\circ}$, ou seja, além de a principal transição consistir de uma transferência de carga para o anel central, também há uma transferência para o anel fenílico. Este fenômeno também é evidenciado pelo momento de transição, que passa a ter contribuições nas direções y e z. 


\subsubsection{Estudo da diprotonação dos corantes catiônicos}

A diprotonação também é responsável pela metacromasia dos corantes catiônicos, o que os torna úteis como, por exemplo, sondas de regiões ácidas em argilas. Para iniciar este estudo, foram obtidos os mapas de potencial eletrostático (MEP) para os corantes monoprotonados (Figura 11), com o intuito de verificar quais átomos poderiam ser protonados.

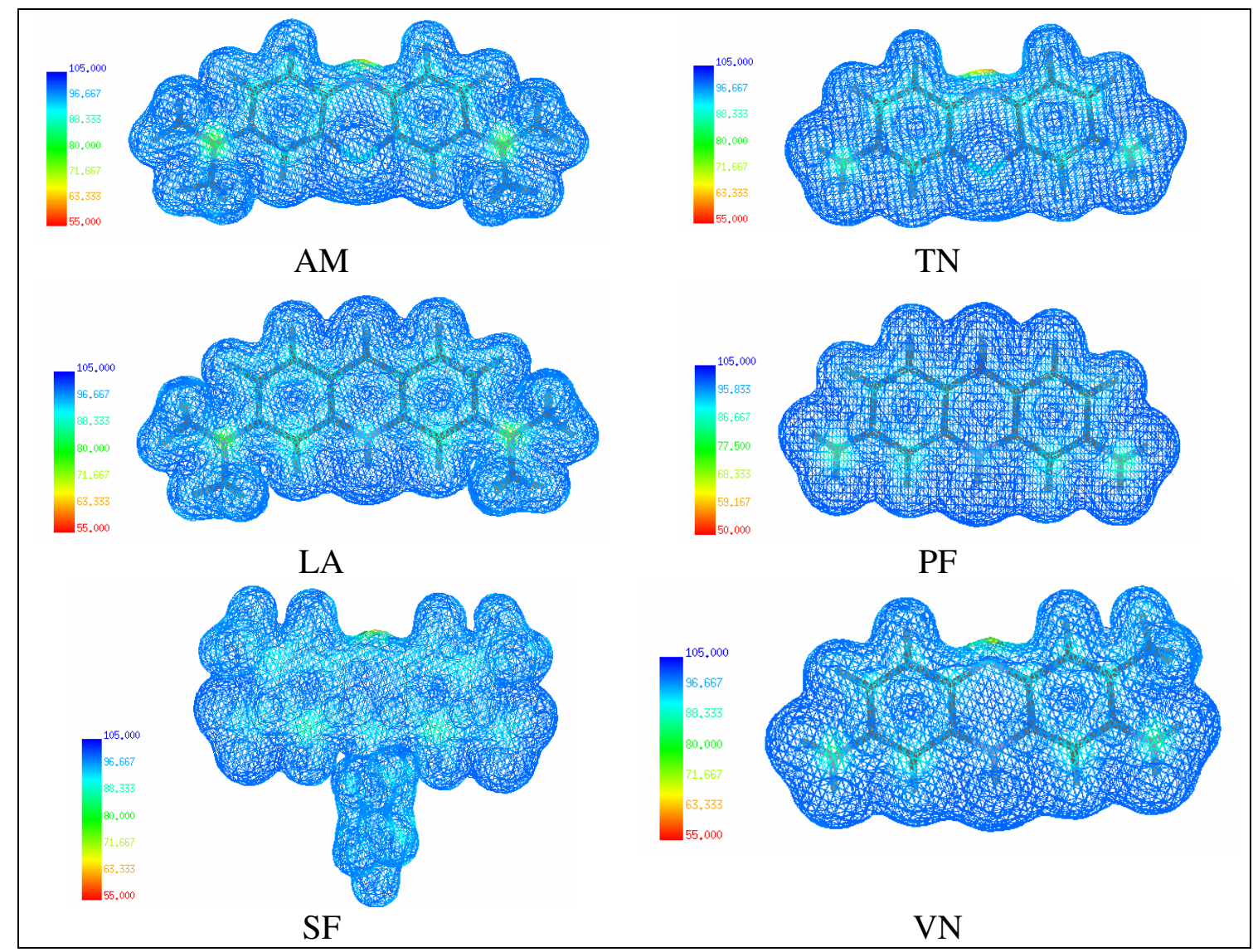

Figura 11. Gráfico do MEP para os corantes catiônicos estudados com carga $=+1$ (energia eletrostática de interação $=100 \mathrm{kcal} \cdot \mathrm{mol}^{-1}$ ). 
As partes mais claras do MEP (Figura 11) correspondem aos átomos de $\mathrm{N}$ e indicam que esses são os possíveis sítios de protonação, pois é uma região com densidade de carga mais negativa.

Os corantes catiônicos estudados apresentam três tipos diferentes de $\mathrm{N}$ que podem ser protonados: $\mathrm{N}_{\mathrm{a}}(\mathrm{N}$ do anel central, presente em todos os corantes, mas já protonado em LA e $\mathrm{PF}), \mathrm{N}_{\mathrm{t}}(\mathrm{N}$ da amina terciária, presente em $\mathrm{AM}, \mathrm{LA}, \mathrm{VN})$ e $\mathrm{N}_{\mathrm{p}}(\mathrm{N}$ da amina primária, presente em TN, PF, VN e SF). Todos os corantes, com exceção do VN, são simétricos em relação ao eixo y (Figura 1), então a protonação de um dos $\mathrm{N}$ alifáticos $\left(\mathrm{N}_{\mathrm{t}}\right.$ ou $\left.\mathrm{N}_{\mathrm{p}}\right)$ equivale à protonação do outro $\mathrm{N}$ alifático.

Experimentalmente, observa-se que a forma diprotonada absorve em comprimentos de onda maiores que a forma monoprotonada. O deslocamento da banda de absorção experimental do monômero diprotonado $\left(\lambda_{\exp +2}\right)$ em relação à banda do monômero monoprotonado $\left(\lambda_{\text {exp+1 }}\right)$ pode ser observado na Tabela 1 . O espectro teórico do monômero diprotonado deve apresentar um deslocamento equivalente ao deslocamento experimental $\left(\Delta \lambda_{\text {exp }}\right)$. Dessa forma, é possível analisar qual a estrutura mais adequada para representar a diprotonação do corante, ou seja, aquela que tem espectro teórico mais próximo do esperado, já considerando o erro inerente ao cálculo. Com base nisso, propõe-se na Tabela 9 os comprimentos de onda esperados para a forma diprotonada dos monômeros estudados. 
Tabela 9. Deslocamento da banda de absorção experimental do monômero diprotonado em relação à banda do monômero monoprotonado $\left(\Delta \lambda_{\text {exp }}\right.$, em nm), comprimentos de onda calculados para monômero monoprotonado $\left(\lambda_{+1}\right.$, em nm) e previsão para o comprimento de onda do corante diprotonado $\left(\lambda_{+2}\right.$, em nm)

\begin{tabular}{cccc}
\hline Corante & $\Delta \boldsymbol{\lambda}_{\text {exp }}{ }^{\text {a }}$ & $\boldsymbol{\lambda}_{+\mathbf{1}}{ }^{\mathbf{b}}$ & $\boldsymbol{\lambda}_{+2}{ }^{\mathbf{c}}$ previsto \\
\hline AM & 85 & 651 & 736 \\
TN & 75 & 631 & 704 \\
LA & $--^{\mathrm{d}}$ & 455 & 453 \\
PF & - -- $^{\mathrm{e}}$ & 442 & $---{ }^{\mathrm{e}}$ \\
VN & 95 & 555 & 650 \\
SF & 50 & 554 & 604 \\
\hline
\end{tabular}

${ }^{\text {a }}$ Diferença entre $\lambda_{\text {exp+1 }}$ e $\lambda_{\text {exp+2 }}$ (Tabela 1$)$;

balores teóricos apresentados também na Seção 4.1 ;

${ }^{\mathrm{c}} \lambda_{+2}=\lambda_{+1}+\Delta \lambda_{\exp }$

d as mudanças espectrais observadas para o corante LA são mais difíceis de ser analisadas porque acredita-se que muitas espécies absorvam em comprimentos de onda muito próximos. Em solução aquosa, o monômero absorve em $492 \mathrm{~nm}$, enquanto na presença de argilas, os monômeros nas superfícies externas das partículas de argila absorvem em $500 \mathrm{~nm}$, monômeros na superfície interna em $495 \mathrm{~nm}$ e os monômeros diprotonados na superfície interna em $490 \mathrm{~nm}$ [21];

e esses valores ainda não estão bem estabelecidos.

$\mathrm{Na}$ Tabela 10 são apresentados o máximo de absorção $(\lambda)$ e a energia total $\left(\mathrm{E}_{\mathrm{T}}\right)$ calculados para cada estrutura proposta para os corantes catiônicos diprotonados. A forma diprotonada dos corantes tiazínicos mais estável corresponde à protonação do $\mathrm{N}_{\mathrm{a}}$ e é também esta forma que apresenta espectro mais próximo do esperado. A protonação do $\mathrm{N}$ alifático faz com que os corantes absorvam em comprimentos de onda menores do que a forma monoprotonada.

Já o comportamento dos corantes diazínicos não é uniforme: enquanto a forma protonada no $\mathrm{N}_{\mathrm{a}}$ é mais estável para a SF, para o $\mathrm{VN}$ a estrutura protonada no $\mathrm{N}_{\mathrm{t}}$ é bem mais estável (quase $100 \mathrm{kcal} / \mathrm{mol}$ mais estável em relação à conformação protonada no $\mathrm{N}_{\mathrm{a}}$ ). Porém, como observado para as tiazinas, as formas protonadas no $\mathrm{N}_{\mathrm{a}}$ são as únicas que absorvem em comprimentos de onda maiores que os máximos de absorção da forma monoprotonada. 
Tabela 10. Energia total ( $\mathrm{E}_{\mathrm{T}}$, em u.a. obtida de cálculo DFT em meio aquoso) e máximo de absorção $(\lambda)$ para cada estrutura diprotonada proposta

\begin{tabular}{ccccc}
\hline Corante & N protonado & $\mathbf{E}_{\mathbf{T}}$ (u.a.) & $\begin{array}{c}\Delta \mathbf{E}_{\mathbf{T}} \\
\text { (kcal.mol }^{-\mathbf{1}} \text { )* }\end{array}$ & $\boldsymbol{\lambda}(\mathbf{n m})$ \\
\hline $\mathrm{AM}$ & $\mathrm{N}_{\mathrm{a}}$ & $-1183,277$ & 0,00 & 712 \\
$\mathrm{TN}$ & $\mathrm{N}_{\mathrm{t}}$ & $-1183,269$ & 5,02 & 468 \\
& $\mathrm{~N}_{\mathrm{a}}$ & $-1026,049$ & 0,00 & 664 \\
$\mathrm{LA}$ & $\mathrm{N}_{\mathrm{p}}$ & $-1026,042$ & 4,39 & 459 \\
$\mathrm{PF}$ & $\mathrm{N}_{\mathrm{t}}$ & $-824,440$ & --- & 441 \\
$\mathrm{VN}$ & $\mathrm{N}_{\mathrm{p}}$ & $-667,200$ & --- & 422 \\
& $\mathrm{~N}_{\mathrm{a}}$ & $-801,164$ & 0,00 & 684 \\
& $\mathrm{~N}_{\mathrm{p}}$ & $-801,155$ & 5,64 & 497 \\
& $\mathrm{~N}_{\mathrm{t}}$ & $-801,320$ & $-97,83$ & 469 \\
$\mathrm{SF}$ & $\mathrm{N}_{\mathrm{a}}$ & $-992,915$ & 0,00 & 632 \\
& $\mathrm{~N}_{\mathrm{p}}$ & $-992,905$ & 6,27 & 491 \\
\hline
\end{tabular}

As acridinas apresentam o $\mathrm{N}_{\mathrm{a}}$ já protonados na estrutura monoprotonada, restando, portanto, apenas um sítio para que ocorra uma nova protonação. Assim, o objetivo do estudo da diprotonação nesse caso não foi determinar o átomo em que ocorre a protonação, mas calcular as propriedades da molécula diprotonada e procurar explicar a dificuldade experimental na determinação do máximo de absorção dessas estruturas. Os espectros teóricos da LA e da PF mostram porque os resultados experimentais não são conclusivos com relação à diprotonação: o máximo de absorção da forma diprotonada aparece em comprimento de onda menor e muito próximo do máximo da forma monoprotonada, tornando difícil a sua visualização nos espectros experimentais.

A diprotonação no $\mathrm{N}_{\mathrm{a}}$ gera estruturas que absorvem em comprimentos de onda maiores do que a forma monoprotonada, concordando com os resultados experimentais. As 
estruturas diprotonadas no $\mathrm{N}$ alifático absorvem em comprimentos de onda menores e muito próximos das estruturas monoprotonadas. Tendo em vista que as diferenças de energia entre as diferentes formas diprotonadas são relativamente pequenas (com exceção do VN), talvez a protonação ocorra em qualquer $\mathrm{N}$, porém, nos espectros experimentais, pode haver uma sobreposição de bandas quando a protonação ocorre nos $\mathrm{N}$ alifáticos, dificultando a sua visualização.

\subsubsection{Simulações de MC para os monômeros}

Inicialmente, foram realizadas duas simulações para o AM com potenciais diferentes. Um potencial foi construído a partir dos resultados da otimização da molécula AM com o método AM1 no vácuo e o outro com os resultados obtidos para a molécula otimizada com o método DFT em meio aquoso (IEFPCM). Esta comparação foi realizada para avaliar a influência da geometria e das cargas atômicas nos resultados das simulações, uma vez que não pretendíamos considerar os graus de liberdade interna das moléculas dos corantes. Assim, a melhor metodologia encontrada para o AM será utilizada para estudar os demais corantes.

Como observado no item 4.1, não há muitas diferenças estruturais quando a otimização dos corantes é realizada com métodos diferentes (por isso a escolha de considerar o soluto rígido durante as simulações). Então, as diferenças entre os resultados dos dois potenciais construídos para o AM se devem principalmente às cargas utilizadas, ou seja, há uma maior variação na parte eletrostática do potencial. 


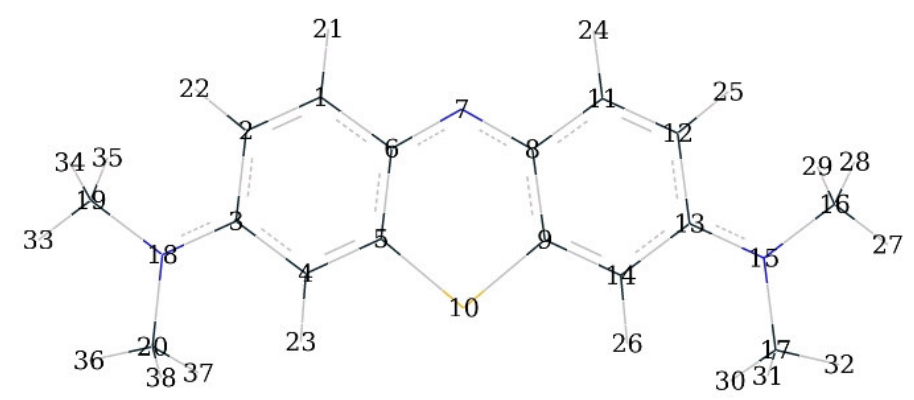

Figura 12. Numeração adotada para o corante AM nesta seção do trabalho.

Tabela 11. Cargas derivadas do potencial eletrostático (CHELPG) calculadas para o corante AM para as geometrias obtidas com AM1 e DFT no vácuo e com DFT em meio aquoso (IEFPCM) e correspondente momento de dipolo (em Debye)

\begin{tabular}{|c|c|c|c|}
\hline Átomo & AM1 & DFT & DFT/IEFPCM \\
\hline $1 \mathrm{C}$ & $-0,190$ & $-0,206$ & $-0,257$ \\
\hline $2 \mathrm{C}$ & $-0,279$ & $-0,188$ & $-0,184$ \\
\hline $3 \mathrm{C}$ & 0,315 & 0,294 & 0,290 \\
\hline $4 \mathrm{C}$ & $-0,386$ & $-0,298$ & $-0,330$ \\
\hline $5 \mathrm{C}$ & $-0,334$ & $-0,019$ & 0,002 \\
\hline $6 \mathrm{C}$ & 0,339 & 0,526 & 0,562 \\
\hline $7 \mathrm{~N}$ & $-0,351$ & $-0,638$ & $-0,703$ \\
\hline $8 \mathrm{C}$ & 0,342 & 0,526 & 0,562 \\
\hline $9 \mathrm{C}$ & $-0,330$ & $-0,019$ & 0,002 \\
\hline $10 \mathrm{~S}$ & 0,563 & $-0,034$ & $-0,025$ \\
\hline $11 \mathrm{C}$ & $-0,192$ & $-0,206$ & $-0,257$ \\
\hline $12 \mathrm{C}$ & $-0,278$ & $-0,188$ & $-0,184$ \\
\hline $13 \mathrm{C}$ & 0,323 & 0,294 & 0,290 \\
\hline $14 \mathrm{C}$ & $-0,400$ & $-0,298$ & $-0,330$ \\
\hline $15 \mathrm{~N}$ & $-0,102$ & $-0,182$ & $-0,142$ \\
\hline $16 \mathrm{C}$ & $-0,289$ & 0,026 & 0,022 \\
\hline $17 \mathrm{C}$ & $-0,285$ & 0,021 & $-0,038$ \\
\hline $18 \mathrm{~N}$ & $-0,093$ & $-0,182$ & $-0,142$ \\
\hline $19 \mathrm{C}$ & $-0,299$ & 0,026 & 0,022 \\
\hline $20 \mathrm{C}$ & $-0,302$ & 0,021 & $-0,038$ \\
\hline Dipolo (Debye) & 2,275 & 1,902 & 3,074 \\
\hline
\end{tabular}


A Tabela 11 apresenta as cargas atômicas obtidas para as estruturas obtidas com cada otimização (a numeração adotada se encontra na Figura 12). As cargas calculadas para cada geometria diferem consideravelmente. Um ponto interessante é que as cargas das geometrias DFT refletem melhor a simetria da molécula em relação ao eixo de simetria.

O momento de dipolo para as três estruturas apresenta contribuição significativa apenas no eixo y, no sentido do átomo de $\mathrm{N}$ do anel para o átomo S. É interessante notar que, enquanto a estrutura obtida com AM1 tem carga positiva no $\mathrm{S}$ e negativa no $\mathrm{N}$ do anel, as estruturas obtidas com DFT, tanto no vácuo quanto em meio aquoso, têm os dois átomos carregados negativamente, mas a carga do $\mathrm{S}$ é bem menor que a do N. O valor do dipolo total, como esperado, cresce quando calculado em meio aquoso.

A diferença nas cargas utilizadas tem maior efeito sobre a contribuição eletrostática do potencial do soluto, mas se reflete na energia total (assim como no momento de dipolo). Como pode ser verificado na Figura 13, a energia do sistema AM-água para a geometria do soluto obtida com DFT/IEFPCM oscila em torno de $-0,45 \mathrm{eV}$, enquanto para a geometria AM1 a energia do sistema oscila em torno de $-0,41 \mathrm{eV}$.

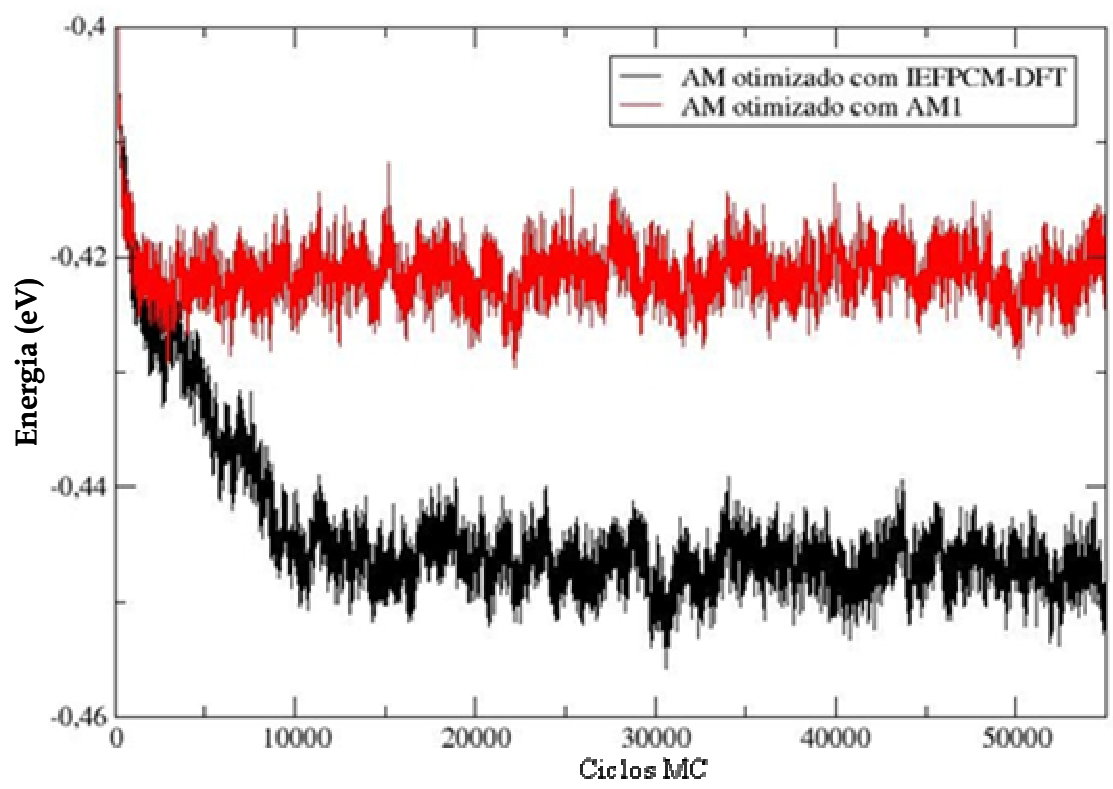

Figura 13. Energia ao longo dos ciclos MC para o corante AM otimizado com AM1 e com DFT/IEFPCM. 
Como não é possível calcular o espectro para todas as milhares de configurações geradas, geralmente apenas algumas são selecionadas. Na verdade, não há necessidade de realizar todos esses cálculos, pois as mudanças configuracionais são pequenas e, consequientemente, as configurações sucessivas geradas na simulação são estatisticamente dependentes ou correlacionadas. As configurações correlacionadas quase não acrescentam nova informação às médias e por isto as correlações estatísticas são indesejáveis. A forma sistemática para selecionar estruturas sem afetar a média real é utilizar a função de autocorrelação de energia [141]. A Figura 14 apresenta a função de auto-correlação para o AM (otimizado com IEFPCM-DFT) em água calculada conforme descrito na página 185 do livro "Computer simulation of liquids" de Allen e Tildesley [102]. Verificou-se que a autocorrelação é inferior a 5\% a cada 800 ciclos, como verificado também por Coutinho et al. [141] para uma série de solutos em água.

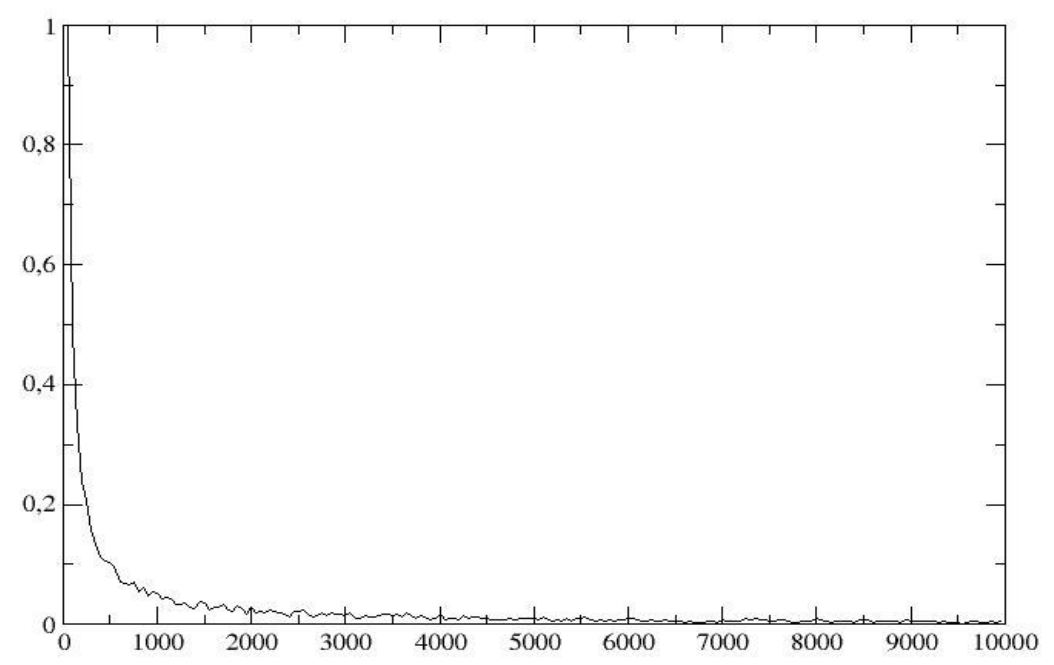

Figura 14. Função de auto-correlação entre as estruturas geradas pelos ciclos MC para o AM.

As camadas de solvatação são definidas a partir da função de distribuição radial (G(r)) obtida da simulação de MC. Como exemplo, na Figura 15 são apresentadas as G(r) do 
enxofre, do nitrogênio do anel, de um carbono do anel e de um carbono de metila (todos do AM) e o hidrogênio da água. A primeira camada de solvatação para o enxofre e os carbonos selecionados termina em torno de $6 \AA$, enquanto para o nitrogênio do anel, embora não esteja bem definida, em torno de 7,5 . Com base nas $G(r)$ de cada átomo do soluto, foi obtida a camada de solvatação para cada configuração. No caso do AM, as camadas de solvatação continham entre 90 e 95 moléculas de água.

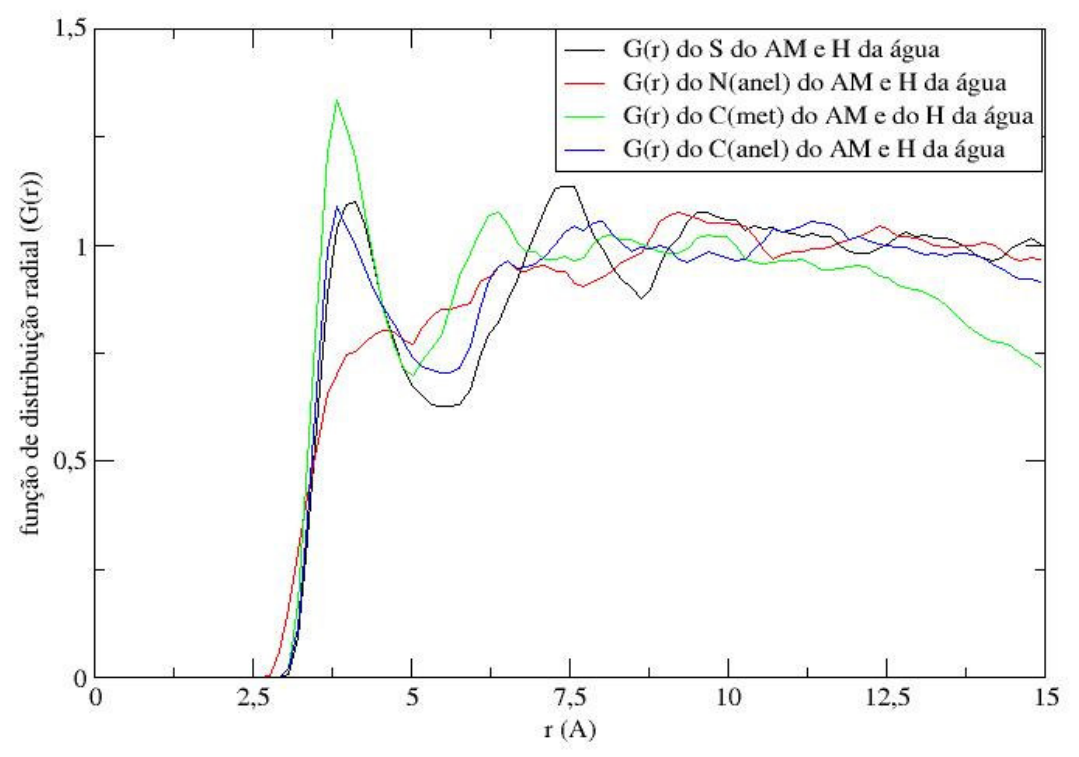

Figura 15. Função de distribuição radial para alguns átomos do AM e hidrogênio da água.

Assim, foram selecionadas as configurações com baixo grau de correlação estatística (ou seja, uma configuração a cada 800 ciclos) e destas isoladas superestruturas que consistem da molécula de AM com a primeira camada de solvatação para obter o espectro com o método ZINDO.

O corante AM em solução diluída apresenta espectro experimental com máximo em torno de $665 \mathrm{~nm}$ e a molécula otimizada com DFT/IEFPCM tem máximo de absorção em 583 nm quando o espectro é calculado no vácuo (como apresentado na Seção 4.1). O espectro das 
diversas superestruturas geradas pelo MC apresenta máximo entre 580 e 600 nm (Figura 16), sendo a média aritmética igual a 588,5 $\mathrm{nm}$ (5 nm acima do valor ZINDO/vácuo). Aliando o IEFPCM ao ZINDO no cálculo da molécula otimizada, obteve-se espectro em 651nm, que é mais próximo do valor experimental do que o resultado obtido para as superestruturas. Porém, as superestruturas contêm apenas a primeira camada de solvatação e, mesmo assim, há um deslocamento do máximo de absorção em direção ao valor experimental. Como o intuito deste estudo é verificar como se dá a interação das moléculas do corante com o solvente, a metodologia escolhida se mostrou adequada.

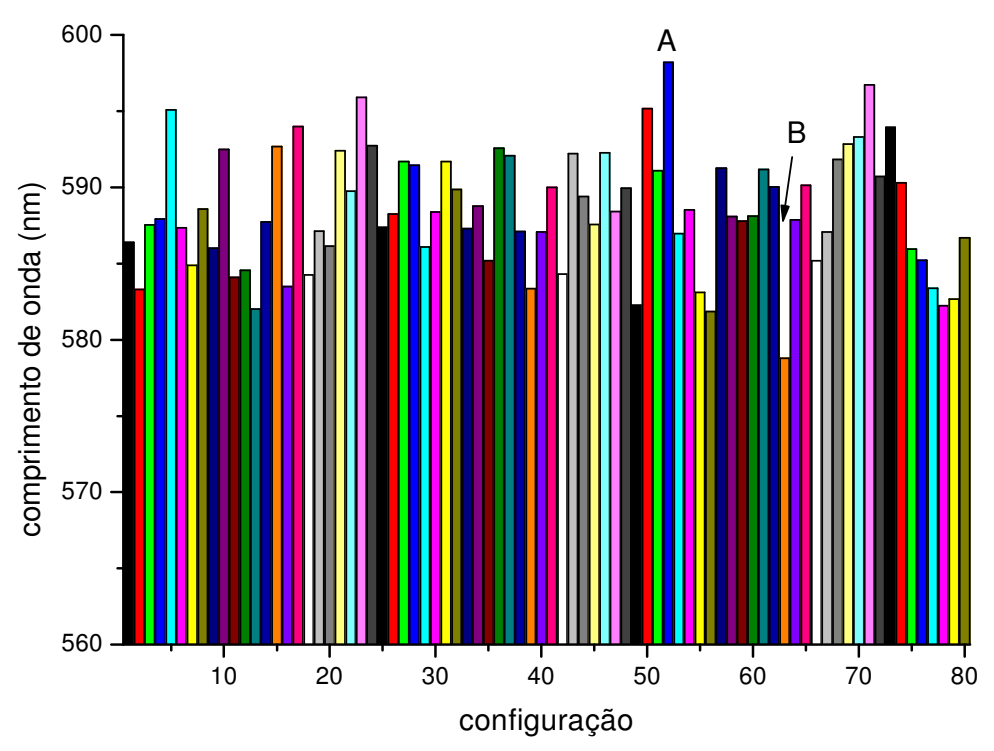

Figura 16. Máximos de absorção calculados para as configurações selecionadas da simulação de MC para o corante AM com potencial construído a partir de cálculos DFT/IEFPCM.

Foram analisadas, então, as superestruturas que apresentaram absorção em comprimento de onda mais baixo (B) e mais alto (A). A Figura 17 apresenta as conformações selecionadas e as seguintes propriedades: $\lambda$, força do oscilador (f) e o número de moléculas de água que compõem a superestrutura. A conformação $A$ apresentou o maior $\lambda$, aproximando-se mais, assim, do $\lambda$ experimental. Nesta conformação, algumas moléculas de água estão bem 
próximas do corante: um $\mathrm{H}$ de água, por exemplo, está a 1,93 ̊̊ do $\mathrm{N}$ do anel central. Já a conformação B apresentou o menor $\lambda$, sendo que as moléculas de água estão mais distantes do corante: as moléculas de água mais próximas do anel central estão a cerca de 4 A do $\mathrm{N}$.

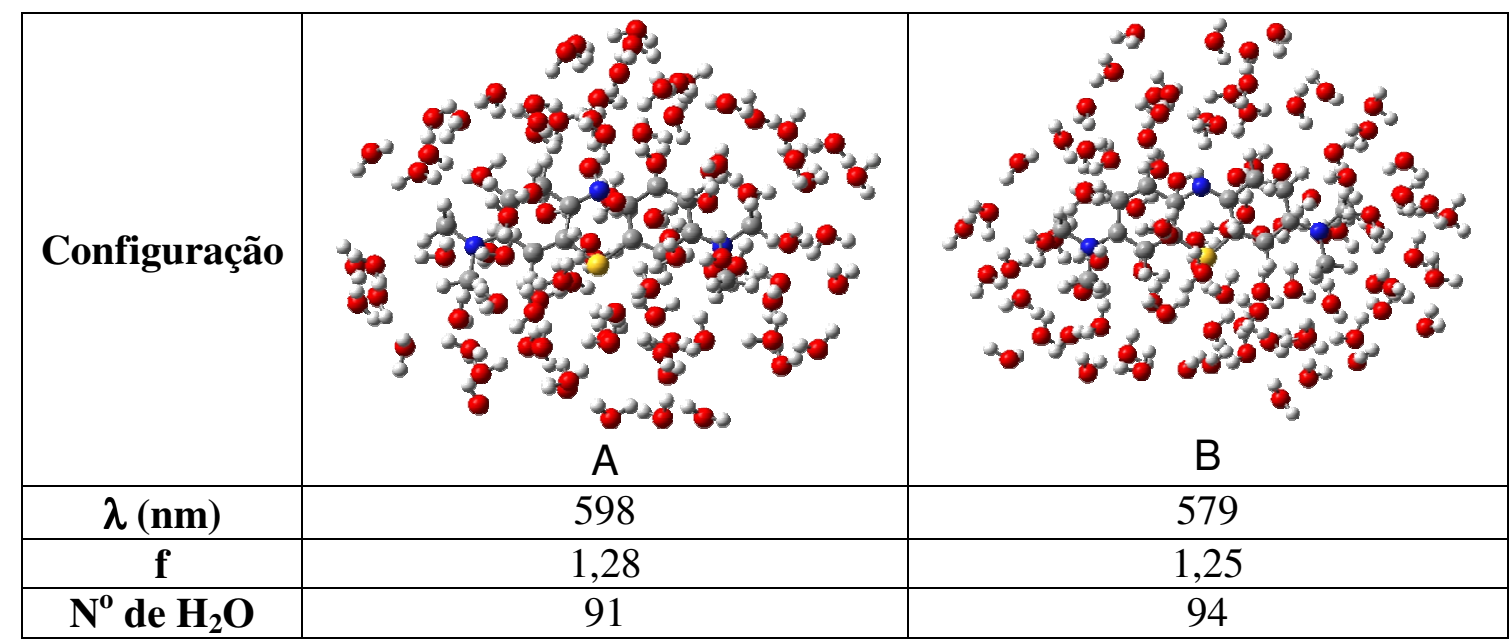

Figura 17. Superestruturas A e B, selecionadas da simulação MC para o AM com potencial construído a partir de cálculos DFT/IEFPCM.

A Figura 18 apresenta as cargas atômicas derivadas do potencial eletrostático (números sobre os átomos, que estão coloridos conforme a escala de cargas) obtidas para os corantes LA e TN para as estruturas otimizadas com DFT/B3LYP em meio aquoso. As cargas obtidas para essa geometria refletem melhor a simetria da molécula em relação ao eixo y do que as cargas obtidas para a geometria AM1-vácuo (como verificado anteriormente para o $\mathrm{AM})$.

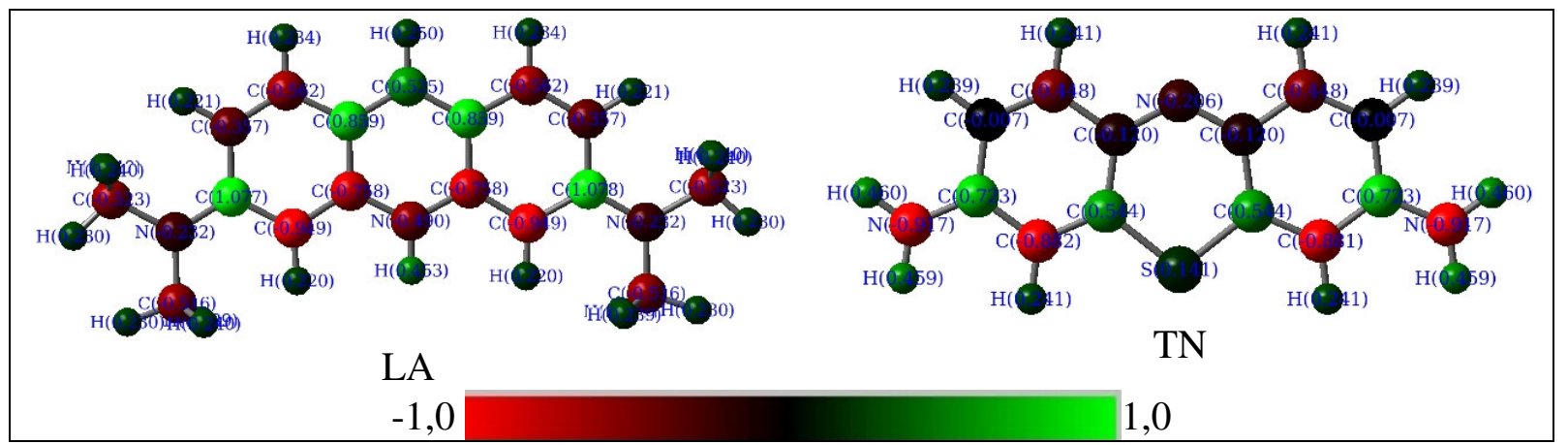

Figura 18. Cargas derivadas do potencial eletrostático calculadas para os corantes catiônicos LA e TN. 
Essas cargas foram implementadas no programa $\mathrm{MC}$ e foram realizadas as simulações para a TN e a LA. Os gráficos da energia $v s$. os ciclos MC para os corantes TN e LA são apresentados na Figura 19 e indicam que as simulações apresentam um bom comportamento, tornando segura a seleção das configurações.
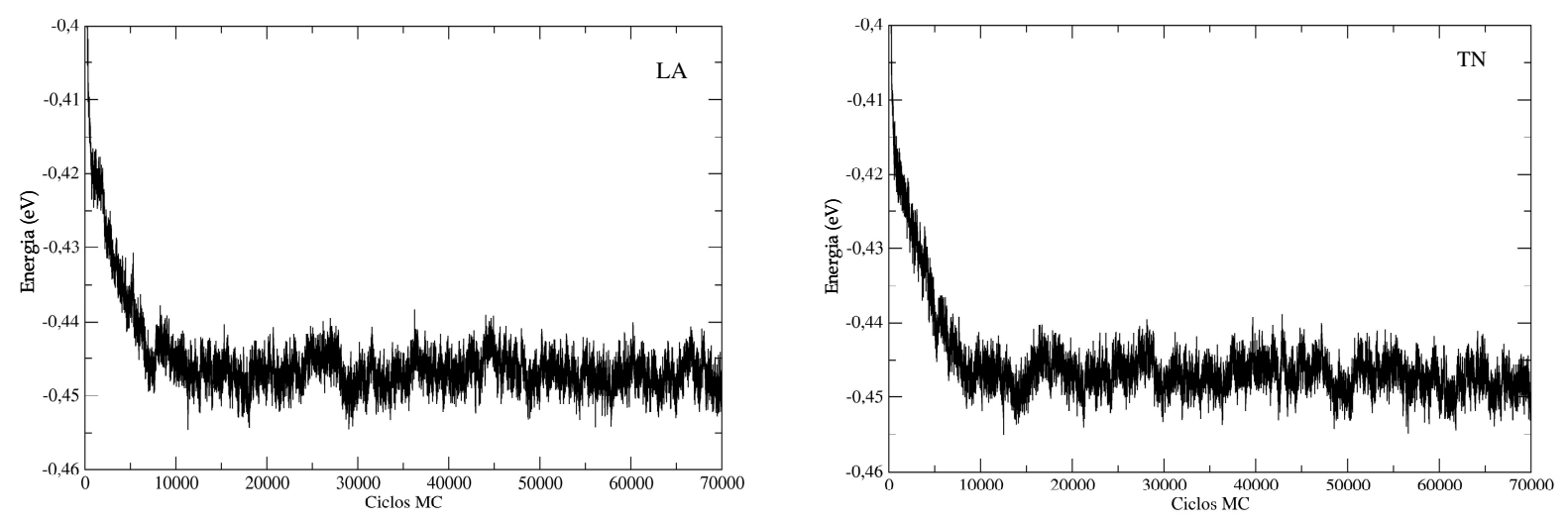

Figura 19. Energia ao longo dos ciclos MC para os corantes LA e TN com potencial construído a partir de cálculos DFT/IEFPCM.

Assim como para o AM, foram selecionadas configurações a cada 800 ciclos MC para os corantes TN e LA e destas isoladas superestruturas que consistem da molécula de corante com parte da primeira camada de solvatação. Como não foi possível realizar o cálculo com a primeira camada de solvatação completa, foi considerada a primeira camada de solvatação completa (com base nas $\mathrm{G}(\mathrm{r})$ ) apenas para os heteroátomos do soluto, enquanto para os átomos de hidrogênio do soluto não foram consideradas moléculas de solvente e para os átomos de carbono foi considerada apenas metade da camada de solvatação. Assim, as conformações para a LA continham cerca de 60 moléculas de água e para a TN pouco mais de 50. A Tabela 12 resume os resultados da simulação. A média dos máximos de absorção para as superestruturas de ambos corantes apresenta um erro maior em relação ao máximo de absorção experimental do que o máximo de absorção calculado no vácuo ou considerando o solvente de forma contínua. As Figuras 20 e 21 apresentam os máximos de absorção obtidos para as diversas superestruturas selecionadas para a LA e para a TN. 
Tabela 12. Dados da simulação de MC (número de ciclos e de configurações selecionadas), resultados dos cálculos ZINDO para as configurações selecionadas da simulação MC, máximo de absorção obtido com ZINDO e IEFPCM e máximo de absorção experimental para os corantes LA e TN

\begin{tabular}{lcc}
\cline { 2 - 3 } & LA & TN \\
\hline Ciclos de termalização & 10.000 & 10.000 \\
Ciclos de produção & 84.000 & 60.000 \\
$N^{o}$ de configuraçães selecionadas & 115 & 74 \\
Média dos máximos de absorção das superestruturas $(\mathrm{nm})^{*}$ & 426 & 498 \\
Máximo de absorção ZINDO-vácuo $(\mathrm{nm})^{*}$ & 452 & 552 \\
Máximo de absorção ZINDO- IEFPCM $(\mathrm{nm})^{*}$ & 455 & 631 \\
Máximo de absorção experimental $(\mathrm{nm})$ & 490 & 600 \\
\hline
\end{tabular}

* Geometria do corante obtida com B3LYP / 6-31+G(d) / IEFPCM (vide Seção 4.1)

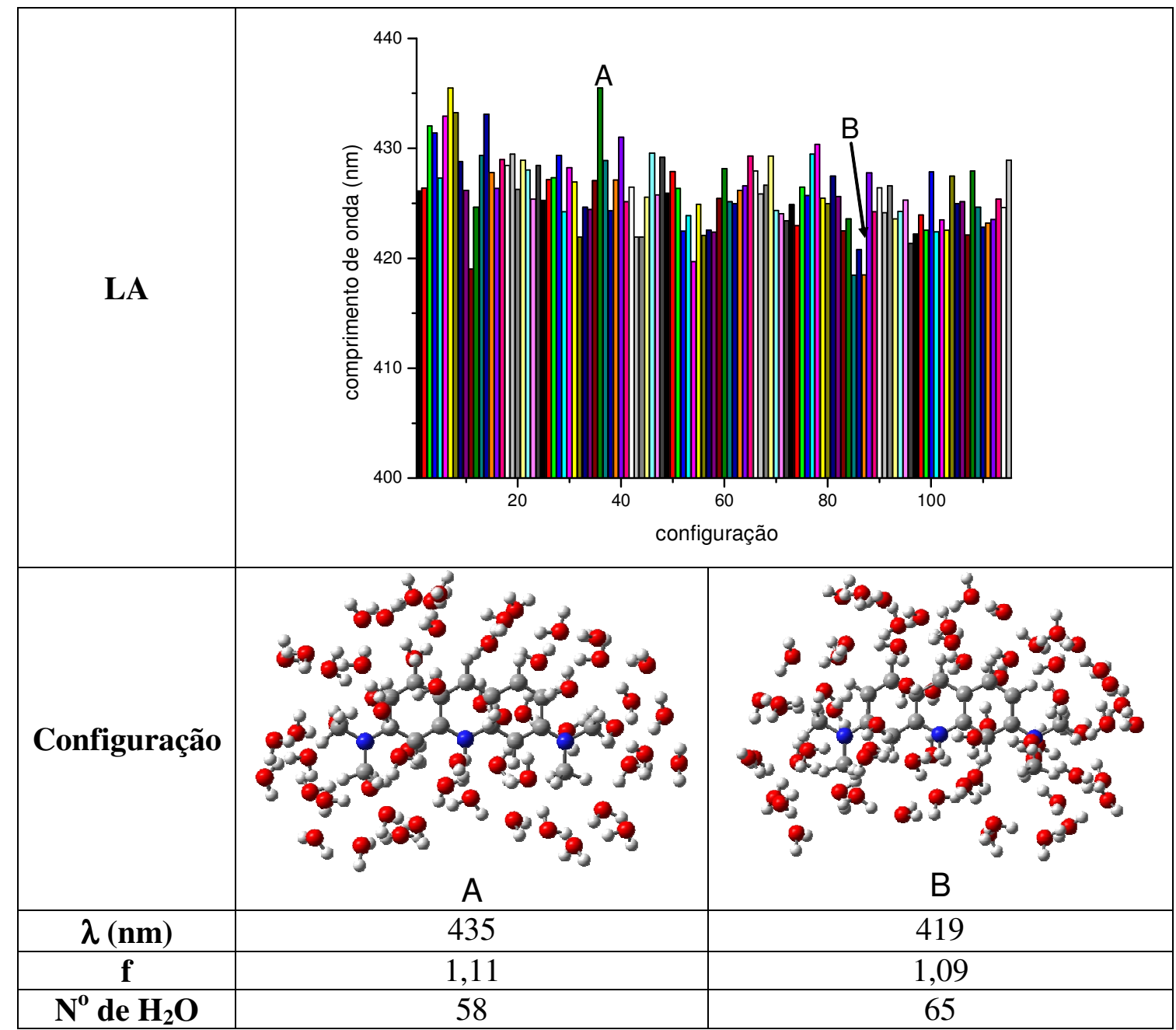

Figura 20. Gráfico de barras com os comprimentos de onda $(\mathrm{nm})$ calculados com ZINDO para as superestruturas selecionadas da simulação de MC para o corante LA; conformações $A$ e $B$ e respectivas propriedades. 
No caso da LA, a conformação A apresentou o maior $\lambda$, sendo assim, é a estrutura que apresenta $\lambda$ mais próximo do valor experimental. Nesta conformação, as moléculas de água estão distribuídas simetricamente ao longo do corante, e o oxigênio da molécula de água mais próximo está a 2,18 ̊̊ do $\mathrm{H}$ ligado ao $\mathrm{N}$ do anel central. Já a conformação B, embora tenha um maior número de moléculas de água, apresentou o menor $\lambda$. As moléculas do solvente estão mais concentradas em certas posições, com a camada de solvatação apresentando um "buraco" na parte superior esquerda. O oxigênio da molécula de água mais próximo está a 2,21 A do H ligado ao N do anel central.

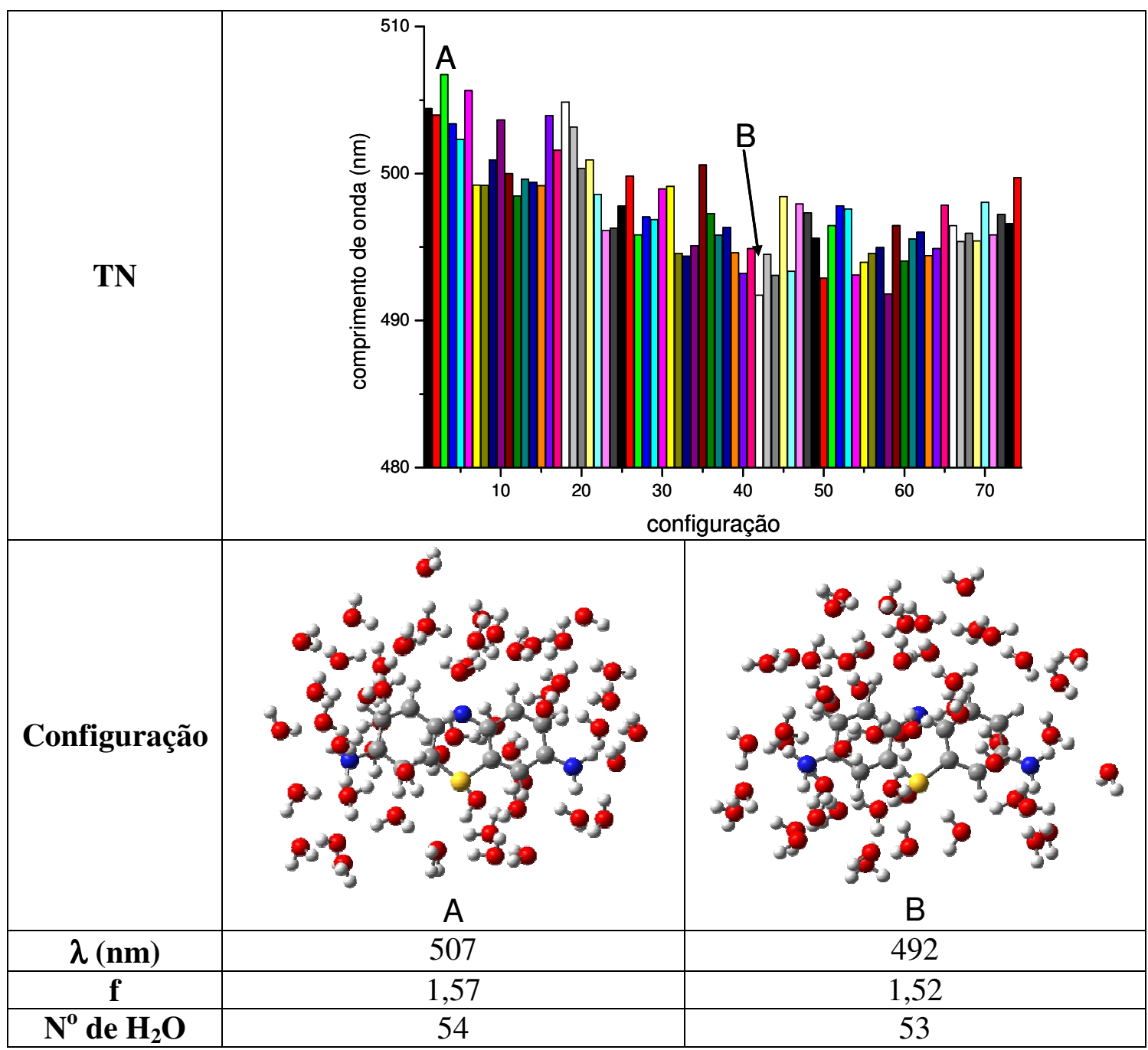

Figura 21. Gráfico de barras com os comprimentos de onda (nm) calculados com ZINDO para as superestruturas selecionadas da simulação de MC para o corante $\mathrm{TN}$; conformações $\mathrm{A}$ e $\mathrm{B}$ e respectivas propriedades. 
As duas conformações selecionadas para a TN têm quase o mesmo número de moléculas de água. Entretanto, a conformação $A$ apresentou o maior $\lambda$ e as moléculas de água estão distribuídas mais simetricamente ao longo do corante. Neste caso, as moléculas de solvente que mais se aproximam da molécula do corante estão próximas às porções alifáticas da molécula (duas moléculas de cada lado a cerca de 2,5 $\mathrm{A}$ do $\mathrm{NH}_{2}$ ) e as outras moléculas que mais se aproximam dos anéis estão a 3 Å. A camada de solvatação da conformação B tem um “buraco" próximo ao átomo de S, uma molécula de água a cerca de $3 \AA$ do $\mathrm{N}$ do anel central e, assim como na outra conformação, moléculas de água a cerca de 2,5 $\AA$ do $\mathrm{NH}_{2}$; mas, neste caso, as demais moléculas estão distantes pelo menos 4 A.

As superestruturas contêm apenas parte da primeira camada de solvatação: inclui a camada completa nas proximidades dos heteroátomos e apenas poucas moléculas de solvente nas extremidades. Pelo que demonstra a análise das estruturas, é provável que essa escolha tenha sido o motivo do $\lambda$ médio ter se deslocado para comprimentos de onda menores do que o valor calculado no vácuo. Em cálculos futuros, mesmo que não seja possível incluir toda a camada de solvatação, poderia ser realizado um teste incluindo no cálculo as moléculas de água de forma mais homogênea ao redor de toda a molécula de corante, pois como visto na seção 4.1.1., a interação das moléculas de água com as extremidades dos corantes não é suficiente para explicar o comportamento espectral das famílias de corantes.

\subsubsection{Estudo dos monômeros "extraídos" de cristais}

Anteriormente, foi observado que os corantes de uma mesma família têm os máximos de absorção teóricos mais próximos do que no espectro experimental, e esta diferença não parece ser causada por ligações hidrogênio. Para tentar explicar essas diferenças, foram estudadas, então, estruturas cristalográficas para alguns corantes: AM, LA e PF. Das celas 
unitárias foi possível "extrair" também dímeros, e tendo em vista a sua importância nos espectros experimentais, foram calculados os espectros de absorção.

Foram encontrados no Cambridge Database [123] os seguintes cristais para cada corante, que têm como diferença principal os contra-íons:

- AM: Mapaz (methylene blue chloride pentahydrate) [136] e Mbluet (methylene blue thiocyanate) [137];

- LA: Cesmao (acridine orange hydroiodide) e Cesmes (acridine orange hydrochloride monohydrate) [138];

- PF: Proflc (proflavine dichloride dehydrate) [139] e Proflv (proflavine monohydrate) [140].

As geometrias dos monômeros "extraídos" dos cristais são comparadas com as geometrias obtidas anteriormente com a otimização utilizando B3LYP/6-31+G(d)/IEFPCM (Tabelas 13 - 15). A Figura 22 apresenta a estrutura geral dos corantes e a numeração adotada para a apresentação dos resultados nesta seção do trabalho.

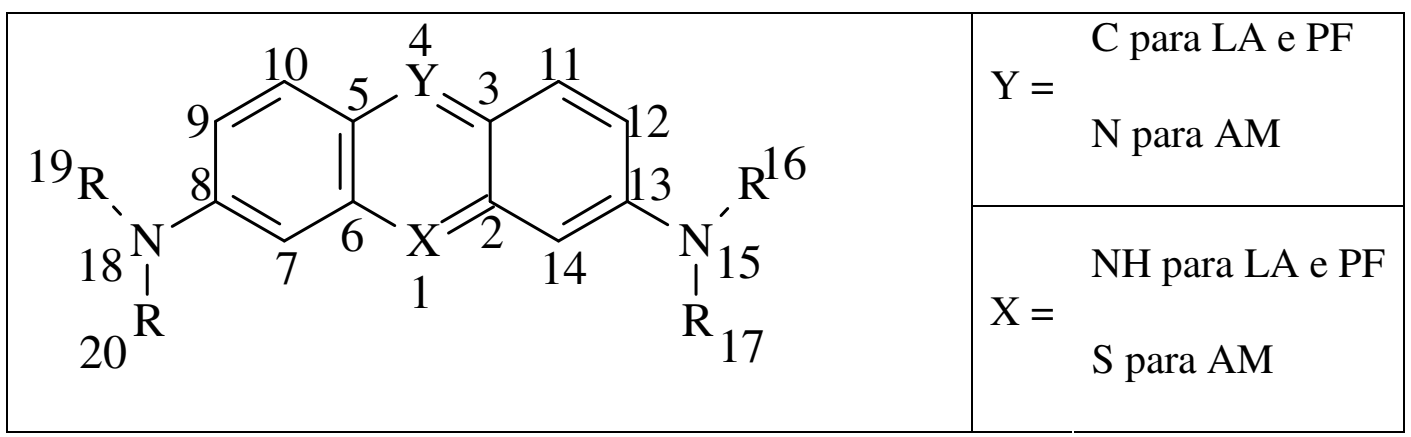

Figura 22. Estrutura geral e numeração adotada.

Como visto anteriormente, as estruturas otimizadas são planares e os ângulos e ligações são perfeitamente simétricos em relação a uma linha entre os átomos 1 e 4. 
Tabela 13. Parâmetros estruturais selecionados para cada monômero cristalino e para o monômero otimizado de AM

\begin{tabular}{cccc}
\hline Ângulo Diedro $\left(^{\mathbf{0}}\right)$ & Otimizado & Mapaz & Mbluet \\
\hline C6-C5-C10-C9 & 0,0074 & $-0,4861$ & 0,0000 \\
C6-C5-N4-C3 & 0,0019 & $-0,6182$ & 0,0000 \\
C2-C3-C11-C12 & $-0,0023$ & $-0,7981$ & 0,0000 \\
C3-C2-S1-C6 & $-0,0131$ & 1,3118 & 0,0000 \\
C11-C12-C13-N15 & 179,9850 & 178,7510 & 180,0000 \\
C10-C9-C8-N18 & 179,9800 & 178,7880 & 180,0000 \\
Comprimento da ligação (̊) & & & \\
S1-C2 & 1,7506 & 1,7387 & 1,7430 \\
C6-S1 & 1,7506 & 1,7209 & 1,7357 \\
C3-N4 & 1,3371 & 1,3363 & 1,3290 \\
N4-C5 & 1,3371 & 1,3374 & 1,3531 \\
C7-C8 & 1,4236 & 1,4212 & 1,4015 \\
C13-C14 & 1,4236 & 1,4018 & 1,3908 \\
C8-C9 & 1,4405 & 1,4457 & 1,4462 \\
C12-C13 & 1,4406 & 1,4231 & 1,4367 \\
C10-C5 & 1,4319 & 1,4167 & 1,4081 \\
C3-C11 & 1,4319 & 1,4209 & 1,4052 \\
C13-N15 & 1,3518 & 1,3427 & 1,3467 \\
C8-N18 & 1,3517 & 1,3303 & 1,3135 \\
\hline
\end{tabular}

Assim com o monômero otimizado, o monômero Mbluet também é planar, mas as ligações são mais curtas. O monômero Mapaz não é planar, a região próxima ao átomo de $\mathrm{S}$ está fora do plano e, também neste caso, as ligações são mais curtas. 
Tabela 14. Parâmetros estruturais selecionados para cada monômero cristalino e para o monômero otimizado de LA

\begin{tabular}{|c|c|c|c|}
\hline Ângulo Diedro $\left(^{0}\right)$ & Otimizado & Cesmao & Cesmes \\
\hline C6-C5-C10-C9 & $-0,0050$ & $-2,0384$ & 1,0379 \\
\hline C6-C5-C4-C3 & $-0,0014$ & $-0,3239$ & $-1,8726$ \\
\hline C2-C3-C11-C12 & 0,0234 & $-1,7317$ & 0,1739 \\
\hline C3-C2-N1-C6 & 0,0046 & $-1,1578$ & 0,8813 \\
\hline C11-C12-C13-N15 & 179,9710 & $-179,3370$ & 178,3250 \\
\hline C10-C9-C8-N18 & 179,9610 & $-179,7890$ & $-177,5150$ \\
\hline \multicolumn{4}{|c|}{ Comprimento da ligação (̊̊) } \\
\hline $\mathrm{N} 1-\mathrm{C} 2$ & 1,3742 & 1,3541 & 1,3605 \\
\hline $\mathrm{C} 6-\mathrm{N} 1$ & 1,3742 & 1,3670 & 1,3676 \\
\hline $\mathrm{C} 3-\mathrm{C} 4$ & 1,3985 & 1,3825 & 1,3864 \\
\hline $\mathrm{C} 4-\mathrm{C} 5$ & 1,3985 & 1,3777 & 1,3972 \\
\hline $\mathrm{C} 7-\mathrm{C} 8$ & 1,4127 & 1,3839 & 1,3900 \\
\hline $\mathrm{C} 13-\mathrm{C} 14$ & 1,4127 & 1,3998 & 1,3961 \\
\hline $\mathrm{C} 8-\mathrm{C} 9$ & 1,4433 & 1,4451 & 1,4434 \\
\hline $\mathrm{C} 12-\mathrm{C} 13$ & 1,4433 & 1,4496 & 1,4449 \\
\hline $\mathrm{C} 10-\mathrm{C} 5$ & 1,4260 & 1,4298 & 1,4095 \\
\hline C3-C11 & 1,4260 & 1,4241 & 1,4279 \\
\hline C13-N15 & 1,3604 & 1,3440 & 1,3609 \\
\hline C8-N18 & 1,3604 & 1,3604 & 1,3504 \\
\hline
\end{tabular}

Os dois monômeros cristalinos de LA são torcidos, ou seja, uma parte dos átomos está acima do plano (C9, C10, N1 e C14) e outra abaixo (C7 e C11). O monômero Cesmes tem um grupo alifático abaixo e outro acima do plano da molécula, enquanto Cesmao tem os dois grupos alifáticos do mesmo lado do plano. 
Tabela 15. Parâmetros estruturais selecionados para cada monômero cristalino e para o monômero otimizado de PF

\begin{tabular}{cccc}
\hline Ângulo Diedro $\left(^{\mathbf{0}}\right)$ & Otimizado & Proflc & Proflv \\
\hline C6-C5-C10-C9 & 0,0000 & $-0,1928$ & $-5,5111$ \\
C6-C5-C4-C3 & 0,0000 & $-2,9603$ & $-1,9995$ \\
C2-C3-C11-C12 & 0,0000 & $-0,1205$ & 5,5168 \\
C3-C2-N1-C6 & 0,0000 & 3,8945 & $-5,5057$ \\
C11-C12-C13-N15 & 180,0000 & $-176,6950$ & $-170,6240$ \\
C10-C9-C8-N18 & 180,0000 & $-177,6460$ & 170,6280 \\
Comprimento da ligação (̊) & & & \\
N1-C2 & 1,3731 & 1,3693 & 1,3348 \\
C6-N1 & 1,3732 & 1,3933 & 1,3348 \\
C3-C4 & 1,3983 & 1,3970 & 1,3995 \\
C4-C5 & 1,3984 & 1,3782 & 1,3996 \\
C7-C8 & 1,4037 & 1,4128 & 1,3810 \\
C13-C14 & 1,4037 & 1,3572 & 1,3810 \\
C8-C9 & 1,4372 & 1,4352 & 1,4540 \\
C12-C13 & 1,4372 & 1,3906 & 1,4540 \\
C10-C5 & 1,4282 & 1,4428 & 1,4019 \\
C3-C11 & 1,4282 & 1,4336 & 1,4019 \\
C13-N15 & 1,3553 & 1,4755 & 1,3637 \\
C8-N18 & 1,3552 & 1,3274 & 1,3637 \\
\hline & & & \\
& & & \\
& & & \\
\hline
\end{tabular}

Assim como para LA, os monômeros cristalinos de PF são torcidos. Proflc tem um dos anéis externos com ligações mais curtas do que o outro anel externo. Proflv é mais simétrico que Proflc, mas o anel central está dobrado ao meio, de forma que os anéis externos e as porções alifáticas das moléculas estão acima do plano.

No caso dos monômeros otimizados, foi verificado que o espectro de absorção consiste em uma transferência de carga na direção longitudinal, dos átomos das extremidades para os átomos do anel central. O mesmo acontece para os monômeros cristalinos, mas, 
embora as diferenças nas estruturas sejam pequenas, estas causam mudanças nas energias de excitação.

Comparando os comprimentos de onda de absorção obtidos para os monômeros otimizados $(\mathrm{AM}=651 \mathrm{~nm}, \mathrm{LA}=455 \mathrm{~nm}$ e PF = 442nm com ZINDO/IEFPCM, Seção 4.1 $)$, os valores experimentais (Tabela 1) e os resultados dos cálculos ZINDO/IEFPCM para os monômeros dos cristais (Tabela 16), pode-se observar que Mapaz e Cesmao absorvem em comprimentos de onda mais próximos do valor experimental que as correspondentes estruturas otimizadas, enquanto o monômero otimizado de PF absorve mais próximo do monômero experimental.

Tabela 16. Energias de absorção $(\varepsilon$, em eV) e comprimentos de onda ( $\lambda$, em nm) com as respectivas forças de oscilador $(f)$ e contribuições aos momentos de transição $\left(\mu_{\mathrm{x}}, \mu_{\mathrm{y}}\right.$ e $\mu_{\mathrm{z}}$ em u.a.) calculados com ZINDO/IEFPCM para cada monômero extraído dos cristais

\begin{tabular}{ccccccc}
\hline Cristal & $\boldsymbol{\varepsilon}$ & $\boldsymbol{\lambda}$ & $\boldsymbol{f}$ & $\boldsymbol{\mu}_{\mathbf{x}}$ & $\boldsymbol{\mu}_{\mathbf{y}}$ & $\boldsymbol{\mu}_{\mathbf{z}}$ \\
\hline Mapaz & 1,8817 & 659 & 1,2737 & $-5,26$ & 0,00 & 0,00 \\
Mbluet & 1,8852 & 658 & 1,2521 & $-5,21$ & 0,00 & 0,00 \\
Cesmao & 2,7355 & 453 & 1,0717 & $-4,00$ & $-0,02$ & 0,00 \\
Cesmes & 2,7101 & 457 & 1,0719 & 4,02 & 0,00 & 0,03 \\
Proflc & 2,8972 & 428 & 0,8753 & $-3,51$ & $-0,05$ & 0,01 \\
Proflv & 2,9209 & 424 & 0,8867 & 0,00 & 0,00 & 3,52 \\
\hline
\end{tabular}

Como mencionado anteriormente, o comportamento espectral experimental é um pouco diferente dos resultados teóricos se analisamos as famílias. A diferença entre os máximos de absorção da LA e da PF é igual a $50 \mathrm{~nm}$ e os cálculos teóricos fornecem uma diferença de apenas $13 \mathrm{~nm}$. Essa diferença poderia ser atribuída à presença (ou ausência) de grupos $\mathrm{N}\left(\mathrm{CH}_{3}\right)_{2}$, que, provavelmente, seria responsável por interações soluto-solvente não eletrostáticas. Entretanto, a diferença entre os máximos de absorção para os monômeros extraídos dos cristais passa a cerca de $30 \mathrm{~nm}$, o que representa melhor o comportamento experimental, indicando que o efeito responsável por essa diferença é na verdade a geometria. 
Dessa forma, mesmo que os nossos cálculos tenham fornecido resultados excelentes, a geometria não é tão planar como previsto anteriormente.

\subsection{Estudo dos dímeros dos corantes catiônicos}

\subsubsection{Estudo dos dímeros "extraídos" de cristais}

A Figura 23 apresenta as estruturas propostas para os dímeros extraídos das mesmas celas unitárias utilizadas no estudo dos monômeros na Seção 4.1.5. A seguir serão apresentadas as principais características desses dímeros, dentre elas a menor distância entre os monômeros.

Foram encontradas quatro conformações para o dímero de AM: Mapaz A e B, do cristal Mapaz, e Mbluet A e B, do cristal Mbluet. Mapaz A e Mbluet A são dímeros do tipo sanduíche, ou seja, os monômeros são praticamente paralelos entre si e paralelos ao plano xy. Em Mapaz A, um anel externo de um monômero está sobreposto ao anel central do outro monômero e a distância entre os monômeros (medida do C6 de um monômero ao S do outro) é igual a 3,6 Å, enquanto em Mbluet A um monômero está rotacionado de $180^{\circ}$ em relação ao outro monômero, com os anéis praticamente se sobrepondo, e a distância entre o N4 de um monômero ao C2 do outro monômero é de 3,5 Å.

Mapaz B e Mbluet B são dímeros co-planares, ou seja, os monômers estão no mesmo plano xy. No primeiro caso, um monômero está rotacionado de $180^{\circ}$ e a região dos monômeros que estão mais próximas são os átomos alifáticos (distância entre C16 de um

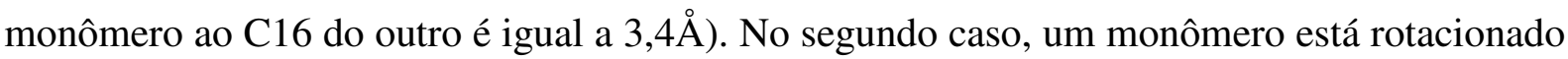


de $90^{\circ}$ e a menor distância entre os monômeros (do H ligado ao C14 de um monômero ao H metílico do outro) é igual a $3,4 \AA$.

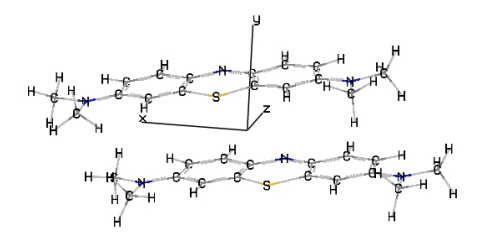

Mapaz A

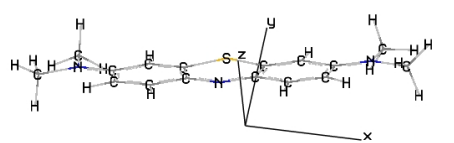

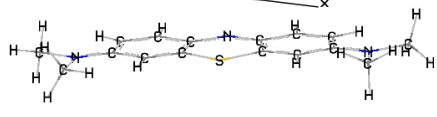

Mbluet A

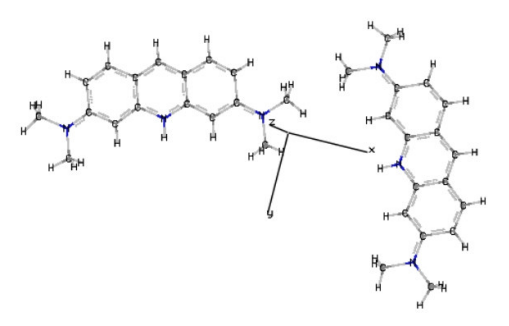

Cesmao A

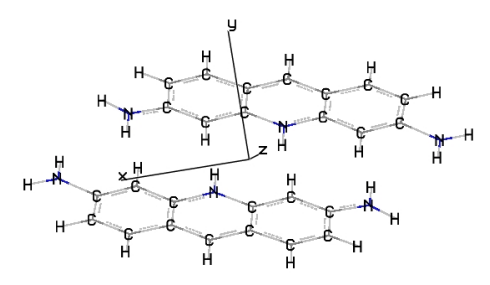

Proflc

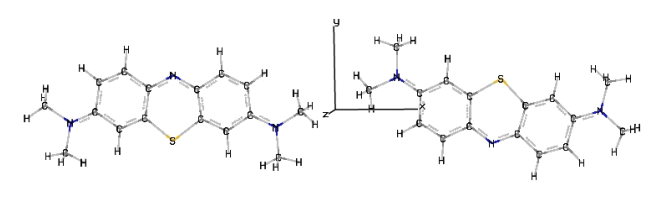

Mapaz B

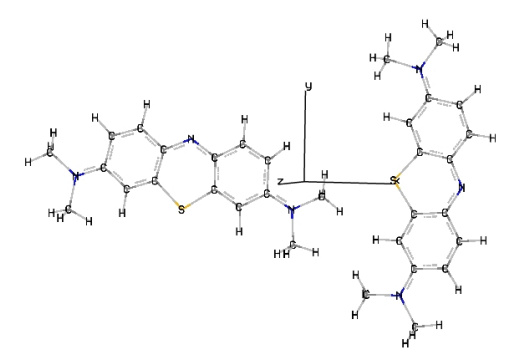

Mbluet B

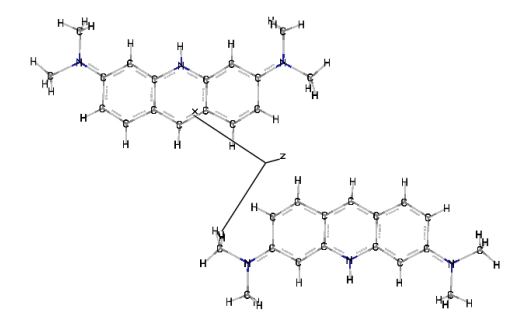

Cesmao B
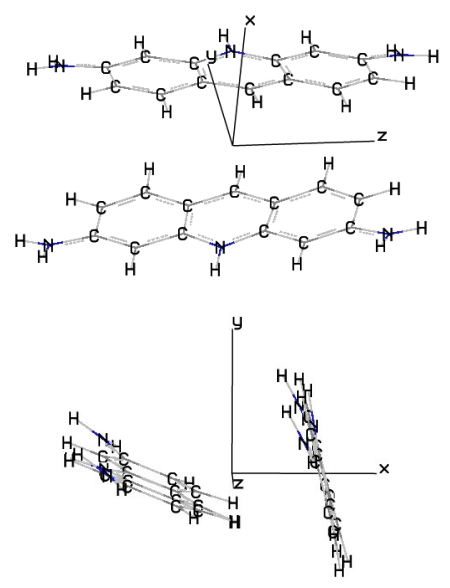

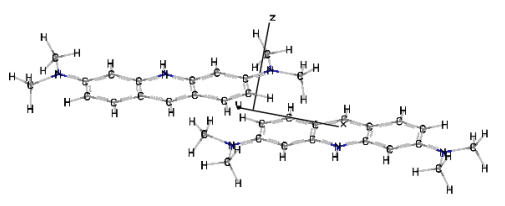

Proflv A

Figura 23. Estruturas dos dímeros extraídos dos cristais de AM (Mapaz e Mbluet), LA (Cesmao e Cesmes) e PF (Proflc e Proflv) com a orientação adotada. 
Para a LA, foram encontradas três conformações de dímeros: Cesmao A e B, extraídos do cristal Cesmao, ambos co-planares, e um dímero do cristal Cesmes, que é do tipo sanduíche. Em Cesmao A, um monômero está rotacionado de $90^{\circ}$ em relação ao outro e a regiões mais próximas são os grupos alifáticos (a distância do C16 de um monômero ao C17

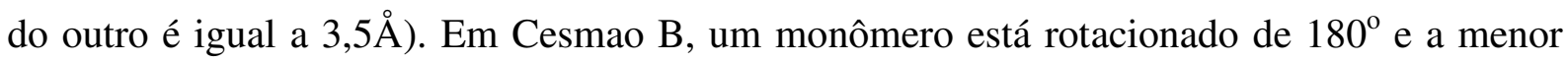
distância entre os monômeros (do H ligado ao C10 de um monômero ao H ligado ao C9 do outro) é igual a 3,1 A. Em Cesmes, os monômeros são praticamente paralelos e um monômero está rotacionado de $180^{\circ}$, um $\mathrm{N}\left(\mathrm{CH}_{3}\right)_{2}$ de um monômero está sobreposto a um anel externo do outro monômero e a distância do N18 de um monômero ao C8 do outro é igual a $3,6 \AA$.

Para a PF, assim como para a LA, foram encontradas três conformações de dímeros: Proflv A e B, extraídos do cristal Proflv, e um dímero do cristal Proflc. Proflv A e B apresentam conformação entre sanduíche e T (em que o plano que abranje um monômero é perpendicular ao plano do outro monômero). No primeiro caso, C10, C4 e C11 de um monômero apontam para os anéis do outro monômero e a menor distância entre os monômeros (do H ligado ao C10 de um monômero e o C10 do outro monômero) é de 2,7 Å. Em Proflv B, a menor distância pode ser medida do N15 de um monômero ao H ligado ao C7 do outro e é igual a 2,9 Å. Proflc é quase um dímero sanduíche, com os monômeros quase paralelos entre si e ao plano xz, com um anel externo de um monômero sobreposto ao anel central do outro monômero; a menor distância entre os monômeros é 3,7 ̊̊ (do N1 de um monômero ao C14 do outro).

Foram calculadas as energias de cada monômero e dímero (Tabela 17) com o intuito de compará-las e verificar se é possível identificar a energia de atração entre os monômeros para formar os dímeros. A energia de interação é positiva, ou seja, é repulsiva, grande para os dímeros derivados do cristal Mapaz e menor para os demais cristais. Por isso é tão difícil 
obter estruturas para os dímeros por otimização direta com o método e base empregados (DFT/B3LYP/6-31+g(d)).

Tabela 17. Energia total calculada com B3LYP/6-31G(d)/IEFPCM para os monômeros ( $\mathrm{E}_{\mathrm{T}, \mathrm{Mon}}$ em u.a.) e dímeros ( $\mathrm{E}_{\mathrm{T}, \mathrm{Dim}}$ em u.a.) extraídos dos cristais

\begin{tabular}{|c|c|c|c|c|}
\hline Cristal & $\mathbf{E}_{T, M o n}($ u.a.) & Dímero & $\mathbf{E}_{\text {T,Dim }}$ (u.a.) & $\begin{array}{c}\mathrm{E}_{\mathrm{T}, \mathrm{Dim}}-2\left(\mathrm{E}_{\mathrm{T}, \mathrm{Mon}}\right) \\
(\text { kcal.mol } \\
\text { (1) })\end{array}$ \\
\hline \multirow[t]{2}{*}{ Mapaz } & $-1182,850$ & $\mathrm{~A}$ & $-2365,614$ & 53,9 \\
\hline & & B & $-2365,630$ & 43,9 \\
\hline \multirow[t]{2}{*}{ Mbluet } & $-1182,803$ & A & $-2365,597$ & 5,6 \\
\hline & & B & $-2365,599$ & 4,4 \\
\hline \multirow[t]{2}{*}{ Cesmao } & $-823,714$ & A & $-1647,425$ & 1,9 \\
\hline & & B & $-1647,425$ & 1,9 \\
\hline Cesmes & $-823,981$ & -- & $-1647,956$ & 3,8 \\
\hline Proflc & $-666,753$ & -- & $-1333,498$ & 5,0 \\
\hline \multirow[t]{2}{*}{ Proflv } & $-666,752$ & A & $-1333,498$ & 3,8 \\
\hline & & B & $-1333,503$ & 0,6 \\
\hline
\end{tabular}

Uma outra forma de verificar se os dímeros obtidos podem ser considerados como dímeros em solução, é calculando o espectro. A Tabela 18 apresenta as energias e os comprimentos de onda de absorção, forças do oscilador, dipolos de transição e os $\mathrm{OM}$ envolvidos nos principais estados excitados calculados com ZINDO/IEFPCM para cada dímero extraído dos cristais. Para todos os dímeros, os OM envolvidos são HOMO-1, HOMO, LUMO e LUMO+1 (a representação gráfica desses orbitais é apresentada nas Figuras 24 a 26). Estes OM apresentam o mesmo comportamento dos OM dos monômeros, ou seja, os orbitais preenchidos têm contribuições dos átomos das extremidades das moléculas e os OM virtuais são formados também pelo anel central da molécula. Entretanto, os monômeros contribuem de diferentes formas para os estados excitados. 
Tabela 18. Energias de absorção $(\varepsilon$, em eV) e comprimentos de onda ( $\lambda$, em nm) com respectivos força do oscilador $(f)$, contribuições ao momento de transição $\left(\mu_{\mathrm{x}}, \mu_{\mathrm{y}}\right.$ e $\mu_{\mathrm{z}}$, em u.a.) e orbitais moleculares $(\mathrm{H}=\mathrm{HOMO}$ e $\mathrm{L}=\mathrm{LUMO}$ ) envolvidos no principais estados excitados (E.E.) calculados com ZINDO/IEFPCM para cada dímero extraído dos cristais

\begin{tabular}{|c|c|c|c|c|c|c|c|}
\hline Dímero & $\varepsilon$ (E.E.) & $\lambda$ & $f$ & $\mu_{\mathbf{x}}$ & $\mu_{\mathbf{y}}$ & $\mu_{\mathrm{z}}$ & Excitação* \\
\hline \multirow[t]{4}{*}{ Mapaz A } & $1,5957(1)$ & 777 & 0,0065 & $-0,05$ & 0,07 & 0,40 & $\mathrm{H}-1 \rightarrow \mathrm{L}+1(0,25)$ \\
\hline & & & & & & & $\mathrm{H} \rightarrow \mathrm{L}(0,65)$ \\
\hline & $2,0556(2)$ & 603 & 2,1964 & 6,53 & $-0,94$ & 0,11 & $\mathrm{H}-1 \rightarrow \mathrm{L}+1(0,29)$ \\
\hline & & & & & & & $\mathrm{H} \rightarrow \mathrm{L}(0,63)$ \\
\hline \multirow[t]{4}{*}{ Mapaz B } & $1,8518(1)$ & 669 & 2,5121 & 7,41 & $-0,70$ & 0,14 & $\mathrm{H}-1 \rightarrow \mathrm{L}(0,45)$ \\
\hline & & & & & & & $\mathrm{H}-1 \rightarrow \mathrm{L}+1(-0,19)$ \\
\hline & & & & & & & $\mathrm{H} \rightarrow \mathrm{L}(0,20)$ \\
\hline & & & & & & & $\mathrm{H} \rightarrow \mathrm{L}+1(0,44)$ \\
\hline \multirow[t]{4}{*}{ Mbluet A } & $1,6766(1)$ & 739 & 0,0000 & $-0,03$ & 0,00 & $-0,01$ & $\mathrm{H}-1 \rightarrow \mathrm{L}+1(0,35)$ \\
\hline & & & & & & & $\mathrm{H} \rightarrow \mathrm{L}(0,60)$ \\
\hline & $2,0817(2)$ & 596 & 2,5911 & $-7,05$ & $-1,03$ & $-0,23$ & $\mathrm{H}-1 \rightarrow \mathrm{L}(0,48)$ \\
\hline & & & & & & & $\mathrm{H} \rightarrow \mathrm{L}+1(0,49)$ \\
\hline \multirow[t]{6}{*}{ Mbluet B } & $1,8765(1)$ & 661 & 1,1823 & 4,04 & 3,07 & 0,00 & $\mathrm{H}-1 \rightarrow \mathrm{L}(0,42)$ \\
\hline & & & & & & & $\mathrm{H}-1 \rightarrow \mathrm{L}+1(-0,24)$ \\
\hline & & & & & & & $\mathrm{H} \rightarrow \mathrm{L}(0,25)$ \\
\hline & & & & & & & $\mathrm{H} \rightarrow \mathrm{L}+1(0,44)$ \\
\hline & $1,9024(2)$ & 652 & 1,3256 & $-3,33$ & 4,17 & 0,00 & $\mathrm{H}-1 \rightarrow \mathrm{L}(0,49)$ \\
\hline & & & & & & & $\mathrm{H} \rightarrow \mathrm{L}+1(-0,48)$ \\
\hline \multirow[t]{4}{*}{ Cesmao A } & $2,7203(1)$ & 456 & 1,2226 & 3,95 & 1,65 & 0,07 & $\mathrm{H}-1 \rightarrow \mathrm{L}(-0,47)$ \\
\hline & & & & & & & $\mathrm{H} \rightarrow \mathrm{L}+1(0,48)$ \\
\hline & $2,7510(2)$ & 451 & 0,9322 & 1,47 & $-3,42$ & $-0,06$ & $\mathrm{H}-1 \rightarrow \mathrm{L}(0,49)$ \\
\hline & & & & & & & $\mathrm{H} \rightarrow \mathrm{L}+1(0,47)$ \\
\hline \multirow[t]{2}{*}{ Cesmao B } & $2,7384(1)$ & 453 & 2,1276 & 4,78 & 2,98 & 0,14 & $\mathrm{H}-1 \rightarrow \mathrm{L}+1(-0,45)$ \\
\hline & & & & & & & $\mathrm{H} \rightarrow \mathrm{L}(0,52)$ \\
\hline
\end{tabular}

* Entre parênteses estão os coeficientes de expansão CI. 
Tabela 18 (conclusão). Energias de absorção $(\varepsilon$, em eV) e comprimentos de onda $(\lambda$, em nm) com respectivos força do oscilador $(f)$, contribuições ao momento de transição $\left(\mu_{\mathrm{x}}, \mu_{\mathrm{y}}\right.$ e $\mu_{\mathrm{z}}$, em u.a.) e orbitais moleculares (H=HOMO e $\mathrm{L}=\mathrm{LUMO}$ ) envolvidos no principais estados excitados (E.E.) calculados com ZINDO/IEFPCM para cada dímero extraído dos cristais

\begin{tabular}{|c|c|c|c|c|c|c|c|}
\hline Dímero & $\varepsilon$ (E.E.) & $\lambda$ & $f$ & $\mu_{\mathrm{x}}$ & $\mu_{\mathbf{y}}$ & $\mu_{\mathrm{z}}$ & Excitação* \\
\hline \multirow[t]{4}{*}{ Cesmes } & $2,7018(1)$ & 459 & 2,0717 & 5,38 & $-1,16$ & 0,99 & $\mathrm{H}-1 \rightarrow \mathrm{L}(-0,25)$ \\
\hline & & & & & & & $\mathrm{H}-1 \rightarrow \mathrm{L}+1(-0,34)$ \\
\hline & & & & & & & $\mathrm{H} \rightarrow \mathrm{L}(0,38)$ \\
\hline & & & & & & & $\mathrm{H} \rightarrow \mathrm{L}+1(-0,37)$ \\
\hline \multirow[t]{4}{*}{ Proflc } & $2,6747(1)$ & 463 & 0,0000 & $-0,02$ & $-0,01$ & 0,00 & $\mathrm{H}-1 \rightarrow \mathrm{L}+1(0,28)$ \\
\hline & & & & & & & $\mathrm{H} \rightarrow \mathrm{L}(0,62)$ \\
\hline & $2,9664(2)$ & 418 & 1,4739 & $-4,37$ & $-1,07$ & 0,11 & $\mathrm{H}-1 \rightarrow \mathrm{L}(0,49)$ \\
\hline & & & & & & & $\mathrm{H} \rightarrow \mathrm{L}+1(0,47)$ \\
\hline \multirow[t]{8}{*}{ Proflv A } & $2,8336(1)$ & 438 & 0,0081 & 0,00 & 0,00 & 0,34 & $\mathrm{H}-1 \rightarrow \mathrm{L}(-0,44)$ \\
\hline & & & & & & & $\mathrm{H}-1 \rightarrow \mathrm{L}+1(0,10)$ \\
\hline & & & & & & & $\mathrm{H} \rightarrow \mathrm{L}(0,15)$ \\
\hline & & & & & & & $\mathrm{H} \rightarrow \mathrm{L}+1(0,49)$ \\
\hline & $2,9696(2)$ & 417 & 1,6158 & 0,00 & 0,00 & 4,71 & $\mathrm{H}-1 \rightarrow \mathrm{L}(0,45)$ \\
\hline & & & & & & & $\mathrm{H}-1 \rightarrow \mathrm{L}+1(-0,22)$ \\
\hline & & & & & & & $\mathrm{H} \rightarrow \mathrm{L}(0,23)$ \\
\hline & & & & & & & $\mathrm{H} \rightarrow \mathrm{L}+1(0,38)$ \\
\hline \multirow[t]{4}{*}{ Proflv B } & $2,9084(1)$ & 426 & 1,6860 & $-4,53$ & 1,72 & $-0,45$ & $\mathrm{H}-1 \rightarrow \mathrm{L}(0,27)$ \\
\hline & & & & & & & $\mathrm{H}-1 \rightarrow \mathrm{L}+1(-0,35)$ \\
\hline & & & & & & & $\mathrm{H} \rightarrow \mathrm{L}(0,51)$ \\
\hline & & & & & & & $\mathrm{H} \rightarrow \mathrm{L}+1(0,10)$ \\
\hline
\end{tabular}

* Entre parênteses estão os coeficientes de expansão CI. 


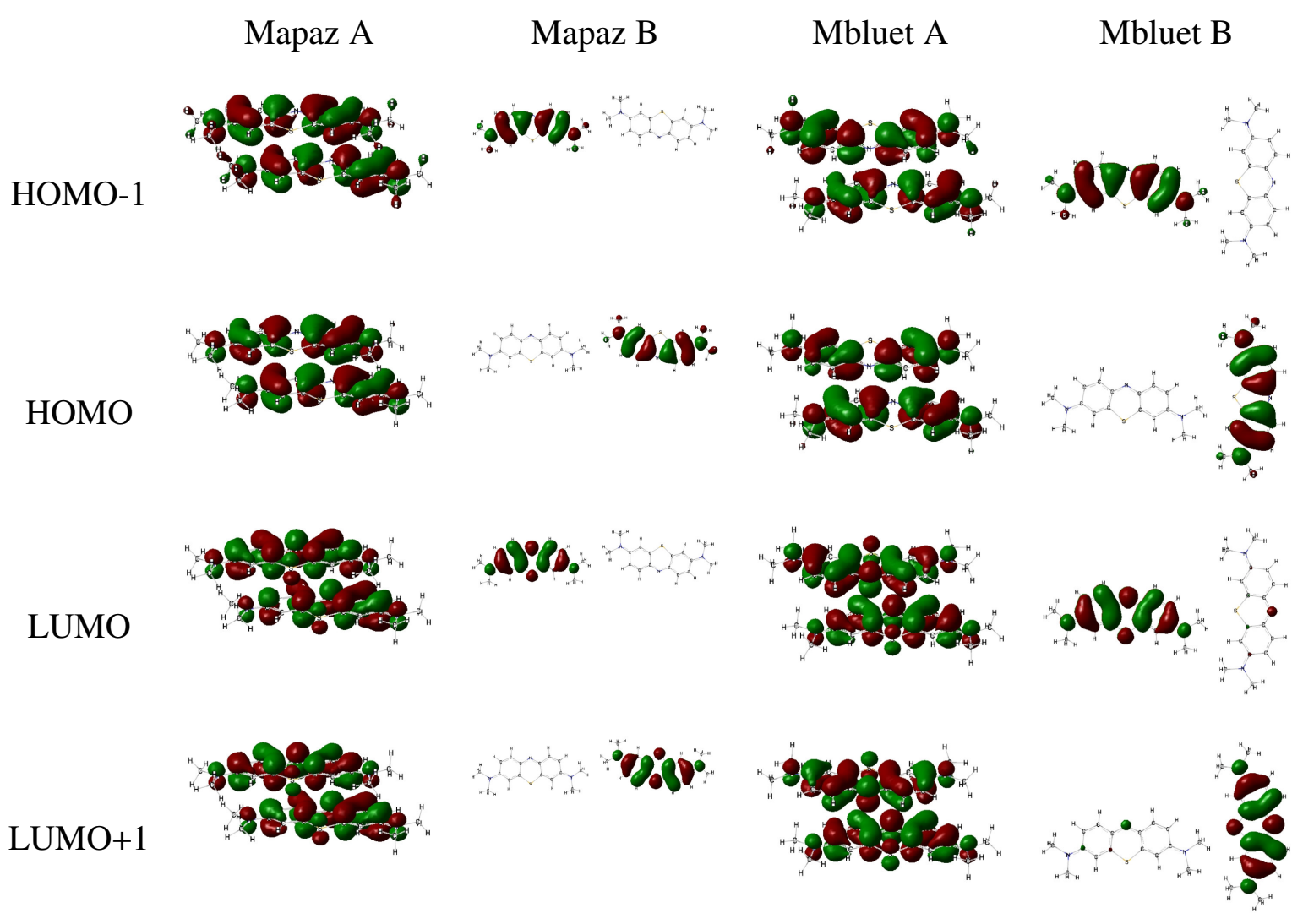

Figura 24. Representação gráfica dos OM de fronteira para os dímeros de AM.

Mapaz A apresenta o split mencionado na Introdução, com uma transição proibida (em $777 \mathrm{~nm} \operatorname{com} f=0,0)$ e uma banda de energia mais alta $(603 \mathrm{~nm} \operatorname{com} f=2,2)$ do que a energia de transição do monômero, com excelente concordância com os valores experimentais (apresentados na Tabela 1). Como observado anteriormente para os monômeros (Seção 4.1), a transição envolve principalmente o HOMO e o LUMO (ou seja, os coeficientes CI são maiores), para os quais ambos os monômeros contribuem, com uma transferência de carga na direção longitudinal (o dipolo de transição na direção $\mathrm{x}, \mu_{\mathrm{x}}$, tem o maior valor) dos átomos das extremidades para os átomos do anel central (os heteroátomos, principalmente) de cada monômero.

Mapaz B não apresenta a banda proibida e tem uma transição em 670nm, valor este bastante próximo do máximo de absorção do monômero. HOMO-1 e LUMO têm 
contribuições de apenas um dos monômeros e HOMO e LUMO+1 são compostos pelo outro monômero, então, as transições principais correspondem a transições individuais dos monômeros. As contribuições de menor coeficiente CI, ou seja, HOMO-1 para LUMO+1 e HOMO para LUMO, consistem de uma transferência de carga de um monômero para o outro.

Mbluet A tem propriedades espectrais similares a Mapaz A, mas os máximos de absorção ocorrem em comprimentos de onda menores e, conseqüentemente, não reproduzem tão bem o espectro experimental. Mbluet B tem dois máximos, mas ambos são similares aos máximos dos monômeros. Como observado para Mapaz B, as transições correspondem a excitações individuais dos monômeros. O dipolo de transição para o primeiro estado excitado tem uma maior contribuição na direção $\mathrm{x}$, correspondendo, portanto, à excitação do monômero orientado ao longo dessa direção, enquanto o segundo estado corresponde à excitação do monômero disposto ao longo da direção y.

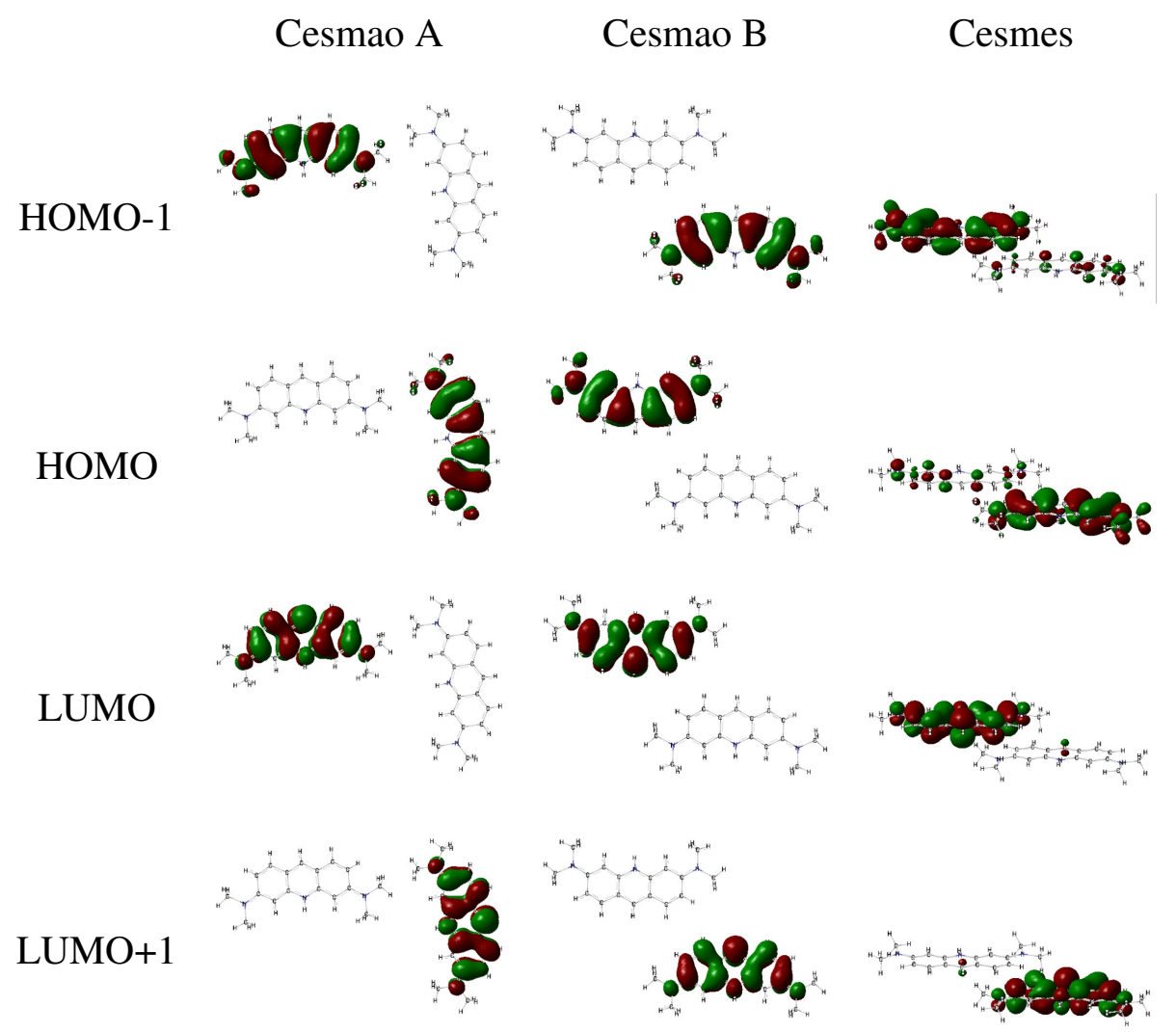

Figura 25. Representação gráfica dos OM de fronteira para os dímeros de LA. 
Cesmao A tem comportamento igual ao do Mbluet $\mathrm{B}$, mas neste caso, o primeiro estado excitado ocorre no mesmo comprimento de onda do monômero otimizado e não apresenta excitações nas quais ocorra uma transferência de carga de um monômero para o outro. Cesmao B, assim como Mapaz B, não apresenta a banda proibida e tem uma transição em 453 nm, que é similar à banda do monômero otimizado; HOMO-1 e LUMO+1 têm contribuições de apenas um monômero e HOMO e LUMO são compostos pelo outro monômero, então as principais transições correspondem a uma excitação individual de cada monômero. Assim como Cesmao B, Cesmes não apresenta o split, mas, neste caso, as transições de um monômero para o outro (HOMO-1 para LUMO+1 e HOMO para LUMO) são bastante importantes.

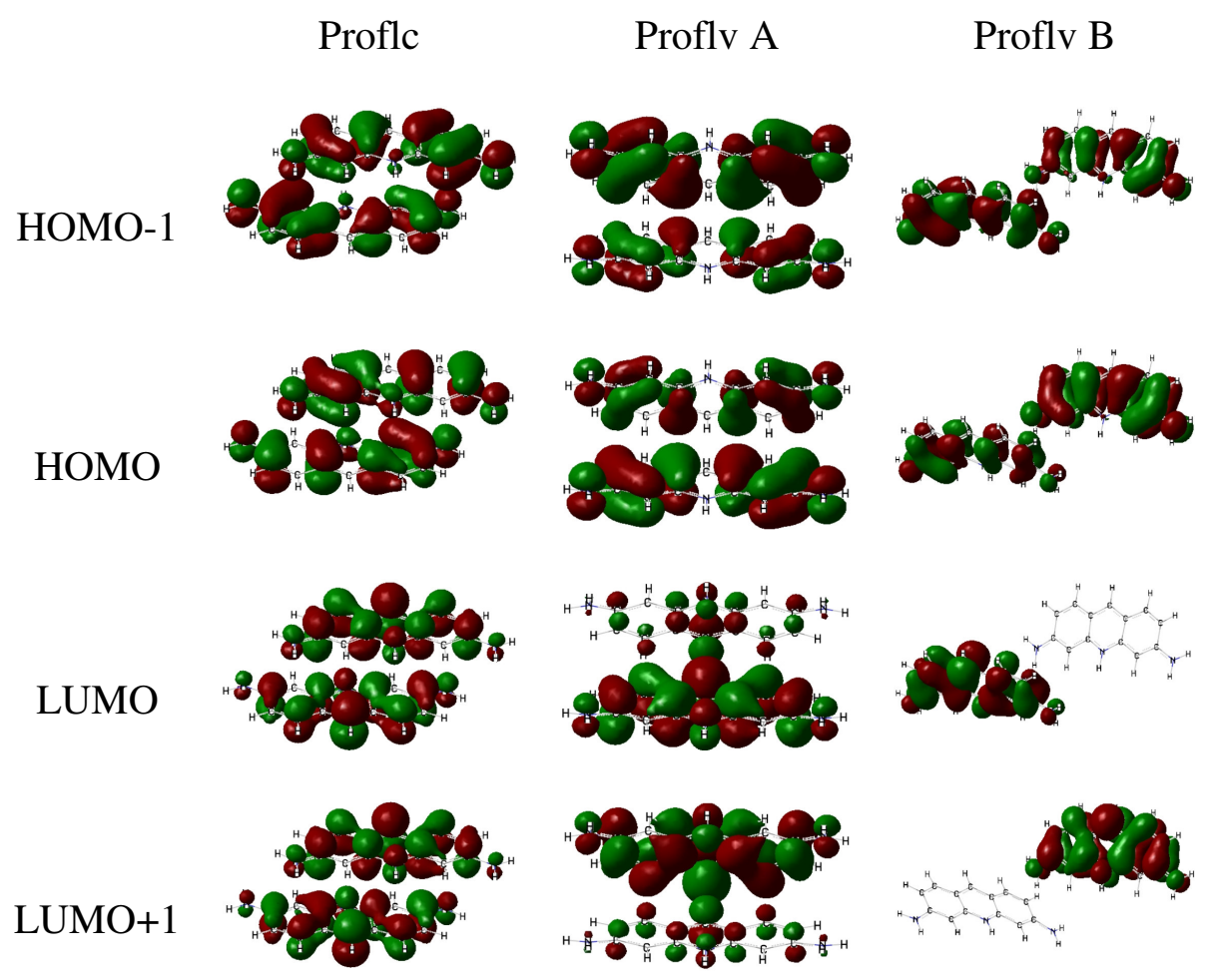

Figura 26. Representação gráfica dos OM de fronteira para os dímeros de PF.

Proflc apresenta o comportamento previsto para um dímero, assim como Mapaz A, com uma transição proibida (em $464 \mathrm{~nm} \operatorname{com} f=0,0)$ e uma banda de energia mais alta (418 
nm $\operatorname{com} f=1,5)$ que a banda do monômero. O segundo estado excitado envolve uma transição do HOMO para o LUMO+1 e do HOMO-1 para o LUMO e, dessa forma, os dois monômeros contribuem para a banda. O split é observado também para a Proflv A: enquanto o monômero do cristal absorve em 424 nm, o dímero tem uma transição proibida em $438 \mathrm{~nm}$ e uma outra banda em $418 \mathrm{~nm}$, com transferência de carga de um monômero para o outro, evidenciada pelas excitações HOMO-1 para LUMO e HOMO para LUMO+1. Proflv B apresenta somente uma transição importante, que é similar à transição do monômero. É interessante notar, entretanto, que os OM ocupados têm contribuição dos dois monômeros, enquanto os virtuais têm contribuição de apenas um monômero, levando a uma concentrarão de carga quando a excitação ocorre.

\subsubsection{Simulações MC do dímero de $\mathrm{AM}$}

Nesta seção, são apresentados os resultados de duas simulações para o dímero de AM: uma chamada de "caixa pequena", em que a caixa de simulação tem o mesmo tamanho da caixa utilizada para os monômeros, ou seja, conta com 1000 moléculas de água, e outra de “caixa grande”, com 2000 moléculas de água. A geometria e as cargas dos monômeros que compõem o dímero foram obtidas individualmente com DFT-IEFPCM.

A Figura 27 apresenta a variação da energia com os ciclos MC para as duas simulações. Observa-se que o sistema menor se encontra termalizado após 15 mil ciclos, enquanto o maior apenas após 50 mil ciclos. Como no caso dos monômeros, depois da termalização o sistema é bem comportado, indicando que a seleção das configurações é confiável. 


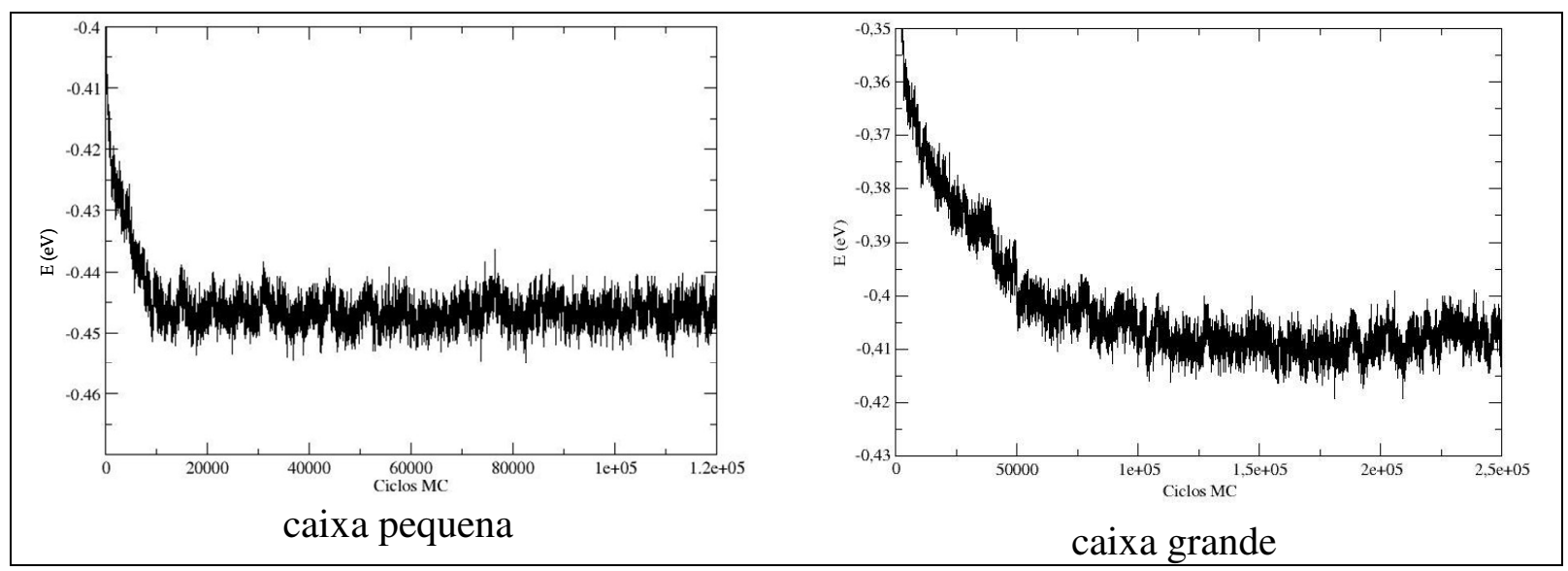

Figura 27. Energia ao longo dos ciclos MC para as simulações do dímero do corante.

Foram, então, selecionadas configurações a cada 800 ciclos e calculados os espectros para os dímeros. Neste caso, não foram incluídas moléculas de solvente, pois o objetivo principal era analisar as conformações adquiridas pelo dímero.

Para os dímeros é necessário observar os dois primeiros estados excitados e as respectivas forças de oscilador, para verificar se ocorre o split mencionado na seção anterior, confirmando a formação do dímero, ou se o espectro corresponde somente à soma dos espectros dos monômeros. Todas as conformações selecionadas apresentaram split, sendo a força do oscilador do primeiro estado excitado próxima a zero e a força do oscilador do segundo estado tem valor próximo a dois, como pode ser verificado nos dois Apêndices. Aqui, nos restringimos a mostrar apenas os $\lambda$ do $2^{\circ}$ estado excitado para cada conformação selecionada das simulações (Figura 28). 


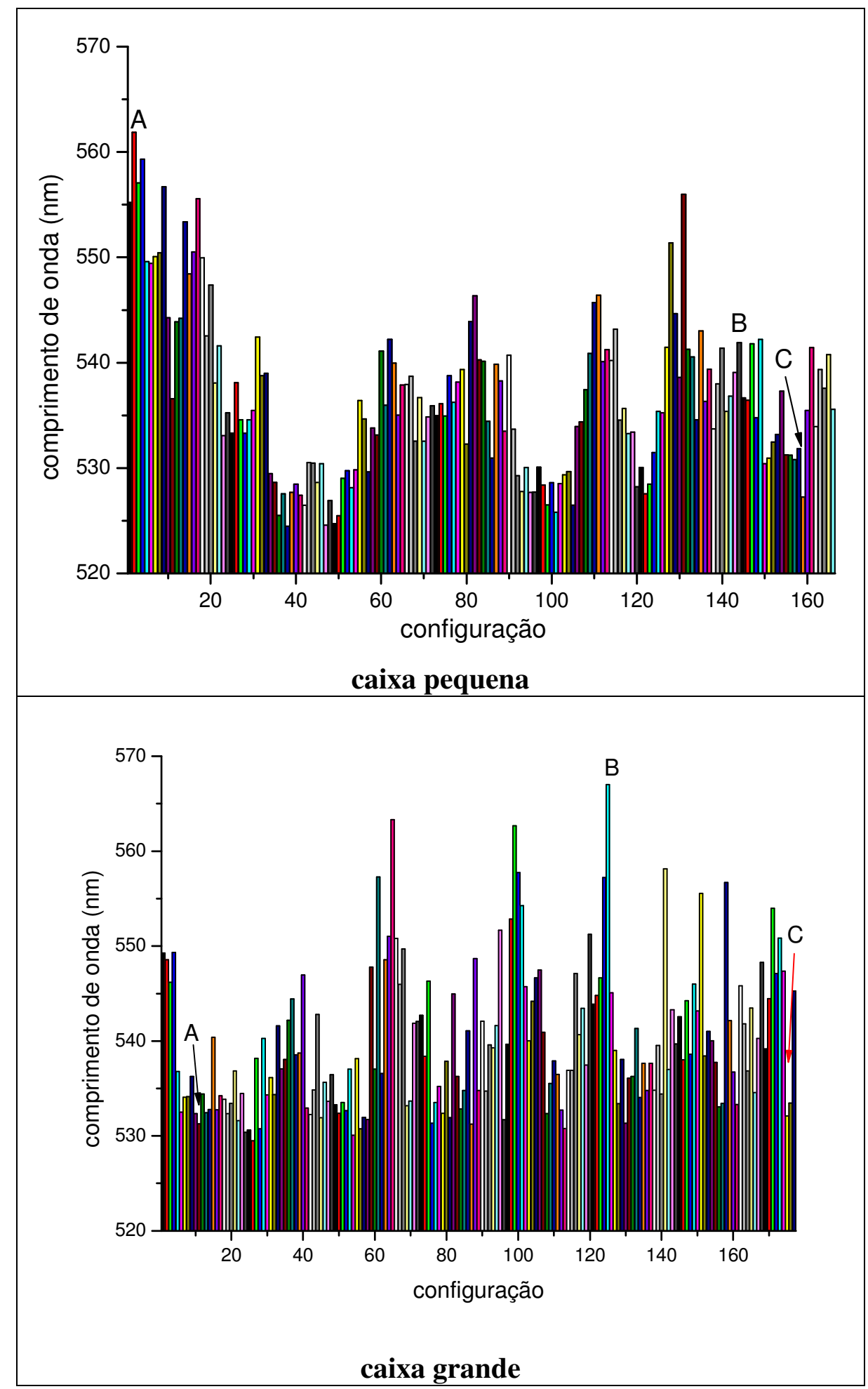

Figura 28. Gráfico de barras com os comprimentos de onda (nm) calculados com ZINDO para as configurações selecionadas das duas simulações para o dímero do AM.

No espectro experimental do AM, a banda do monômero ocorre em $665 \mathrm{~nm}$ e a do dímero em $605 \mathrm{~nm}$, ou seja, há um deslocamento de $60 \mathrm{~nm}$ na transição principal. O 
monômero otimizado com DFT/IEFPCM absorve em 583 nm (calculado com ZINDO/vácuo). Sendo a média dos $\lambda$ das conformações obtidas com a simulação da caixa pequena de $537 \mathrm{~nm}$ e a média para a caixa grande de $540 \mathrm{~nm}$, observa-se que no espectro teórico há um deslocamento de cerca de $45 \mathrm{~nm}$. O deslocamento observado para os dímeros sanduíche da seção anterior (Mapaz A e Mbluet B) é de cerca de $55 \mathrm{~nm}$.

A seguir, são apresentadas algumas conformações selecionadas (A, B e C na Figura 28) das duas simulações com as respectivas propriedades geométricas e espectrais.

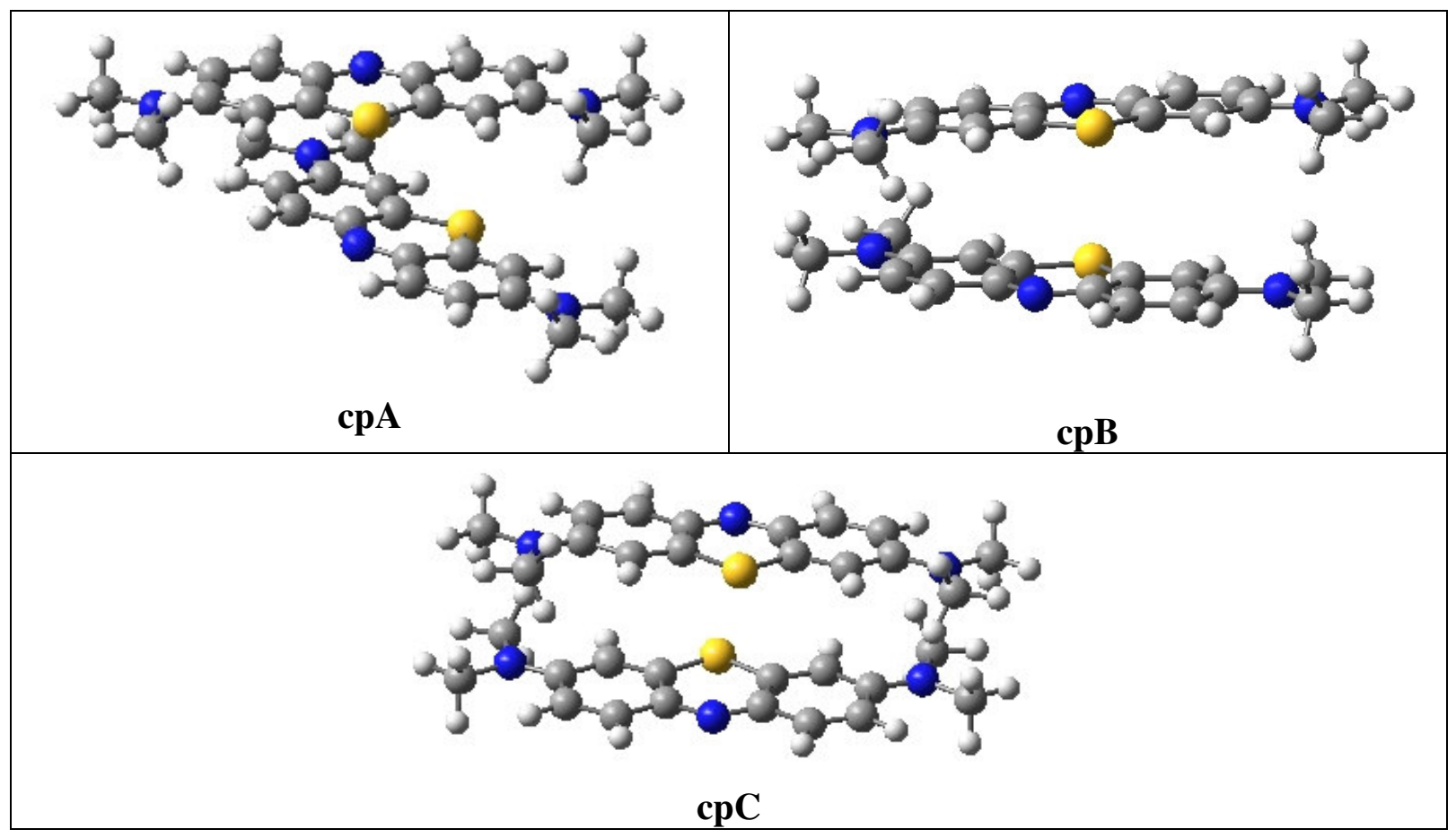

Figura 29. Configurações selecionadas da simulação para o dímero do AM com a caixa pequena (cp).

A simulação da caixa pequena (cp) partiu da conformação sanduíche, mas com um monômero rotacionado de $180^{\circ}$ em relação ao outro. Na configuração cpA, o ângulo de rotação de um monômero em relação ao outro diminuiu para $120^{\circ}$, um monômero está ligeiramente inclinado em relação ao outro e a menor distância entre os monômeros, que pode ser medida do $\mathrm{N}$ do anel central de um monômero ao $\mathrm{S}$ do outro monômero, é de $3,8 \AA$. Esse dímero apresenta uma banda em $645 \mathrm{~nm} \operatorname{com} f=0,46$ e outra em $562 \mathrm{~nm} \operatorname{com} f=1,94$. 
Na configuração cpB, o ângulo passa a ser $150^{\circ}$, com os monômeros mantendo-se em planos praticamente paralelos entre si, à uma distância de 3,7 ̊̊. Os $\lambda$ apresentados por esse dímero são: $676 \mathrm{~nm} \operatorname{com} f=0,14$ e $542 \mathrm{~nm} \operatorname{com} f=2,15$.

Na configuração cpC, os monômeros se encontram na conformação de partida, ou seja, o ângulo de rotação é $180^{\circ}$. A distância entre os monômeros é de $3,8 \AA$ e as bandas de absorção ocorrem em $691 \mathrm{~nm} \operatorname{com} f=0,00$ e $527 \mathrm{~nm} \operatorname{com} f=2,56$.

Tendo em vista que o ângulo de rotação de um monômero em relação ao outro e a distância entre os monômeros não se alteraram significativamente durante a simulação (esperava-se obter configurações com ângulos de rotação de $0^{\circ}$ a $180^{\circ}$ e com distâncias variadas), foi realizada uma nova simulação, dessa vez partindo do dímero com ângulo de rotação entre os monômeros igual a $0^{\circ}$ e com a caixa de simulação maior (caixa grande, cg), de forma que o tamanho da caixa não restringisse o movimento das moléculas de corante.

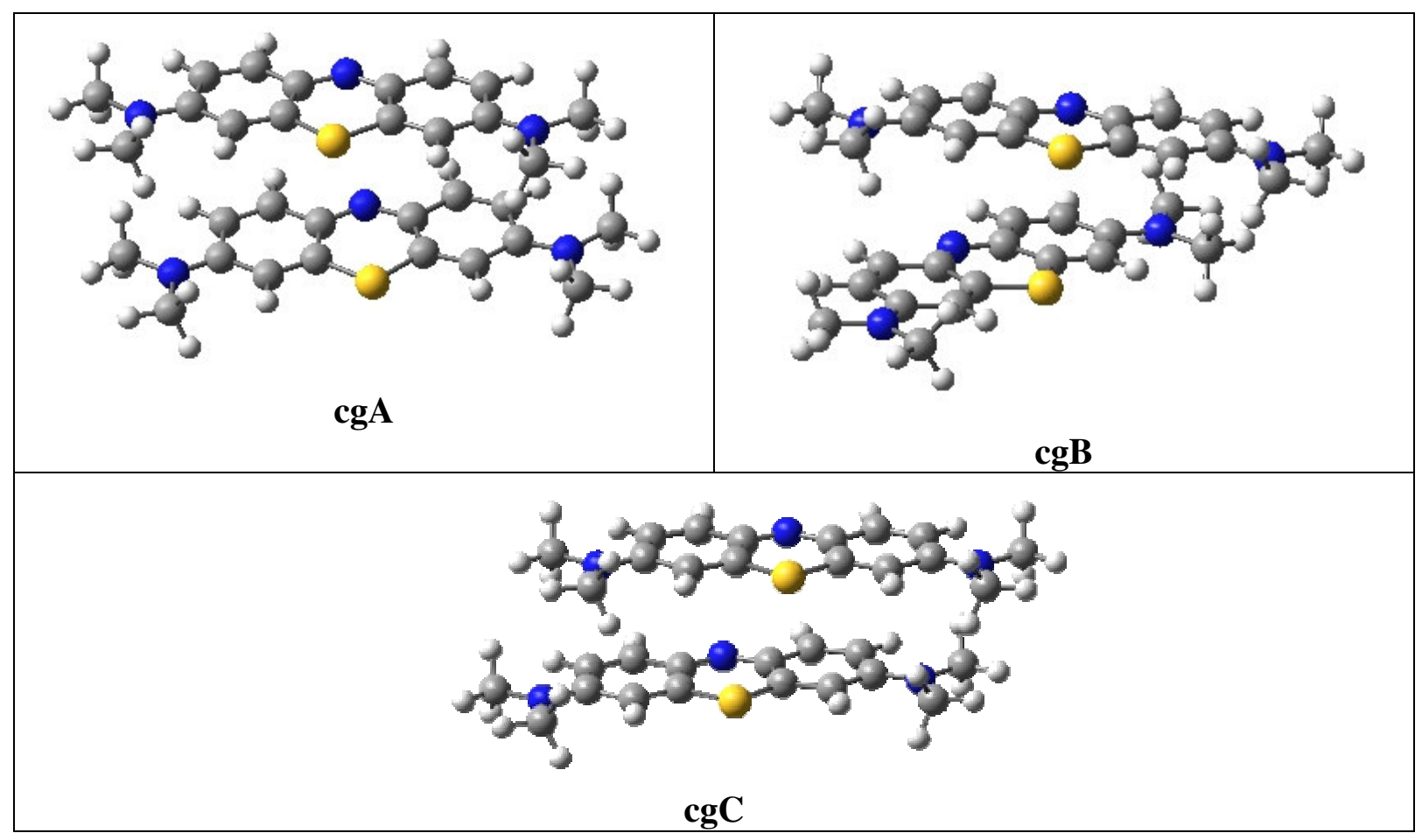

Figura 30. Configurações selecionadas da simulação para o dímero do AM com a caixa grande (cg). 
Nas três conformações selecionadas da simulação com a caixa grande, os monômeros estão em planos paralelos entre si. Na configuração cgA, o ângulo de rotação de um monômero em relação ao outro é de $10^{\circ}$, e a distância entre os $\mathrm{N}$ dos anéis centrais é de 4,0 A. Esse dímero apresenta uma banda em $682 \mathrm{~nm} \operatorname{com} f=0,01$ e outra em $531 \mathrm{~nm} \operatorname{com} f=2,51$.

$\mathrm{Na}$ configuração $\operatorname{cgB}$, o ângulo passa a ser $40^{\circ}$ e a distância entre os átomos de $\mathrm{S}$ é de 3,8 $\mathrm{A}$. Os $\lambda$ apresentados por esse dímero são: $653 \mathrm{~nm} \operatorname{com} f=0,34$ e $567 \mathrm{~nm} \operatorname{com} f=1,74$.

Já na configuração cgC, a distância entre os monômeros é de 3,8 Å, o ângulo de rotação volta a ser $0^{\circ}$, entretanto um monômero está deslocado em relação ao outro, no sentido longitudinal das moléculas, em cerca de 1,5 $\mathrm{A}$. As bandas de absorção ocorrem em $674 \mathrm{~nm} \operatorname{com} f=0,00$ e $532 \mathrm{~nm} \operatorname{com} f=2,56$.

As conformações adquiridas pelo dímero, teoricamente, não deveriam depender da configuração de partida. Foram realizadas outras simulações, partindo de diferentes conformações, entretanto, os resultados não diferem significativamente dos aqui apresentados. Provavelmente, não há problemas com o número de ciclos realizados, uma vez que o sistema sai da configuração de início e retorna a ela diversas vezes. Algumas alternativas para tentar encontrar outras configurações em uma mesma simulação seriam: realizar a simulação no ensemble NPT, introduzir graus de liberdade interna às moléculas do corante ou construir um potencial a partir das estruturas cristalográficas, que não são tão planares como as estruturas otimizadas.

Os dímeros sanduíche em que os monômeros se encontram perfeitamente sobrepostos, ou seja, têm um ângulo de rotação de um monômero em relação ao outro igual a $0^{\circ}$ ou $180^{\circ}$ ( $\mathrm{pC}$ e $\operatorname{cgC}$ ), têm a banda mais intensa em $\lambda$ menores do que as outras conformações, de forma que o deslocamento em relação ao monômero é de cerca de $55 \mathrm{~nm}$, como verificado para alguns dos dímeros retirados dos cristais. São as conformações em que o ângulo é diferente de $0^{\circ}$ e $180^{\circ}$ que fazem com que o $\lambda$ médio seja mais alto. 
Mesmo considerando uma estrutura completamente planar para o monômero, os dímeros com ângulo $=0^{\circ}$ e $180^{\circ}$ reproduzem muito bem o comportamento experimental. Assim, pode-se concluir que a conformação experimental que absorve em $605 \mathrm{~nm}$ deve realmente corresponder a um sanduíche em que o ângulo entre os monômeros é de $0^{\circ}$ ou de $180^{\circ}$.

\subsection{Modelos para a argila montmorilonita}

A montmorilonita é uma argila do tipo 2:1, dioctaédrica e expansível. A sua estrutura cristalográfica foi determinada por Tsipursky e Drits $[142,143]$ e pode ser representada pela estrutura apresentada na Figura 31, composta por 328 átomos. Para os cálculos de química quântica foi selecionado o cluster destacado na Figura 31. Foram ligados átomos de hidrogênio aos átomos de oxigênio que tiveram ligações rompidas e, assim, a estrutura utilizada corresponde a $\mathrm{Si}_{30} \mathrm{O}_{47} \mathrm{H}_{44}$.

A adsorção de moléculas orgânicas em silicatos se dá, geralmente, por um dos cinco mecanismos enumerados a seguir [75]:

1. substituição dos cátions inorgânicos interlamelares por cátions orgânicos;

2. ligações hidrogênio do tipo $\mathrm{NH} \cdots \mathrm{O}, \mathrm{OH} \cdots \mathrm{O}, \mathrm{CH} \cdots \mathrm{O}$ etc;

3. atração do tipo van der Waals, que pode ser dominante na adsorção de moléculas grandes e íons;

4. interação eletrostática;

5. coordenação com os cátions interlamelares.

Dessa forma, uma propriedade importante para avaliar o cluster que será utilizado na interação com os corantes é a carga atômica. Assim, foram calculadas para o cluster 
selecionado as cargas atômicas de Mulliken, utilizando o método semi-empírico AM1 (Figura 32).

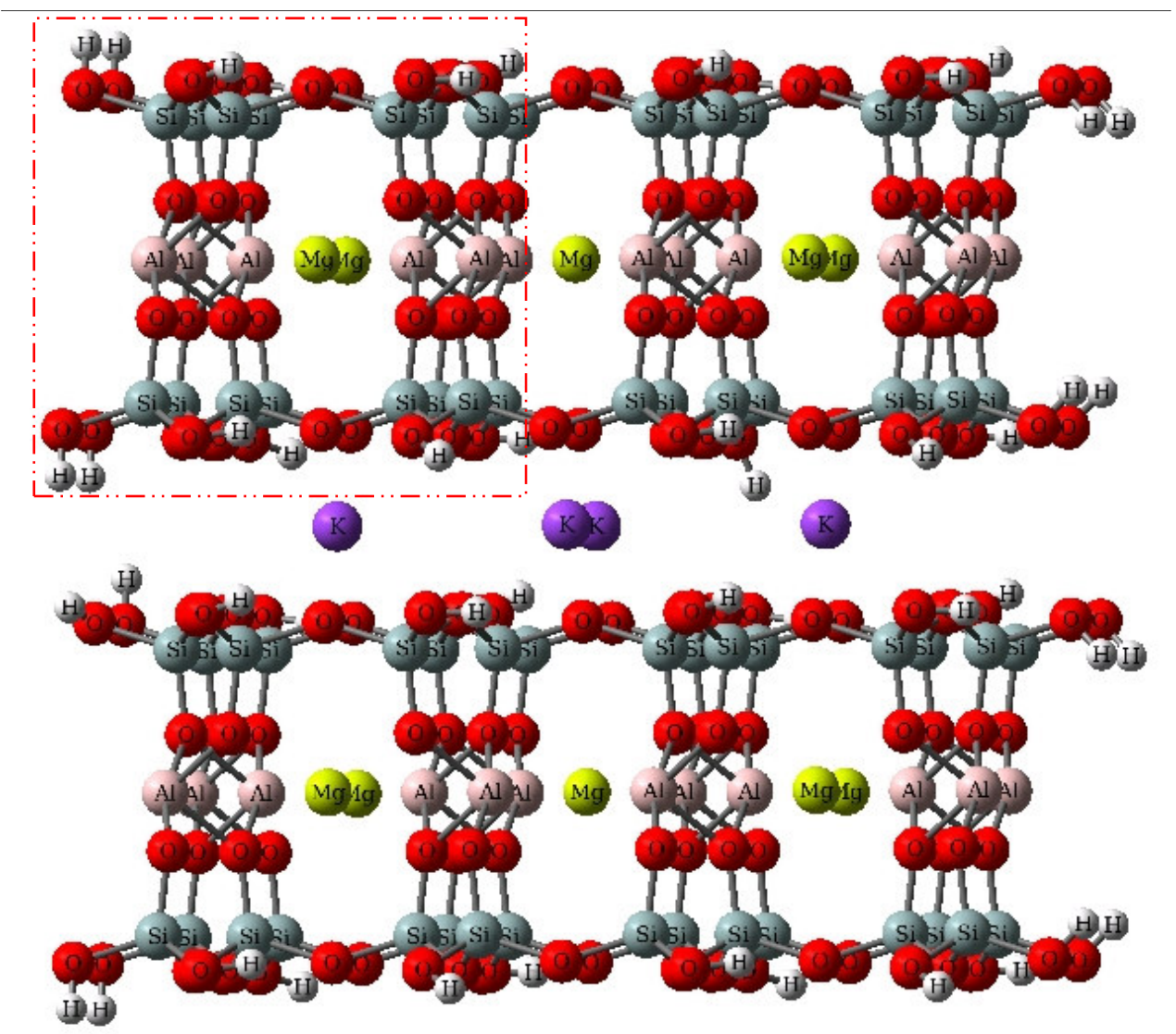

Figura 31. Estrutura da argila montmorilonita determinada por Tsipursky et al. [142,143].

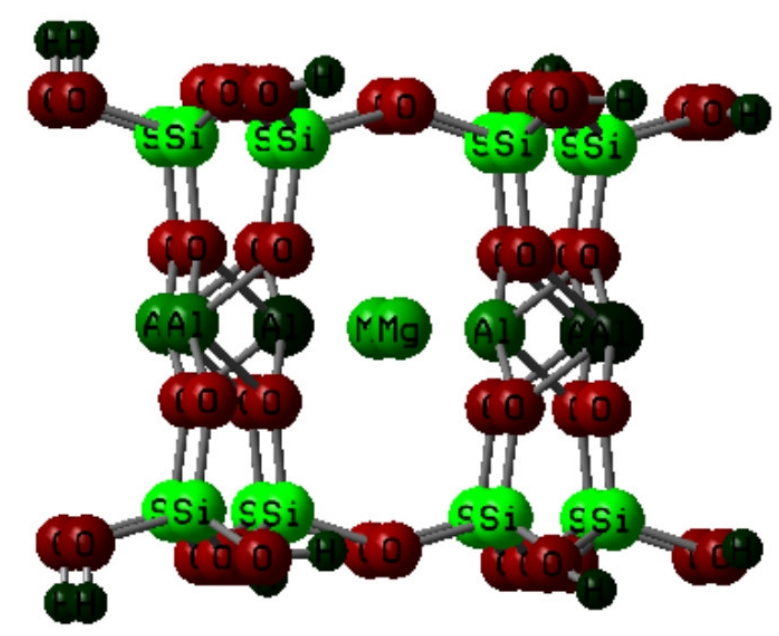

$-1,31$ 1,31

Figura 32. Cargas atômicas calculadas para o cluster extraído da estrutura proposta por Tsipursky et al. [142,143] para a montmorilonita. 
Os átomos de Si têm carga positiva em torno de 1,3, os $\mathrm{Mg}$ em torno de 0,8 e os $\mathrm{Al}$ em verde claro em torno de 0,5 e os $\mathrm{Al}$ em verde escuro em torno de 0,10 . Os átomos de $\mathrm{O}$ têm cargas que variam entre $-0,50$ e $-0,65$. Chartejee et al. [67] partiram da estrutura da pirofilita para obter a estrutura da montmorilonita e, para esta, realizaram o cálculo das cargas atômicas com o método MNDO. O cluster utilizado pelos autores $\left(\mathrm{SiAlO}_{7} \mathrm{H}_{7}\right)$ é diferente do aqui utilizado, porém as cargas calculadas apresentam a mesma tendência que as cargas obtidas aqui, ou seja, o Si concentra mais carga positiva do que o $\mathrm{Al}$ e os átomos de $\mathrm{O}$ têm a carga negativa distribuída entre eles de forma homogênea.

Em uma outra linha de estudo teórico sobre a argila montmorilonita, Skipper et al. [58] realizam simulações utilizando apenas o plano siloxano (Figura 33) para representar a montmorilonita. Este é o plano em que ocorrem as interações com o meio e compreende apenas átomos de $\mathrm{Si}$ e de $\mathrm{O}$. O restante da estrutura é substituído por 4 cargas pontuais negativas. Os autores atribuem as seguintes cargas atômicas: 0,8 para o O e 1,2 para o Si. Para comparação, selecionou-se também um cluster de fórmula $\mathrm{Si}_{30} \mathrm{O}_{47} \mathrm{H}_{44}$ (correspondente a um plano siloxano) para o cálculo das cargas atômicas de Mulliken (Figura 34). Neste caso, as cargas nos átomos de $\mathrm{Si}$ passam de cerca de 1,3 no primeiro cluster para mais de 1,4 (os $\mathrm{Si}$ das extremidades continuam com carga 1,3). Mas a maior variação se dá na carga dos átomos de O, que passa a ser, em média, -0,8. Este valor está de acordo com as cargas calculadas por Chaterjee et al. [67] e com as cargas utilizadas por Skipper et al. [58]. Dessa forma, dentre os clusters propostos, o plano siloxano foi o escolhido para os cálculos com os corantes catiônicos. 


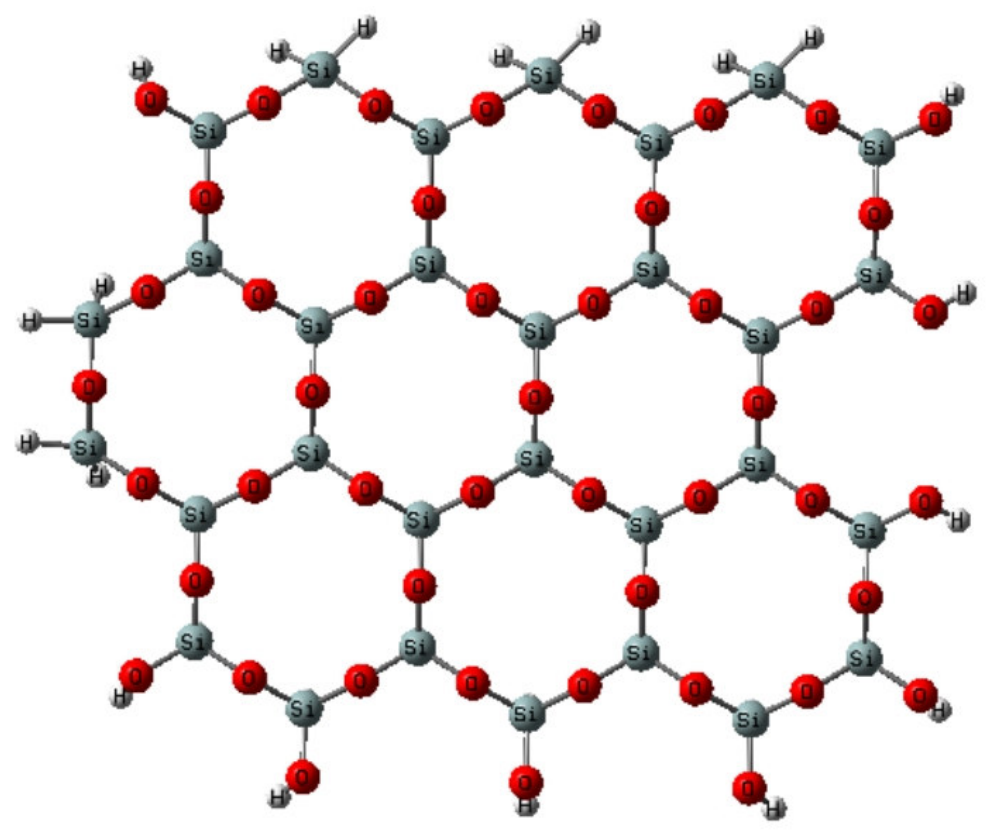

Figura 33. Plano siloxano da argila montmorilonita.

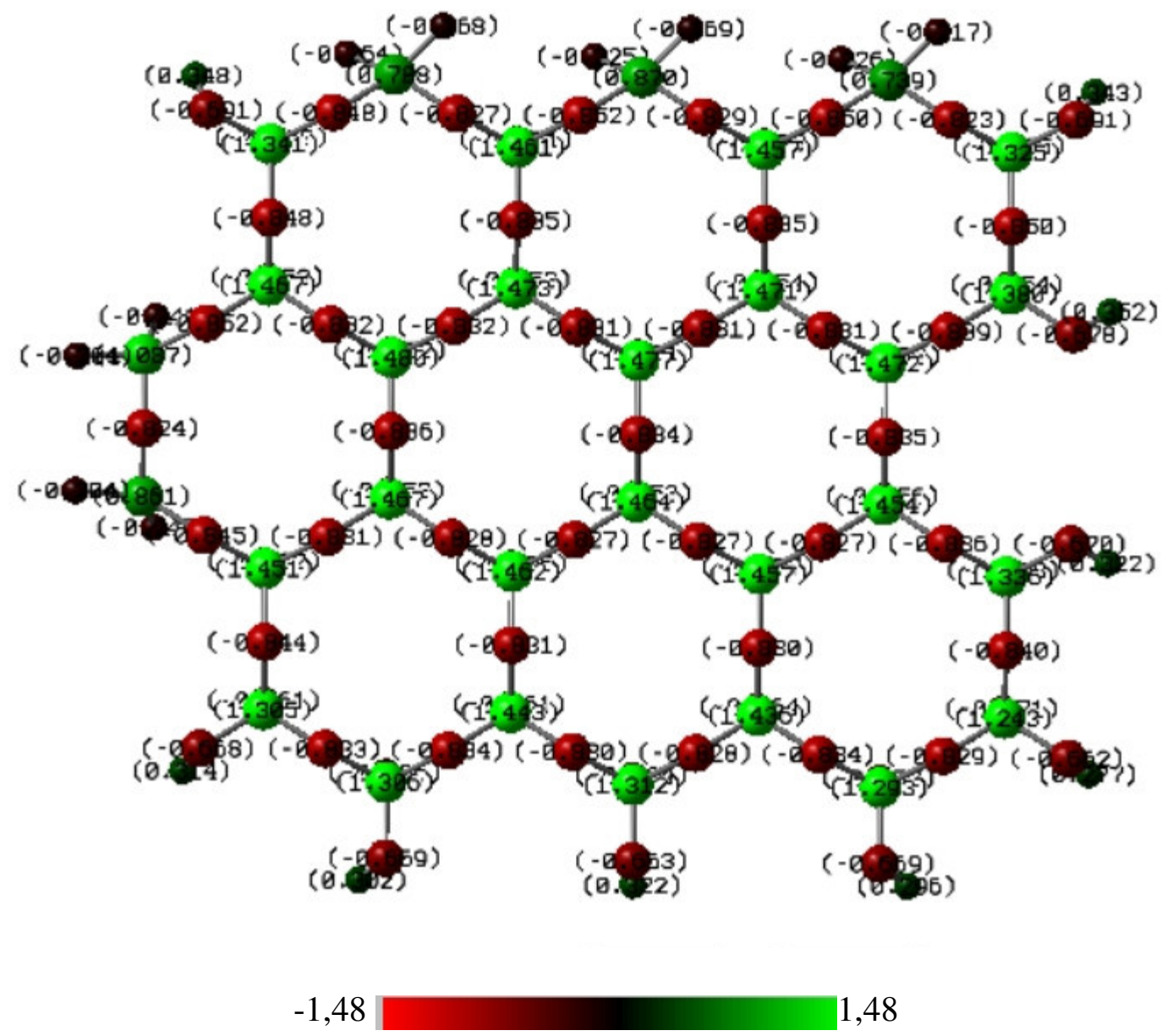

Figura 34. Cargas atômicas calculadas para o plano siloxano. 


\subsection{Interação corante-argila}

$\mathrm{Na}$ seção anterior, foram mencionados cinco mecanismos para a adsorção de moléculas orgânicas em silicatos. Com exceção dos mecanismos 1 e 5, que envolvem os cátions interlamelares, os outros mecanismos envolvem os átomos da superfície do silicato. Assim, neste estudo inicial sobre a interação dos corantes com a argila, foi utilizada para representar a argila apenas uma parte de sua estrutura: o plano siloxano (de fórmula $\left.\mathrm{Si}_{30} \mathrm{O}_{47} \mathrm{H}_{44}\right)$.

As estruturas dos corantes foram previamente obtidas com a otimização DFT/IEFPCM (Seção 4.1.1). Para a SF, no entanto, foram utilizadas duas estruturas diferentes: uma obtida pela otimização sem restrições com DFT/IEFPCM (que nesta seção será chamada de SF 90) e outra obtida com o ângulo entre o anel e o plano dos três anéis fundidos fixo em $20^{\circ}$ (apresentada na Seção 4.1.2 e aqui será chamada de SF $20^{\circ}$ ).

$\mathrm{Na}$ Seção 4.1.5, verificou-se que o empacotamento cristalino e a conseqüente proximidade a outras moléculas de corante faz com que as estruturas dos corantes não sejam planares (como previsto pelas otimizações no vácuo e em meio aquoso), mas torcidas. Aqui, o objetivo era verificar se a argila poderia também alterar a geometria dos corantes. Para isso as otimizações foram realizadas partindo-se das moléculas dos corantes colocadas paralelas ao plano da argila, de forma a proporcionar a maior superfície de interação entre as estruturas.

A estrutura otimizada do plano siloxano com o corante LA é apresentada na Figura 35. Tanto o corante quanto a argila se dobram de forma que as extremidades de ambos se aproximam. O mesmo ocorre para os demais corantes. A estrutura do plano siloxano após as otimizações é destacada na Figura 36 e as estruturas dos corantes na Figura 37. Como é possível observar nas Figuras 35 e 36, a borda da argila mais próxima do corante se dobra enquanto a borda oposta apenas os átomos de oxigênio saem do plano. É interessante notar 
também o aumento nas cargas atômicas do plano siloxano: comparando a Figura 34 com a Figura 35, observa-se que a cargas dos átomos de Si aumentam de 1,4 para cerca de 1,8 e a dos átomos de $\mathrm{O}$ de -0,8 para -1,0, após otimização com os corantes.

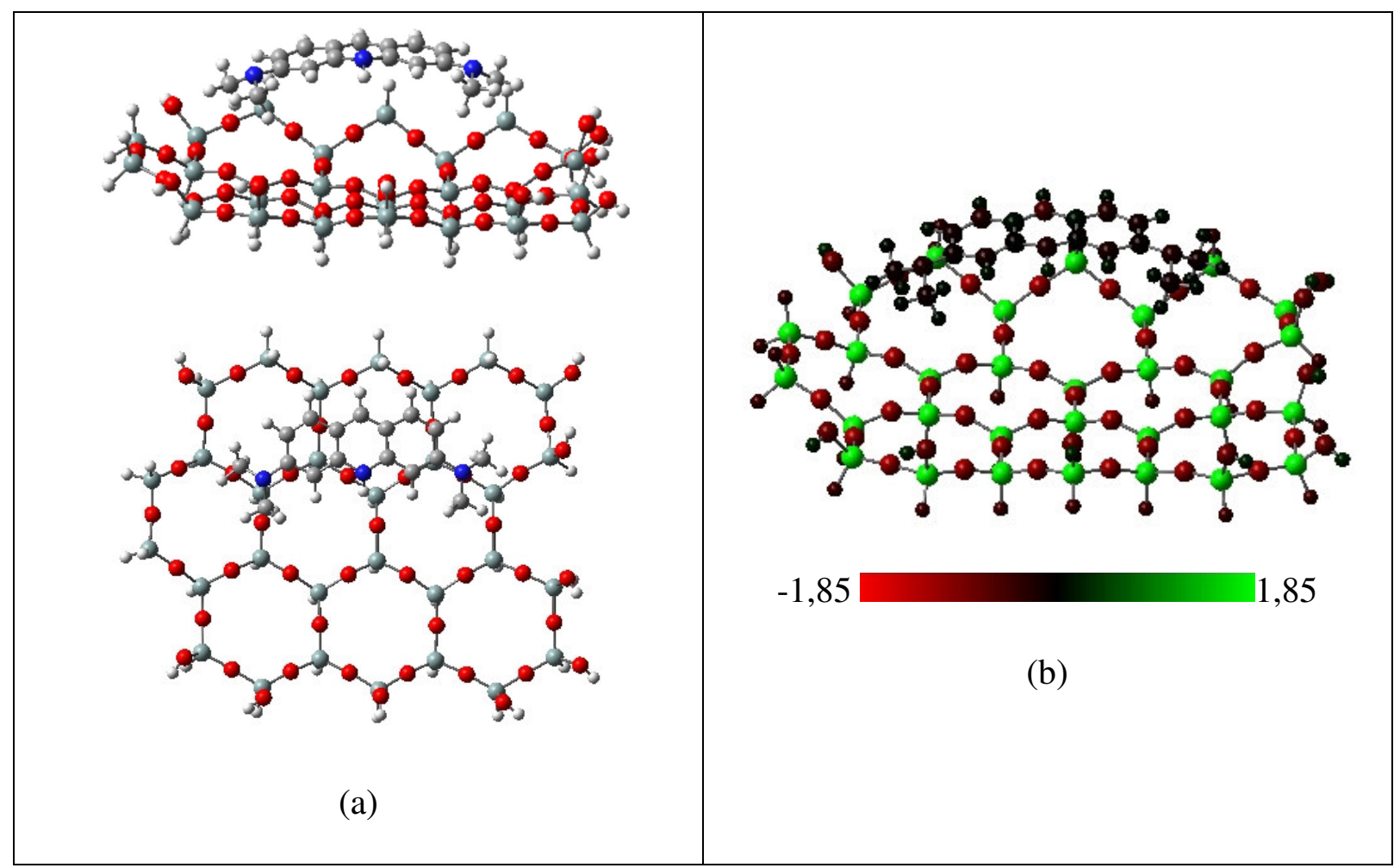

Figura 35. (a) Estrutura otimizada (vista lateral e superior) e (b) cargas atômicas do cluster formado pelo plano siloxano e o corante LA.

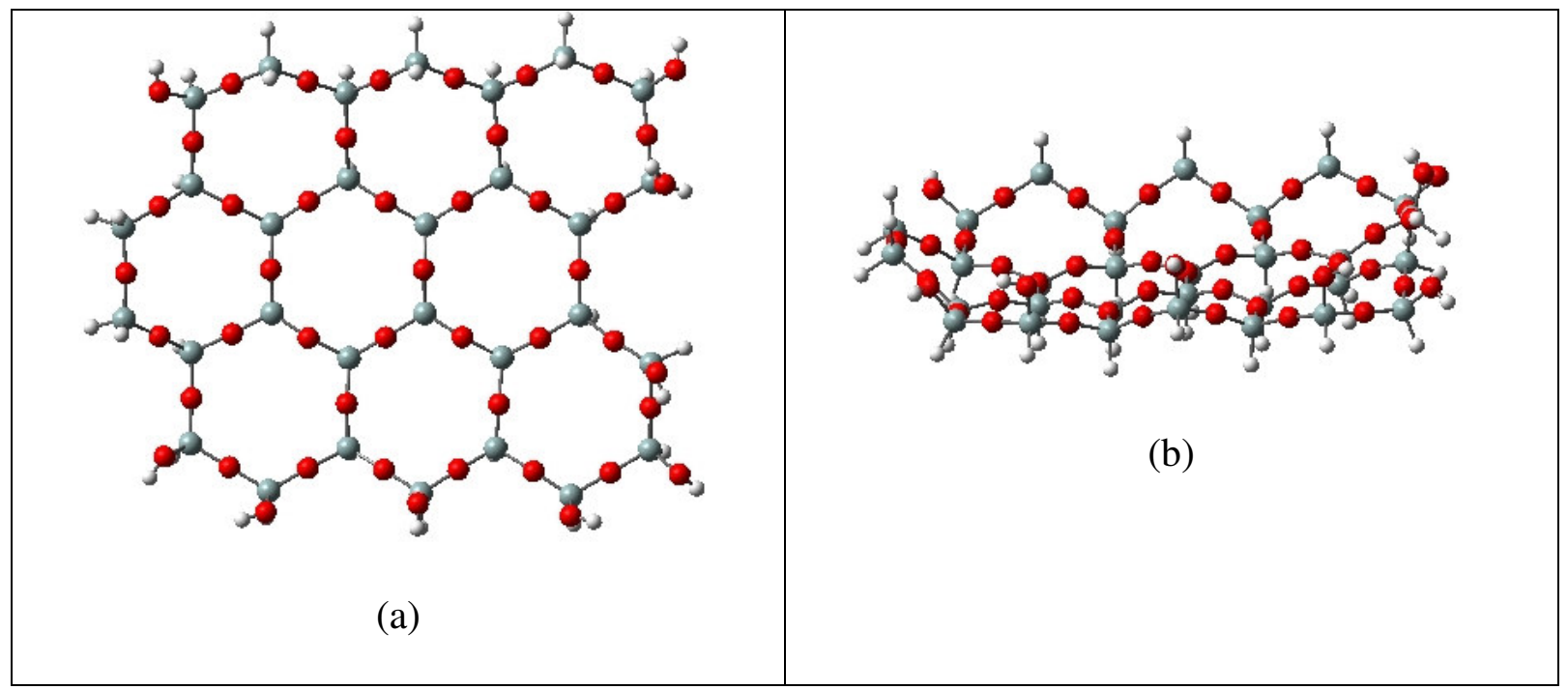

Figura 36. Plano siloxano após otimização com os corantes: (a) projeção superior e (b) projeção lateral. 


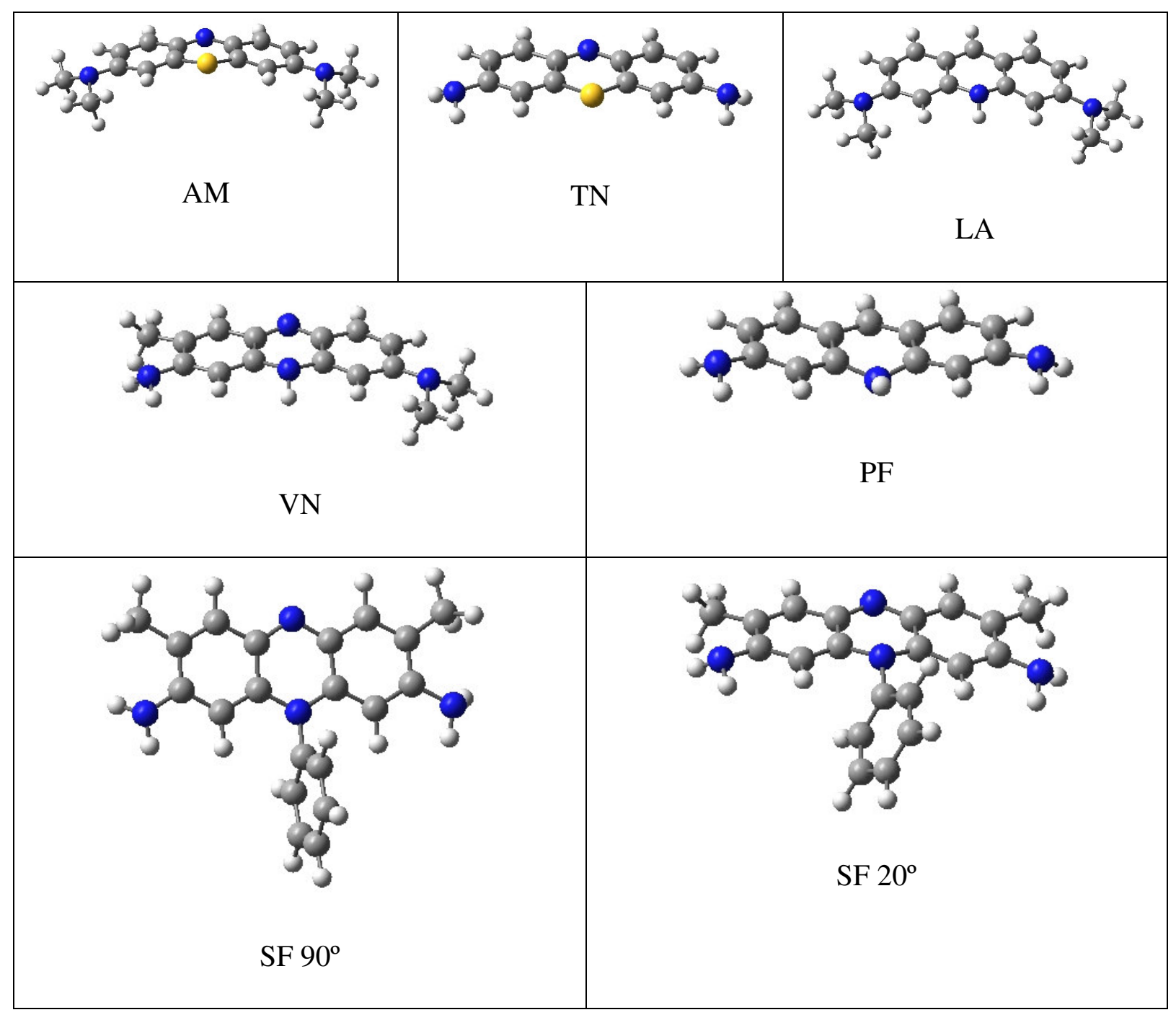

Figura 37. Geometria obtida para cada corante após otimização com plano siloxano.

As estruturas obtidas para os corantes foram isoladas e, então, calculado o espectro para cada uma com o método ZINDO e os calores de formação e energias totais com o método AM1. Comparando o $\lambda$ das estruturas obtidas da otimização na presença da argila com o $\lambda$ das estruturas otimizadas com AM1 no vácuo (vide Tabela 19), observa-se que o erro em relação ao espectro experimental continua praticamente o mesmo e os calores de formação e as energias totais são maiores que os obtidos para as estruturas no vácuo. 
Tabela 19. Comprimento de onda de absorção $(\lambda$, em nm) e correspondente erro em relação ao valor experimental calculado para os corantes otimizados com o plano siloxano, energia total $\left(\mathrm{E}_{\mathrm{T}}\right.$, em eV) e calor de formação $\left(\Delta \mathrm{H}_{\mathrm{f}}\right.$, em kcal) para os corantes otimizados com AM1 no vácuo e na presença da argila

\begin{tabular}{|c|c|c|c|c|c|c|c|c|}
\hline \multirow[b]{2}{*}{ Corante } & \multicolumn{4}{|c|}{ Corantes otimizados com argila } & \multicolumn{4}{|c|}{$\begin{array}{l}\text { Corantes otimizados no vácuo } \\
\text { (para comparação) }\end{array}$} \\
\hline & $\lambda(\mathbf{n m})$ & $\begin{array}{l}\text { erro } \\
(\%)^{*}\end{array}$ & $\begin{array}{c}\Delta \mathbf{H}_{\mathrm{f}} \\
\text { (kcal) }\end{array}$ & $\mathbf{E}_{\mathbf{T}}(\mathbf{e V})$ & $\lambda(\mathbf{n m})$ & $\begin{array}{l}\text { erro } \\
(\%)^{*}\end{array}$ & $\begin{array}{c}\Delta \mathbf{H}_{\mathbf{f}} \\
(\mathbf{k c a l})\end{array}$ & $\mathbf{E}_{\mathbf{T}}(\mathbf{e V})$ \\
\hline AM & 571 & 14 & 260,7 & $-3102,6$ & 581 & 13 & 242,4 & $-3103,4$ \\
\hline $\mathrm{TN}$ & 533 & 11 & 242,7 & $-2481,3$ & 550 & 8 & 224,5 & $-2482,1$ \\
\hline LA & 448 & 9 & 237,6 & $-3064,6$ & 455 & 7 & 215,3 & $-3065,5$ \\
\hline $\mathrm{PF}$ & 434 & 2 & 217,1 & $-2443,3$ & 429 & 4 & 196,5 & $-2444,2$ \\
\hline VN & 549 & 3 & 247,2 & $-2974,0$ & 520 & 4 & 221,7 & $-2975,2$ \\
\hline $\mathrm{SF} 20^{\circ}$ & 535 & 1 & 267,3 & $-3641,6$ & 524 & 2 & 253,5 & $-3642,2$ \\
\hline $\mathrm{SF} 90^{\circ}$ & 508 & 4 & 262,8 & $-3641,8$ & 504 & 5 & 243,2 & $-3642,7$ \\
\hline
\end{tabular}

* Diferença entre o $\lambda$ calculado e experimental.

A seguir, são analisados os ângulos diedros que demonstram as maiores alterações nas estruturas após a otimização com a argila (Tabela 20). A numeração adotada é a mesma da Figura 22.

Na estrutura planar, obtida com a otimização no vácuo ou em meio aquoso, os ângulos diedros C3-C2-X1-C6 e o C9-C8-N18-R19 são iguais a 0, o C11-C12-C13-N15 igual a 180 . O primeiro ângulo dá indícios sobre a planaridade do anel central, enquanto os outros dois indicam se os grupos ligados nas extremidades se encontram no plano dos anéis. As estruturas apresentadas na Figura 37 e os dados estruturais da Tabela 20 indicam que a SF $90^{\circ}$ é o corante que ficou com o anel central mais planar, seguido pela TN. Os corantes restantes têm esse anel mais dobrado. É interessante notar que a PF é o único corante em que o heteroátomo 
$\mathrm{X}$ se desloca em direção à argila (o ângulo C3-C2-X1-C6 é negativo); nos demais corantes, o anel central se dobra de forma que o heteroátomo se distancia da argila. Essa diferença na geometria deve ser causada pela maior proximidade da PF em relação à argila (de 4 a 5 Aं; os demais estão de 5 a $6 \AA$ da argila).

Tabela 20. Alguns ângulos diedros selecionados dos corantes otimizados com o plano siloxano

\begin{tabular}{|c|c|c|c|}
\hline & \multicolumn{3}{|c|}{ Ângulos diedros $\left({ }^{0}\right)$} \\
\hline Corante & C3-C2-X1-C6 & C11-C12-C13-N15 & C9-C8-N18-R19 \\
\hline $\mathrm{AM}$ & 16 & 176 & 21 \\
\hline $\mathrm{TN}$ & 7 & 179 & 30 \\
\hline LA & 16 & 172 & 28 \\
\hline PF & -22 & 176 & 33 \\
\hline VN & 14 & 178 & $\begin{array}{l}39(\mathrm{C}-\mathrm{C}-\mathrm{N}-\mathrm{H}) \\
30(\mathrm{C}-\mathrm{C}-\mathrm{N}-\mathrm{C})\end{array}$ \\
\hline $\mathrm{SF} 20^{\circ}$ & 18 & 175 & 40 \\
\hline $\mathrm{SF} 90^{\circ}$ & -1 & 176 & 48 \\
\hline
\end{tabular}

Os ângulos C11-C12-C13-N15 e C9-C8-N18-R19 apresentam o mesmo sinal para todos os corantes, indicando que os átomos que os compõem (que pertencem às extremidades das moléculas de corante) se dobram na mesma direção, ou seja, em direção à argila. Quando essas extremidades são compostas por $\mathrm{NH}_{2}$, o ângulo C9-C8-N18-R19 é ainda maior (Tabela 20), indicando que os átomos de $\mathrm{H}$ da extremidade dos corantes catiônicos estão mais próximos da argila, indicando uma maior interação desses átomos com os átomos de $\mathrm{O}$ do plano siloxano.

No caso da SF, a estrutura "SF 90" tem o ângulo $\alpha$ (ângulo formado entre o anel fenílico e o plano que engloba os anéis fundidos) igual a $83^{\circ}$ quando interage com a argila; enquanto na "SF $20^{\circ}$ ", o $\alpha$ passa para $39^{\circ}$. O sistema composto por "SF $90^{\circ}$ " + argila é mais 
estável que o sistema "SF $20^{\circ} "$ + argila. Entretanto, o $\lambda$ aumenta em direção ao valor experimental com a diminuição do ângulo $\alpha$, como verificado na Seção 4.1.2.

Estes resultados indicam que a argila influencia significativamente na geometria dos corantes, mas este estudo é ainda preliminar, pois poderiam ter sido estudadas outras conformações para o sistema corante-argila alterando tanto a posição dos corantes ao longo da argila quanto a inclinação da molécula do corante em relação à argila. Como visto anteriormente [2], a carga positiva do corante se distribui na parte inferior do corante. Assim, uma outra estrutura interessante para o estudo do sistema corante-argila seria obtida, por exemplo, partindo-se de uma conformação em que o corante forma um ângulo de $90^{\circ}$ com a argila. Poderia, ainda, ter sido modificado o modelo de argila escolhido, que poderia consistir numa ampliação do plano siloxano ou na utilização de uma lamela completa, de forma a minimizar as alterações em sua estrutura.

Infelizmente, não houve mais tempo para executar os cálculos propostos acima, mas considerando o avanço computacional seria interessante inclusive utilizar outros métodos para a otimização, como o método DFT, bem como considerar o efeito solvente e, dessa forma, poder discutir com mais profundidade a influência da argila na geometria e nas propriedades eletrônicas dos corantes catiônicos aqui estudados. 
5. CONCLUSÕES 
Os dois métodos utilizados para otimizar os monômeros dos corantes catiônicos aqui estudados (AM1 e DFT) forneceram estruturas planares, com exceção da safranina (SF), cujo anel fenílico foi posicionado perpendicularmente ao plano da molécula. No caso específico da SF, foram realizados cálculos variando o ângulo diedro $(\alpha)$ do anel fenílico e verificou-se que a estrutura com $\alpha=70^{\circ}$ é a mais estável no estado excitado. Dentre as conformações propostas, a conformação com ângulo $\alpha=30^{\circ}$ absorve em comprimento de onda mais próximo do valor experimental e nesta conformação os anéis fundidos não são planares, mas torcidos.

A introdução do solvente nos cálculos dos monômeros não trouxe alterações significativas nas geometrias das moléculas, mas tornou os espectros mais próximos dos espectros experimentais. O espectro é caracterizado por uma transferência de carga (caracterizada pelos momentos de transição e pelas representações dos orbitais envolvidos) das extremidades para o centro das moléculas.

A utilização de DFT para otimização das geometrias, e de ZINDO/IEFPCM para a obtenção dos espectros, mostrou ser a melhor metodologia para o estudo dos corantes catiônicos, fornecendo valores para os máximos de absorção com erros em torno de $5 \%$ em relação aos espectros experimentais.

As simulações de MC foram realizadas para o azul de metileno (AM), tionina (TN) e laranja de acridina (LA). Verificou-se que a utilização de um potencial construído a partir de cálculos de Química Quântica com DFT/IEFPCM forneceu valores de energia mais baixos do que o potencial construído a partir de cálculos AM1/vácuo. A média dos espectros das superestruturas (formadas pela molécula de corante e a primeira camada de solvatação) tem um erro em relação ao valor experimental maior do que o valor obtido com ZINDO/IEFPCM, 
mas as superestruturas com $\lambda$ mais próximos do experimental forneceram informações importantes a respeito da camada de solvatação.

As principais diferenças estruturais, embora pequenas, entre os monômeros otimizados e aqueles retirados dos cristais estão nas extremidades: quase todos os monômeros “cristalinos" não são planares (como verificado também para a SF, no estudo da rotação do anel fenílico), pois as extremidades saem do plano e, dessa forma, são menos simétricos. O espectro de absorção calculado para esses monômeros se aproxima ainda mais do valor experimental, indicando que a interação com o meio (solvente, outras moléculas de soluto ou sistemas microheterogêneos) pode torcer a rígida estrutura dos três anéis fundidos.

$\mathrm{O}$ estudo da diprotonação indicou que a protonação no $\mathrm{N}$ do anel gera estruturas que absorvem em $\lambda$ maiores do que a forma monoprotonada, concordando com os resultados experimentais. No entanto, as estruturas protonadas no $\mathrm{N}$ alifático absorvem em $\lambda$ menores $\mathrm{e}$ muito próximos das estruturas monoprotonadas.

Foram propostas quatro conformações para os dímeros de AM (duas sanduíche e duas co-planares) e três para os dímeros de LA (uma sanduíche e duas co-planares) e de PF (todas sanduíche) a partir das celas unitárias dos cristais. O método utilizado para calcular a energia total dos dímeros indica que há uma força repulsiva entre os monômeros, indicando a dificuldade de obter estruturas para os dímeros pela otimização direta. Apenas as estruturas Mapaz A, Mbluet A, Proflc e Proflv A, todas sanduíche, podem ser consideradas como dímeros interagentes, uma vez que apenas essas estruturas apresentam o split no espectro. Já as conformações Mapaz B, Mbluet B, Cesmao A e B, todas co-planares, não poderiam ser classificadas como dímeros, pois o espectro de cada uma corresponde à soma dos espectros dos monômeros. Cesmes e Proflv B não são dímeros co-planares, mas também não poderiam ser classificados como sanduíche, uma vez que os monômeros que os compõem não estão em 
planos paralelos. Nestes dois últimos há uma transferência de carga de um monômero para o outro.

As simulações MC para o dímero de AM forneceram configurações com conformações apenas sanduíche. Todas as configurações selecionadas apresentaram split, indicando que todas podem ser consideradas como dímeros interagentes. Mesmo considerando uma estrutura completamente planar para o monômero, os dímeros com ângulo de rotação de um monômero em relação ao outro igual a $0^{\circ}$ e $180^{\circ}$ reproduzem muito bem o comportamento experimental.

Os dois modelos utilizados para a argila montmorilonita apresentaram coerência em relação à distribuição de cargas atômicas mesmo quando comparados a outros sistemas utilizados na literatura. Para iniciar o estudo de interação com os corantes, foi selecionado aquele que parece mais simples: o plano siloxano.

A otimização da argila com os corantes catiônicos fez com que a estrutura dos corantes se "dobrasse" ao meio. As extremidades dos corantes sempre se dobram em direção à argila. Quando essas extremidades são compostas por $\mathrm{NH}_{2}$, a proximidade é ainda maior, indicando uma maior interação desses átomos com os átomos de $\mathrm{O}$ do plano siloxano.

Todos os métodos e modelos aqui utilizados levam a concluir que a determinação da estrutura dos corantes catiônicos estudados não é trivial, pois depende fortemente do meio. No vácuo ou em meio aquoso foram obtidas estruturas planares, mas foi possível verificar como a molécula dos corantes podem ter sua estrutura alterada pela presença da argila ou por outra molécula de corante (no caso dos dímeros). 
6. TRABALHOS FUTUROS 
O estudo sobre os corantes catiônicos aqui realizado pode ainda ser aprofundado, principalmente no que se refere à interação com a argila (que foi apenas iniciada neste trabalho). Algumas sugestões são:

- otimizar o estado excitado dos corantes catiônicos e estudar o espectro de fluorescência;

- estudar o estado de transição da reação de diprotonação;

- verificar a influência de moléculas discretas de solvente na geometria incluindo graus de liberdade internos nas simulações de MC;

- incluir a camada de solvatação completa para o cálculo do espectro dos monômeros;

- realizar otimizações das estruturas corante-argila, partindo de diferentes conformações e utilizando outros modelos de argila e, possivelmente, incluindo o solvente;

- realizar simulações dos corantes com a argila, mas no ensemble NPT para evitar problemas com o tamanho da caixa de simulação. 
7. REFERÊNCIAS BIBLIOGRÁFICAS 
1. FERNANDES, V. C. Estudo teórico da estrutura eletrônica de corantes catiônicos. 2000. 96f. Dissertação (Mestrado) - Instituto de Química de São Carlos, Universidade de São Paulo, São Carlos, 2000.

2. HOMEM-DE-MELLO, P. Estudo teórico sobre a interação de corantes em argilas. 2002. 182f. Dissertação (Mestrado) - Instituto de Química de São Carlos, Universidade de São Paulo, São Carlos, 2002.

3. ALLINGER, N. L. Química orgânica. Rio de Janeiro: Guanabara Dois, 1978. 961p.

4. SCHUBERT, M.; LEVINE, A. Polymerization of dyestuffs in solution. Thionine and methylene blue. J. Am. Chem. Soc., v. 63, n. 1, p. 69-78, 1941.

5. COHEN, R.; YARIV, S. Metachromasy in clay minerals. Sorption of acridine orange by montmorillonite. J. Chem. Soc., Faraday Trans. 1, v. 80, p. 1705-16, 1984.

6. NEUMANN, M. G.; TIERA, M. The use of basic dyes as photochemical probes. Quim. Nova, v. 16, p. 280-7, 1993.

7. NEUMANN, M. G.; GESSNER, F.; CIONE, A. P. P.; SARTORI, R. A.; SCHIMITT, C. C. Interações entre corantes e argilas em suspensão aquosa. Quim. Nova, v. 23, n. 6, p. 818$24,2000$.

8. AARON, J. J.; MAAFI, M.; PARKANYI, C.; BONIFACE, C. Quantitative treatment of the solvent effects on the electronic absorption and fluorescence spectra of acridines and phenazines. The ground and excited singlet-state dipole moments. Spectrochim. Acta A, v. 51, n. 4, p. 603-615, 1994.

9. CLERC, S.; BARENHOLZ, Y. A Quantitative model for using acridine orange as a transmembrane pH gradient probe. Anal. Biochem., v. 259, p. 104-11, 1998.

10. MOHR, H. Methylene blue and thionine in pathogen inactivation of plasma and platelet concentrates. Transfus. Apheresis Sci., v. 25, p. 183-4, 2001.

11. FLOYD, R. A.; SCHNEIDER JR., J. E. DITTMER, D. P. Methylene blue photoinactivation of RNA viruses. Antiviral Res., v. 61, p. 141-51, 2004. 
12. PONS, O.R.; GREGORIO, D. M.; MATEO, J. V. G.; CALATAYUD, J. M. Flowinjection analysis study of the chemiluminescent behaviour of proflavine and acriflavine. Anal. Chim. Acta, v. 438, p. 149-56, 2001.

13. CHATTERJEE, D; MAHATA, A. Demineralization of organic pollutants on the dye modified $\mathrm{TiO}_{2}$ semiconductor particulate system using visible light. Appl. Catal. B, v. 33, p. 119-25, 2001.

14. GANESAN, V.; JOHN, S. A.; RAMARAJ, R. Multielectrochromic properties of methylene blue and phenosafranine dyes incorporated into Nafion ${ }^{\circledR}$ film. J. Electroanal. Chem., v. 502, p. 167-73, 2001.

15. JANA, A. K. Solar cells based on dyes. J. Photochem. Photobiol. A, v. 132, p. 1-17, 2000.

16. ENSAFI, A. A.; KAZEMZADEH, A. Monitoring nitrite with optical sensing films. Microchem J., v. 72, p. 193-9, 2002.

17. TATIKOLOV, A. S.; COSTA, S. M. B. Complexation of polymethine dyes with human serum albumin: a spectroscopic study. Biophys. Chem., v. 107, p. 33-49, 2004.

18. CHOUDHURY, M.; BASU, R. Studies of charge transfer interaction of nucleotides with proflavine. J. Photochem. Photobiol. A, v. 85, p. 89-92, 1995

19. FERREIRA, J. A. Estudo das interações entre surfactantes e partículas de argila em suspensão aquosa utilizando corantes catiônicos. 1998. 118f. Dissertação (Mestrado) Instituto de Química de São Carlos, Universidade de São Paulo, São Carlos, 1998.

20. NEUMANN, M. G.; SCHIMITT, C. C.; GESSNER, F. Time-dependent spectrophotometric study of interaction of basic dyes with clays II: thionine on natural and synthetic montmorillonites and hectorites. J. Colloid Interface Sci., v. 177, n. 2, p. 495-501, 1998.

21. CIONE, A. P. P.; NEUMANN, M. G.; GESSNER, F. Time-dependent spectrophotometric study of interaction of basic dyes with clays III: mixed dyes aggregates on SWy-1 and laponite. J. Colloid Interface Sci., v. 198, p. 106-112, 1998. 
22. MORAES, M. E. Estudo da influência do cátion interlamelar nas interações corante-argila. 2001. 170f. Dissertação (Mestrado) - Interunidades, Universidade de São Paulo, São Carlos, 2001.

23. ANTONOV, L.; GERGOV, G.; PETROV, V.; KUBISTA, M.; NYGREN, J. UV-Vis Spectroscopic and chemometric study on the aggregation of ionic dyes in water. Talanta, $\mathrm{v}$. 49, p. 99-106, 1999.

24. FERTONANI, I. A. P. Protonação do estado triplete da safranina na presença de miscelas e polieletrólitos aniônicos. 1994. 102f. Tese (Doutorado) - Instituto de Química de São Carlos, Universidade de São Paulo, São Carlos, 1994.

25. CAVALHEIRO, C. C. S. Estudo das interações entre corantes catiônicos e partículas de argilas em suspensão. 1995. 208f. Tese (Doutorado) - Instituto de Química de São Carlos, Universidade de São Paulo, São Carlos, 1995.

26. FERREIRA, J. A. Estudo das interações entre corantes catiônicos e partículas de argila em suspensão. Influência das substituições e da densidade de carga. 1995. $78 f$. Monografia (Bacharelado) - Instituto de Química de São Carlos, Universidade de São Paulo, São Carlos, 1995.

27. GEHLEN, M. H. Estudos fotofísicos de sistemas miscelares usando corantes acridínicos. 1989. 156f. Dissertação (Mestrado) - Instituto de Química de São Carlos, Universidade de São Paulo, São Carlos, 1989.

28. NAKAZONE, S. S. Estudo das interações entre corantes aniônicos e partículas de argila em suspensão aquosa. 1999. 132f. Dissertação (Mestrado) - Instituto de Química de São Carlos, Universidade de São Paulo, São Carlos, 1999.

29. YARIV, S. Wettability of clay minerals. In: SCHRADER, M.E.; LOEB, G., eds. Modern approaches to wettability: theory and applications. New York, Plenum Press, 1992. p. 279-326.

30. YARIV, S; LURIE, D. Metachromasy in clay minerals. Part I. Sorption of methyleneblue by montmorillonite. Isr. J. Chem., v. 9, p. 537-552, 1971.

31. SCHOONHEYDT, R. A.; HEUGHEBAERT, L. Clay adsorbed dyes: methylene blue on laponite. Clay Miner., v. 27, p. 91-100, 1992. 
32. SCHOONHEYDT, R. A.; CENENS, J.; DE SCHRYVER, F. C. Spectroscopy of proflavine adsorbed on clays. J. Chem. Soc., Faraday Trans. I, v. 82, p. 281-9, 1986.

33. VAN OLPHEN, H.; FRIPIAT, J. J. Data handbook for clay materials and other nonmetallic materials. New York, Pergamon Press, 1979. 346p.

34. CENENS, J.; SCHOONHEYDT, R. A. Visible spectroscopy of methylene blue on hectorite, Laponite B, and Barasym in aqueous suspension. Clays Clay Miner., v. 36, p. 21424, 1988.

35. BOSE, H.; SUNWAR, C. B.; CHAKRAVARTI, S. K. Metachromasy of some thiazine dyes when sorbed on to clay minerals (Montmorillonite). Indian J. Chem., v. 26A, p. 944-6, 1987.

36. NEUMANN, M. G.; SCHIMMIT, C. C.; PREVITALLI, C. M.; BERTOLOTTI, S. G. Photoreduction of resazurin in the presence of aliphatic amines. Dyes Pigm., v. 32, p. 93-9, 1996.

37. GESSNER, F.; SCHIMITT, C. C.; NEUMANN, M. G. Time-dependent spectrophotometric study of interaction of basic dyes with clays I: methylene blue and neutral red on montmorillonites and hectorites. Langmuir, v. 10, p. 3749-53, 1994.

38. CIONE, A. P. P. Estudo das interações entre corantes catiônicos com partículas de argilas em suspensão aquosa: formação de agregados mistos. 1995. 121f. Dissertação (Mestrado) - Instituto de Química de São Carlos, Universidade de São Paulo, São Carlos, 1995.

39. VAN OLPHEN, H. An introduction to clay colloid chemistry. 2.ed. New York, John Wiley, 1977. 896p.

40. GRIM, R. E. Clay mineralogy. 2.ed. New York, McGraw-Hill, 1968. 596p.

41. THOMAS, J. K. Physical aspects of photochemistry and radiation chemistry of molecules adsorbed on silica, .gamma.-alumina, zeolites, and clays. Chem. Rev., v. 93, p. 301-20, 1993.

42. PARISER, R.; PARR, R. G. A semi-empirical theory of the electronic spectra and electronic structure of complex unsaturated molecules I. J. Chem. Phys., v. 21, p. 466-71, 1953. 
43. POPLE, J.A. Electron interaction in unsaturated hydrocarbons. Trans. Faraday Soc., v. 49, p. $1375-85.1953$.

44. DEL BENE, J.; JAFFÉ, H. H. Use of the CNDO method in spectroscopy. I. Benzene, pyridine, and the diazines. J. Chem. Phys., v. 48, p. 1807-13, 1968.

45. ZERNER, M. C.; LOWE, G. H.; KIRCHNER, R. F.; MUELLER-WESTERHOFF, U. T. An intermediate neglect of differential overlap technique for spectroscopy of transitionmetal complexes. Ferrocene. J. Am. Chem. Soc., v. 102, p. 589-99, 1980.

46. ZERNER, M. C.; CORREA DE MELLO, P.; HEHENBERGER, M. On the convergence of the self consistent field method to excited states. Int. J. Quantum Chem., v. 21, p. 251-8, 1982.

47. ANDERSON, W. P.; EDWARDS, W. D.; ZERNER, M. C. Calculated spectra of hydrated ions of the first transition-metal series. Inorg. Chem., v. 25, p. 2728-32, 1986.

48. HANSON, L. K.; FAJER, J.; THOMPSON, M. A.; ZERNER, M. C. Electrochromic effects of charge separation in bacterial photosynthesis: theoretical models. J. Am. Chem. Soc., v. 109, p. 4728-30, 1987.

49. THOMPSON, M. A.; ZERNER, M. C. A theoretical examination of the electronic structure and spectroscopy of the photosynthetic reaction center from Rhodopseudomonas viridis. J. Am. Chem. Soc., v. 113, p. 8210-15, 1991.

50. ADACHI, M.; NAKAMURA, S. Comparison of the INDO/S and the CNDO/S method for the absorption wavelength calculation of organic dyes. Dyes Pigm., v. 17, p. 287-96, 1991.

51. ADACHI, M.; MURATA,Y; NAKAMURA, S. Theoretical and experimental studies of indoaniline dyes. A novel relationship between absorption spectra and molecular structure. $\mathbf{J}$. Am. Chem. Soc., v. 115, p. 4331-8, 1993.

52. ADACHI, M.; MURATA, Y.; NAKAMURA, S. Spectral similarity and difference of naphthalenetetracarboxylic dianhydride, perylenetetracarboxylic dianhydride, and their derivatives. J. Phys. Chem., v. 99, p. 14240-6, 1995.

53. YATES, P. C.; PATEL, B. Semiempirical molecular orbital calculations on dye molecules. J. Mol. Struct. (Theochem), v. 315, p. 117-22, 1994. 
54. LUPAN, L. Correlation of molecular properties of some acridine and thiazine dyes in micellar solution with their electronic structure. Rev. Roum. Chim., v. 43, p. 671-4, 1998.

55. GUILLAUMONT, D.; NAKAMURA, S. Calculation of the absorption wavelength of dyes using time-dependent density-functional theory (TD-DFT). Dyes Pigm., v. 46, p. 85-92, 2000 .

56. QUINTÃO, A. D.; COUTINHO, K.; CANUTO, S. Theoretical study of the hydrogen bond interaction between methylene blue and water and possible role on energy transfer for photodynamics. Int. J. Quantum Chem., v. 90, p634-40, 2002.

57. SKIPPER, N. T.; REFSON, K.; McCONNEL, J. D. C. Computer calculations of waterclay interactions using atomic pair potentials. Clay Miner., v. 24, p. 411-25, 1989.

58. SKIPPER, N. T.; REFSON, K.; McCONNEL, J. D. C. Computer simulation of interlayer water in 2:1 clays. J. Chem. Phys., v. 94, n. 11, p. 7434-45 1991.

59. CHANG, F. C.; SKIPPER, N. T.; SPOSITO, G. Computer simulation of interlayer molecular structure in sodium montmorillonite hydrates. Langmuir, v. 11, p. 2734-41, 1995.

60. BOEK, E. S.; COVENEY, P. V.; SKIPPER, N. T. Molecular modeling of clay hydration: a study of hysteresis loops in the swelling curves of sodium montmorillonites. Langmuir, v. 11, p. 4629-31, 1995.

61. CHANG, F. C.; SKIPPER, N. T.; SPOSITO, G. Monte Carlo and molecular dynamics simulations of interfacial structure in lithium-montmorillonite hydrates. Langmuir, v. 13, p. 2074-82, 1997.

62. GRATHOUSE, J.; SPOSITO, G. Monte Carlo and molecular dynamics studies of interlayer structure in $\mathrm{Li}\left(\mathrm{H}_{2} \mathrm{O}\right)_{3}$-smectites. J. Phys. Chem. B, v. 102, p. 2406-14, 1998.

63. CHANG, F. C.; SKIPPER, N. T.; SPOSITO, G. Monte Carlo and molecular dynamics simulations of electrical double-layer structure in potassium-montmorillonite hydrates.

Langmuir, v. 14, p. 1201-7, 1998.

64. SMITH, D. E. Molecular computer simulations of the swelling properties and interlayer structure of cesium montmorillonite. Langmuir, v. 14, p. 5959-67, 1998. 
65. TEPPEN, B. J.; RASMUSSEN, K.; BERTSCH, P. M.; MILLER, D. M.; SCHÄFER, L. Molecular dynamics modeling of clay minerals. 1. Gibbsite, kaolinite, pyrophyllite, and beidellite. J. Phys. Chem. B, v. 101, p. 1579-87, 1997.

66. TEPPEN, B. J.; YU, C.; MILLER, D. M.; SCHÄFER, L. Molecular dynamics simulations of sorption of organic compounds at the clay mineral/aqueous solution interface. J. Comput. Chem., v. 19, n. 2, p. 144-53, 1998.

67. CHATTERJEE, A.; IWASAKI, T.; HAYASHI, H.; EBINA, T.; TORII, K. Electronic and structural properties of montmorillonite-a quantum chemical study. J. Mol. Catal. A, v. 136, p. 195-202, 1998.

68. CHATTERJEE, A.; IWASAKI, T.; EBINA, T.; HAYASHI, H. Relationship between infrared spectra and isomorphous substitution in smectites: A computer simulation study. J. Mol. Graphics, v. 14, p. 302-5, 1996.

69. GORB, L. G.; AKSENENKO, E. V.; ADAMS, J. W.; LARSON, S. L.; WEISS, C. A.; LESZCZYNSKA, D.; LESZCZYNSKI, J. Computational design of clay minerals: hydration of Mg-exchange cation located in ditrigonal cavity. J. Mol. Struct. (Theochem), v. 425, p. 129-35, 1998.

70. CHATTERJEE, A.; IWASAKI, T.; EBINA, T.; HAYASHI, H. Quantum chemical calculation on clay-water interface. Appl. Surf. Sci., v. 121/122, p. 167-70, 1997.

71. CHATTERJEE, A.; IWASAKI, T.; EBINA, T.; HAYASHI, H. A DFT study on claycation-water interaction in montmorillonite and beidellite. Comp. Mat. Sci., v. 14, p. 119-24, 1999.

72. CHATTERJEE, A.; IWASAKI, T.; EBINA, T. A novel method to correlate layer charge and the catalytic activity of 2:1 dioctahedral smectite clays in terms of binding the interlayer cation surrounded by monohydrate. J. Phys. Chem. A, v. 104, p. 8216-23, 2000.

73. YOUNG, D. A.; SMITH, D. E. Simulations of clay mineral swelling and hydration: dependence upon interlayer ion size and charge. J. Phys. Chem. B, v. 104, p. 9163-70, 2000.

74. MARRY, V.; TURQ, P.; CARTALLIER, T.; LEVESQUE, D. Microscopic simulation of structure and dynamics of water and counterions in a monohydrated montmorillonite. $\mathbf{J}$. Chem. Phys., v. 117, n. 7, p. 3454-63, 2002. 
75. ZHMUD, B. V.; HOUSE, W. A.; SEVASTYANOVA, E. B. Interaction of flutriafol with the surface of silica and layer silicates. Colloids Surf. A, v. 127, p. 187-99, 1997.

76. TITILOYE, J. O.; SKIPPER, N. T. Computer simulation of the structure and dynamics of methane in hydrated Na-smectite clay. Chem. Phys. Lett., v. 329, p. 23-8, 2000.

77. POSPÍŠIL, M.; ČAPCOVÁ, P.; MĚŘÍSKÁ, D.; MALÁČ, Z.; ŠIMONÍK, J. Structure analysis of montmorillonite intercalated with cetylpyridinium and cetyltrimethylammonium: molecular simulations and XRD analysis. J. Colloid Interface Sci., v. 236, p. 127-31, 2001.

78. POSPÍŠIL, M.; ČAPCOVÁ, P.; MALÁČ, Z.; ŠIMONÍK, J. Intercalation of octadecylamine into montmorillonite: molecular simulations and XRD analysis. J. Colloid Interface Sci., v. 245, p. 126-32, 2002.

79. YU, C.; NEWTON, S. Q.; NORMAN, M. A.; MILLER, D. M.; SCHÄFER, L.; TEPPEN, B. J. Molecular dynamics simulations of the adsorption of methylene blue at clay mineral surfaces. Clays Clay Miner., v. 48, n. 6, p. 665-81, 2000.

80. TOMASI, J.; PERSICO, M. Molecular interactions in solution: an overview of methods based on continuous distributions of the solvent. Chem. Rev., v. 94, p. 2027-94, 1994.

81. POMELLI, C.S., TOMASI, J. Description of the solvent effects for large molecules: a linear scaling procedure. J. Mol. Strut. (Theochem), v. 537, p. 97-105, 2001.

82. TOMASI, J.; CAMMI, R.; MENNUCCI, B. Medium effects on the properties of chemical systems: An overview of recent formulations in the polarizable continuum model (PCM). Int. J. Quantum Chem., v. 75, p. 783-803, 1999.

83. PARREIRA, L. T. Interação da formamida com água. 2001. 178f. Dissertação (Mestrado) - Faculdade de Filosofia, Ciência e Letras de Ribeirão Preto, Universidade de São Paulo, Ribeirão Preto, 2001.

84. MIERTUS, S.; SCROCCO, E.; TOMASI, J. Electrostatic interaction of a solute with a continuum. A direct utilization of ab initio molecular potentials for the prevision of solvent effects. Chem. Phys., v. 55, p. 117-29, 1981.

85. MIERTUS, S.; TOMASI, J. Approximate evaluations of the electrostatic free energy and internal energy changes in solution processes. Chem. Phys., v. 65, p. 239-45, 1982. 
86. CRAMER, C. J.; TRUHLAR, D. G. Implicit solvation models: equilibria, structure, spectra, and dynamics. Chem. Rev., v. 99, p. 2161-200, 1999.

87. SCHMIDT, M. GAMESS on-line manual. Disponível em: <http://chem.cias.osakafuu.ac.jp/ shiro/gms05jul/>. Acesso em: 01 nov. 2005.

88. ALEMÁN, C.; GALEMBECK, S. E. Solvation of chromone using combined Discrete/SCRF models. Chem. Phys., v. 232, p. 151-9, 1998.

89. TOMASI, J. PCM a short history of the method. Disponível em: <http://pcm.dcci.unipi.it>. Acesso em: 01 nov. 2005.

90. BARONE, V.; COSSI, M. Quantum calculation of molecular energies and energy gradients in solution by a conductor solvent model. J. Phys. Chem. A, v. 102, p. 1995-2001, 1998.

91. KLAMT, A.; SCHÜÜRMANN, G. COSMO: a new approach to dielectric screening in solvents with explicit expressions for the screening energy and its gradient. J. Chem. Soc., Perkin Trans 2, v. 1993, n. 5, p. 799-805, 1993.

92. CANCÈS, E.; MENNUCCI, B.; TOMASI, J. A new integral equation formalism for the polarizable continuum model: theoretical background and applications to isotropic and anisotropic dielectrics. J. Chem. Phys., v. 107, p. 3032-41, 1997.

93. MENNUCCI, B.; CANCÈS, E.; TOMASI, J. Evaluation of solvent effects in isotropic and anisotropic dielectrics and in ionic solutions with a unified integral equation method: Theoretical bases, computational implementation, and numerical applications. J. Phys. Chem. B, v. 101, p. 10506-17, 1997.

94. CANCÈS, E.; MENNUCCI, B. New applications of integral equations methods for solvation continuum models: ionic solutions and liquid crystals. J. Math. Chem., v. 23, p. 309-26, 1998.

95. CORNI, S.; TOMASI, J. Enhanced response properties of a chromophore physisorbed on a metal particle. J. Chem. Phys., v. 114, p. 3739-51, 2001.

96. CARICATO, M. Theoretical models to describe time-dependent and nonequilibrium solvation. 2005. 159f. Tese (Doutorado) - Classe di Scienze, Scuola Normale Superiore di Pisa, 2005. 
97. KIRKWOOD, J. G. Theory of solutions of molecules containing widely separated charges with special application to zwitterions. J. Chem. Phys., v. 2, p. 351-61, 1934.

98. ONSAGER, L. Electric Moments of Molecules in Liquids. J. Am. Chem. Soc., v. 58, p. 1486-93, 1936.

99. FREITAS, L. C. G.; BARLETTE, V. E. Termodinâmica estatística de líquidos com o método de Monte Carlo. I. Metodologia. Quim. Nova, v. 22, n. 2, p. 254-62, 1999.

100. FRENKEL, D.; SMIT, B. Understanding molecular simulation: from algorithms to applications. San Diego, Academic Press, 1996. 664p.

101. COUTINHO, K. Método Monte Carlo aplicado à simulação de líquidos. 2002. 31f. Apostila (Escola de Modelagem Molecular em Sistemas Biológicos) - Laboratório Nacional de Computação Científica, Petrópolis, 2002.

102. ALLEN, M. P.; TILDESLEY, D. J. Computer simulation of liquids. Oxford, Clarendon Press, 1987. 385p.

103. AXILROL, B. M.; TELLER E. Interaction of the van der Waals type between three atoms. J. Chem. Phys., v. 11, p. 299-300, 1943.

104. DORAN, M. B.; ZUCKER I. J. Higher order multipole three-body van der Waals interactions and stability of rare gas solids. J. Phys. C, v. 4, p. 307-12, 1971.

105. LENNARD-JONES, J. E. The equation of state of gases and critical phenomena. Physica, v. 4, p. 941-56, 1937.

106. HIRSCHFELDER, J. O.; CURTISS, C. F.; BIRD, R. B. Molecular theory of gases and liquids. NewYork, Wiley, 1954. 1280p.

107. NEVES, R. S. Adsorção de fenol em eletrodo de ouro monocristalino com orientação (210) : Um estudo eletroquímico e por simulação computacional. 2004. 173f. Tese (Doutorado) - Instituto de Química de São Carlos, Universidade de São Paulo, São Carlos, 2004. 
108. METROPOLIS, N.; ROSENBLUTH, A.W.; ROSENBLUTH, M. N.; TELLER, A. H.; TELLER, E. Equations of state calculations by fast computing machines. J. Chem. Phys., v. 21, p. 1087-91, 1953.

109. COUTINHO, K.; CANUTO, S. Solvent effects from a sequential Monte Carlo-quantum mechanical approach. Adv. Quantum Chem., v. 28, p. 90-107, 1997.

110. COUTINHO, K.; DE OLIVEIRA, M. J.; CANUTO, S. Sampling configurations in Monte Carlo simulations for quantum mechanical studies of solvent effects. Int. J. Quantum Chem., v. 66, p. 249-53, 1998.

111. FRIEDBERG, R.; CAMERON, J. E. Test of the Monte Carlo method: fast simulation of a small ising lattice. J. Chem. Phys., v. 52, p. 6049-58, 1970.

112. HENRIQUES, V. B. Um estudo do método Monte Carlo de campo médio. 1992. $50 \mathrm{f}$. Dissertação (Mestrado) - Instituto de Física, Universidade de São Paulo, São Paulo, 1992.

113. COUTINHO, K.; CANUTO, S.; ZERNER, M. C. A Monte Carlo-quantum mechanics study of the solvatochromic shifts of the lowest transition of benzene. J. Chem. Phys., v. 112, p. $9874-80,2000$.

114. DEWAR, M. J. S.; ZOEBISCH, E. G.; HEALY, E. F.; STEWART, J. J. P. The development and use of quantum-mechanical molecular-models.76. AM1 - a new generalpurpose quantum-mechanical molecular-model. J. Am. Chem. Soc., v. 107, p. 3902-9, 1985.

115. HOHENBERG, P.; KOHN, W. Inhomogeneous electron gas. Phys. Rev., v. 136, p. 864-71, 1964.

116. KOHN, W.; SHAM, L. J. Self-consistent equations including exchange and correlation effects. Phys. Rev., v. 140, n. 4A, p. 1133-8, 1965.

117. PARR, R. G.; YANG; W. Density-functional theory of atoms and molecules. Oxford: Oxford University Press, 1989. p. 344.

118. STRATMANN, R. E.; SCUSERIA, G. E.; FRISCH, M. J. C. An efficient implementation of time-dependent density-functional theory for the calculation of excitation energies of large molecules. J. Chem. Phys., v. 109, p. 8218-24, 1998. 
119. BAUERNSCHMITT, R.; AHLRICHS, R. Treatment of electronic excitations within the adiabatic approximation of time dependent density functional theory. Chem. Phys. Lett., v. 256, p. 454-64, 1996.

120. CASIDA, M. E.; JAMORSKI, C.; CASIDA, K. C.; SALAHUB, D. R. Molecular excitation energies to high-lying bound states from time-dependent density-functional response theory: characterization and correction of the time-dependent local density approximation ionization threshold. J. Chem. Phys., v. 108, p. 4439-49, 1998.

121. BONDI, A. Van der Waals volumes and radii. J. Phys. Chem., v. 68, p. 441-51, 1964.

122. CAPPELLI C.; SILVA, C. O.; TOMASI, J. Solvent effects on vibrational modes: $a b$ initio calculations, scaling and solvent functions with applications to the carbonyl stretch of dialkyl ketones. J. Mol. Struct. (Theochem), v. 544, p. 191-203, 2001.

123. WAVEFUNCTION. Spartan 5.0. Irvine, CA, 1996. [Programa de Computador].

124. ALLEN, F. H. The Cambridge Structural Database: a quarter of a million crystal structures and rising. Acta Crystallogr. B, v. 58, p. 380-8, 2002.

125. Gaussian 03, Revision B.04, FRISCH, M. J.; TRUCKS, G. W.; SCHLEGEL, H. B.; SCUSERIA, G. E.; ROBB, M. A.; CHEESEMAN, J. R.; MONTGOMERY, JR., J. A.; VREVEN, T.; KUDIN, K. N.; BURANT, J. C.; MILLAM, J. M.; IYENGAR, S. S.; TOMASI, J.; BARONE, V.; MENNUCCI, B.; COSSI, M.; SCALMANI, G.; REGA, N.; PETERSSON, G. A.; NAKATSUJI, H.; HADA, M.; EHARA, M.; TOYOTA, K.; FUKUDA, R.; HASEGAWA, J.; ISHIDA, M.; NAKAJIMA, T.; HONDA, Y.; KITAO, O.; NAKAI, H.; KLENE, M.; LI, X.; KNOX, J. E.; HRATCHIAN, H. P.; CROSS, J. B.; BAKKEN, V.; ADAMO, C.; JARAMILLO, J.; GOMPERTS, R.; STRATMANN, R. E.; YAZYEV, O.; AUSTIN, A. J.; CAMMI, R.; POMELLI, C.; OCHTERSKI, J. W.; AYALA, P. Y.; MOROKUMA, K.; VOTH, G. A.; SALVADOR, P.; DANNENBERG, J. J.; ZAKRZEWSKI, V. G.; DAPPRICH, S.; DANIELS, A. D.; STRAIN, M. C.; FARKAS, O.; MALICK, D. K.; RABUCK, A. D.; RAGHAVACHARI, K.; FORESMAN, J. B.; ORTIZ, J. V.; CUI, Q.; BABOUL, A. G.; CLIFFORD, S.; CIOSLOWSKI, J.; STEFANOV, B. B.; LIU, G.; LIASHENKO, A.; PISKORZ, P.; KOMAROMI, I.; MARTIN, R. L.; FOX, D. J.; KEITH, T.; AL-LAHAM, M. A.; PENG, C. Y.; NANAYAKKARA, A.; CHALLACOMBE, M.; GILL, P. M. W.; JOHNSON, B.; CHEN, W.; WONG, M. W.; GONZALEZ, C.; AND POPLE, J. A. Gaussian, Inc., Pittsburgh PA, 2003. [Programa de Computador].

126. Gaussian 03, Development Version, FRISCH, M. J.; TRUCKS, G. W.; SCHLEGEL, H. B.; SCUSERIA, G. E.; ROBB, M. A.; CHEESEMAN, J. R.; MONTGOMERY, JR., J. A.; VREVEN, T.; KUDIN, K. N.; BURANT, J. C.; MILLAM, J. M.; IYENGAR, S. S.; TOMASI, J.; BARONE, V.; MENNUCCI, B.; COSSI, M.; SCALMANI, G.; REGA, N.; PETERSSON, G. A.; NAKATSUJI, H.; HADA, M.; EHARA, M.; TOYOTA, K.; FUKUDA, 
R.; HASEGAWA, J.; ISHIDA, M.; NAKAJIMA, T.; HONDA, Y.; KITAO, O.; NAKAI, H.; KLENE, M.; LI, X.; KNOX, J. E.; HRATCHIAN, H. P.; CROSS, J. B.; BAKKEN, V.; ADAMO, C.; JARAMILLO, J.; GOMPERTS, R.; STRATMANN, R. E.; YAZYEV, O.; AUSTIN, A. J.; CAMMI, R.; POMELLI, C.; OCHTERSKI, J. W.; AYALA, P. Y.; MOROKUMA, K.; VOTH, G. A.; SALVADOR, P.; DANNENBERG, J. J.; ZAKRZEWSKI, V. G.; DAPPRICH, S.; DANIELS, A. D.; STRAIN, M. C.; FARKAS, O.; MALICK, D. K.; RABUCK, A. D.; RAGHAVACHARI, K.; FORESMAN, J. B.; ORTIZ, J. V.; CUI, Q.; BABOUL, A. G.; CLIFFORD, S.; CIOSLOWSKI, J.; STEFANOV, B. B.; LIU, G.; LIASHENKO, A.; PISKORZ, P.; KOMAROMI, I.; MARTIN, R. L.; FOX, D. J.; KEITH, T.; AL-LAHAM, M. A.; PENG, C. Y.; NANAYAKKARA, A.; CHALLACOMBE, M.; GILL, P. M. W.; JOHNSON, B.; CHEN, W.; WONG, M. W.; GONZALEZ, C.; AND POPLE, J. A. Gaussian, Inc., Pittsburgh PA, 2003. [Programa de Computador].

127. CARICATO, M.; MENNUCCI, B.; TOMASI, J. Solvent effects on the electronic spectra: an extension of the Polarizable Continuum Model to the ZINDO method. J. Phys. Chem. A, v. 108, p. 6248-56, 2004.

128. LEE, C. T.; YANG, W.; PARR, R. G. Development of the Colle-Salvetti correlationenergy formula into a functional of the electron-density. Phys. Rev. B, v. 37, p. 785-9, 1988.

129. MIEHLICH, B.; SAVIN, A.; STOLL, H. Results obtained with the correlation-energy density functionals of Becke and Lee, Yang and Parr. Chem. Phys. Lett., v. 157, p. 200-6, 1989.

130. BECKE, A. D. Density-functional thermochemistry .III. The role of exact exchange. J. Chem. Phys., v. 98, p. 5648-52, 1993.

131. CORNELL, W. D.; CIEPLAK, P.; BAYLY, C. I.; GOULD, I. R.; MERZ, K. M.; FERGUSON, D. M.; SPELLMEYER, D. C.; FOX, T.; CALDWELL, J. W.; KOLLMAN, P. A. A 2nd generation force-field for the simulation of proteins, nucleic-acids, and organicmolecules. J. Am. Chem. Soc., v. 117, p. 5179-97, 1995.

132. HERNANDES, M. Z.; DA SILVA, J. B. P.; LONGO R. L. Chemometric study of liquid water simulations. Part I: the parameters of the TIP4P model potential. J. Comput. Chem., v. 24, p. 973-81, 2003.

133. SINGH, U. C.; KOLLMAN, P. A. An approach to computing electrostatic charges for molecules. J. Comput. Chem., v. 5, p. 129-45, 1984.

134. HOMEM-DE-MELLO, P.; MENNUCCI, B.; TOMASI, J.; DA SILVA, A. B. F. The effects of solvation in the theoretical spectra of cationic dyes. Theor. Chem. Acc., v. 3, p. 274-80, 2005. 
135. SAKATA, K.; HARA, K. Ab initio study of the torsional potential for 9phenylanthracene in the ground and excited states. Chem. Phys. Lett., v. 371, p. 164-71, 2003.

136. MARR, H. E.; STEWART, J. M.; CHIU, M. F. Crystal-structure of methylene-blue pentahydrate. Acta Crystallogr. B, v. 29, p. 847-53, 1973.

137. KAHNHARA, A.; BALLARD, R. E.; NORRIS, E. K. Crystal Structure of methylene blue thiocyanate. Acta Crystallogr. B, v. 29, p. 1124-6, 1973.

138. MATTIA, C. A.; MAZZARELLA, L.; VITAGLIANO, V.; PULITI, R. Stacking interactions in the acridine-dyes - spectrophotometric data and crystal-structure of acridineorange hydroiodide and acridine-orange hydrochloride monohydrate. J. Crystallogr. Spectrosc. Res., v. 14, p. 71-87, 1984.

139. OBENDORF, S. K.; CARELL, H. L.; GLUSKER, J. P. Proflavine dichloride dihydrate (3,6-diaminoacridine dihydrochloride dihydrate). Acta Crystallogr. B, v. 30, p. 1408-11, 1974.

140. ACHARI, A.; NEIDLE, S. 9-Chloroacridine. Acta Crystallogr. B, v. 33, p. 3269-70, 1977.

141. COUTINHO, K.; SAAVEDRA, N.; SERRANO, A.; CANUTO, S. A Monte Carloquantum mechanics study of the spectroscopic properties of molecules in solution. J. Mol. Struct. (Theochem), v. 539, p. 171-9, 2001.

142. Estrutura disponível em:

<http://www.minweb.co.uk/sheetsilicates/montmorillonite.html>. Acesso em: 10 abril 2004.

143. TSIPURSKY, S. I.; DRITS, V. A. The distribution of octahedral cations in the 2: 1 layers of dioctahedral smectites studied by oblique texture electron diffraction. Clay Miner., v. 19, p. 177-93, 1984. 
APÊNDICE A - Comprimento de onda de absorção ( $\lambda$, em nm) e correspondente força do oscilador (f) para o $1^{\circ}$ e o $2^{\circ}$ estado excitado (EE) de cada configuração selecionada da simulação da caixa pequena para o dímero do AM

\begin{tabular}{|c|c|c|c|c|c|c|c|c|c|}
\hline & \multicolumn{2}{|c|}{$1^{\circ} \mathrm{EE}$} & \multicolumn{2}{|c|}{$2^{\circ} \mathrm{EE}$} & & \multicolumn{2}{|c|}{$1^{\circ} \mathrm{EE}$} & \multicolumn{2}{|c|}{$2^{\circ} \mathrm{EE}$} \\
\hline & $\lambda(\mathbf{n m})$ & $\mathbf{f}$ & $\lambda(\mathbf{n m})$ & $\mathbf{f}$ & & $\lambda(\mathbf{n m})$ & $\mathbf{f}$ & $\lambda(\mathbf{n m})$ & $\mathbf{f}$ \\
\hline 1 & 657 & 0,33 & 555 & 1,96 & 28 & 676 & 0,01 & 533 & 2,56 \\
\hline 2 & 645 & 0,46 & 562 & $1,94 A$ & 29 & 668 & 0,02 & 535 & 2,58 \\
\hline 3 & 656 & 0,32 & 557 & 1,90 & 30 & 670 & 0,00 & 535 & 2,59 \\
\hline 4 & 675 & 0,21 & 559 & 1,56 & 31 & 658 & 0,02 & 542 & 2,54 \\
\hline 5 & 658 & 0,27 & 550 & 2,14 & 32 & 659 & 0,00 & 539 & 2,60 \\
\hline 6 & 672 & 0,19 & 549 & 1,92 & 33 & 668 & 0,00 & 539 & 2,56 \\
\hline 7 & 668 & 0,19 & 550 & 2,01 & 34 & 672 & 0,00 & 529 & 2,59 \\
\hline 8 & 667 & 0,22 & 550 & 2,00 & 35 & 685 & 0,00 & 529 & 2,56 \\
\hline 9 & 655 & 0,31 & 557 & 1,97 & 36 & 696 & 0,00 & 526 & 2,56 \\
\hline 10 & 665 & 0,18 & 544 & 2,26 & 37 & 678 & 0,00 & 528 & 2,59 \\
\hline 11 & 672 & 0,08 & 537 & 2,41 & 38 & 698 & 0,00 & 524 & 2,55 \\
\hline 12 & 662 & 0,17 & 544 & 2,31 & 39 & 693 & 0,00 & 528 & 2,51 \\
\hline 13 & 662 & 0,19 & 544 & 2,27 & 40 & 686 & 0,01 & 528 & 2,56 \\
\hline 14 & 669 & 0,22 & 553 & 1,84 & 41 & 679 & 0,00 & 527 & 2,61 \\
\hline 15 & 653 & 0,26 & 548 & 2,22 & 42 & 691 & 0,00 & 526 & 2,56 \\
\hline 16 & 664 & 0,25 & 550 & 2,03 & 43 & 675 & 0,01 & 531 & 2,57 \\
\hline 17 & 655 & 0,32 & 556 & 1,96 & 44 & 672 & 0,01 & 530 & 2,59 \\
\hline 18 & 664 & 0,23 & 550 & 2,03 & 45 & 682 & 0,00 & 529 & 2,58 \\
\hline 19 & 663 & 0,18 & 543 & 2,31 & 46 & 678 & 0,00 & 530 & 2,60 \\
\hline 20 & 652 & 0,15 & 547 & 2,35 & 47 & 694 & 0,00 & 525 & 2,55 \\
\hline 21 & 667 & 0,08 & 538 & 2,48 & 48 & 680 & 0,00 & 527 & 2,58 \\
\hline 22 & 664 & 0,08 & 542 & 2,42 & 49 & 703 & 0,00 & 525 & 2,49 \\
\hline 23 & 673 & 0,02 & 533 & 2,59 & 50 & 687 & 0,00 & 525 & 2,57 \\
\hline 24 & 672 & 0,04 & 535 & 2,50 & 51 & 673 & 0,00 & 529 & 2,62 \\
\hline 25 & 673 & 0,01 & 533 & 2,58 & 52 & 676 & 0,00 & 530 & 2,61 \\
\hline 26 & 662 & 0,04 & 538 & 2,55 & 53 & 681 & 0,00 & 528 & 2,60 \\
\hline 27 & 665 & 0,05 & 535 & 2,53 & 54 & 675 & 0,00 & 530 & 2,59 \\
\hline
\end{tabular}


Apêndice A - continuação. Comprimento de onda de absorção $(\lambda$, em nm) e correspondente força do oscilador (f) para o $1^{\circ}$ e o $2^{\circ}$ estado excitado (EE) de cada configuração selecionada simulação da caixa pequena para o dímero do AM

\begin{tabular}{|c|c|c|c|c|c|c|c|c|c|}
\hline & \multicolumn{2}{|c|}{$1^{\circ} \mathrm{EE}$} & \multicolumn{2}{|c|}{$2^{\circ} \mathrm{EE}$} & & \multicolumn{2}{|c|}{${1^{\circ} \mathrm{EE}}^{\circ}$} & \multicolumn{2}{|c|}{$2^{\circ} \mathrm{EE}$} \\
\hline & $\lambda(\mathbf{n m})$ & f & $\lambda(\mathrm{nm})$ & $\mathbf{F}$ & & $\lambda(\mathbf{n m})$ & $\mathbf{f}$ & $\lambda(\mathbf{n m})$ & f \\
\hline 55 & 663 & 0,00 & 536 & 2,60 & 83 & 661 & 0,00 & 540 & 2,60 \\
\hline 56 & 666 & 0,00 & 535 & 2,60 & 84 & 667 & 0,00 & 540 & 2,54 \\
\hline 57 & 681 & 0,00 & 530 & 2,59 & 85 & 680 & 0,00 & 534 & 2,53 \\
\hline 58 & 669 & 0,00 & 534 & 2,61 & 86 & 671 & 0,00 & 531 & 2,61 \\
\hline 59 & 672 & 0,00 & 533 & 2,60 & 87 & 662 & 0,01 & 540 & 2,58 \\
\hline 60 & 665 & 0,04 & 541 & 2,46 & 88 & 660 & 0,00 & 538 & 2,61 \\
\hline 61 & 670 & 0,01 & 536 & 2,56 & 89 & 675 & 0,02 & 533 & 2,53 \\
\hline 62 & 660 & 0,04 & 542 & 2,49 & 90 & 671 & 0,01 & 541 & 2,45 \\
\hline 63 & 667 & 0,03 & 540 & 2,48 & 91 & 672 & 0,01 & 534 & 2,59 \\
\hline 64 & 664 & 0,01 & 535 & 2,61 & 92 & 681 & 0,00 & 529 & 2,58 \\
\hline 65 & 667 & 0,00 & 538 & 2,56 & 93 & 688 & 0,01 & 528 & 2,55 \\
\hline 66 & 666 & 0,00 & 538 & 2,61 & 94 & 675 & 0,01 & 530 & 2,60 \\
\hline 67 & 667 & 0,00 & 539 & 2,56 & 95 & 683 & 0,00 & 528 & 2,56 \\
\hline 68 & 672 & 0,00 & 533 & 2,61 & 96 & 680 & 0,00 & 528 & 2,56 \\
\hline 69 & 665 & 0,01 & 537 & 2,60 & 97 & 673 & 0,00 & 530 & 2,60 \\
\hline 70 & 676 & 0,02 & 533 & 2,57 & 98 & 676 & 0,00 & 528 & 2,60 \\
\hline 71 & 669 & 0,00 & 535 & 2,59 & 99 & 684 & 0,00 & 526 & 2,60 \\
\hline 72 & 668 & 0,01 & 536 & 2,58 & 100 & 679 & 0,01 & 529 & 2,60 \\
\hline 73 & 663 & 0,01 & 535 & 2,59 & 101 & 689 & 0,00 & 526 & 2,49 \\
\hline 74 & 670 & 0,01 & 536 & 2,56 & 102 & 675 & 0,01 & 529 & 2,58 \\
\hline 75 & 670 & 0,01 & 535 & 2,61 & 103 & 675 & 0,02 & 529 & 2,53 \\
\hline 76 & 664 & 0,00 & 539 & 2,57 & 104 & 677 & 0,01 & 530 & 2,60 \\
\hline 77 & 669 & 0,00 & 536 & 2,57 & 105 & 683 & 0,01 & 526 & 2,57 \\
\hline 78 & 666 & 0,01 & 538 & 2,56 & 106 & 670 & 0,01 & 534 & 2,58 \\
\hline 79 & 671 & 0,00 & 539 & 2,47 & 107 & 667 & 0,00 & 534 & 2,60 \\
\hline 80 & 673 & 0,01 & 532 & 2,60 & 108 & 665 & 0,09 & 537 & 2,48 \\
\hline 81 & 666 & 0,00 & 544 & 2,42 & 109 & 668 & 0,12 & 541 & 2,34 \\
\hline 82 & 657 & 0,01 & 546 & 2,50 & 110 & 662 & 0,20 & 546 & $\begin{array}{r}2,29 \\
\text { contin }\end{array}$ \\
\hline
\end{tabular}


Apêndice A - conclusão. Comprimento de onda de absorção ( $\lambda$, em $\mathrm{nm})$ e correspondente força do oscilador (f) para o $1^{\circ}$ e o $2^{\circ}$ estado excitado (EE) de cada configuração selecionada da simulação da caixa pequena para o dímero do AM

\begin{tabular}{|c|c|c|c|c|c|c|c|c|c|}
\hline & \multicolumn{2}{|c|}{$1^{\circ} \mathbf{E E}$} & \multicolumn{2}{|c|}{$2^{\circ} \mathrm{EE}$} & & \multicolumn{2}{|c|}{$1^{\circ} \mathbf{E E}$} & \multicolumn{2}{|c|}{$2^{\circ} \mathrm{EE}$} \\
\hline & $\lambda(\mathbf{n m})$ & $\mathbf{f}$ & $\lambda(\mathbf{n m})$ & $\mathbf{F}$ & & $\lambda(\mathbf{n m})$ & $\mathbf{f}$ & $\lambda(\mathbf{n m})$ & $\mathbf{f}$ \\
\hline 111 & 660 & 0,19 & 546 & 2,33 & 139 & 664 & 0,10 & 538 & 2,44 \\
\hline 112 & 671 & 0,10 & 540 & 2,31 & 140 & 657 & 0,11 & 541 & 2,44 \\
\hline 113 & 665 & 0,10 & 541 & 2,39 & 141 & 675 & 0,10 & 535 & 2,37 \\
\hline 114 & 672 & 0,09 & 540 & 2,30 & 142 & 660 & 0,10 & 537 & 2,45 \\
\hline 115 & 677 & 0,07 & 543 & 2,14 & 143 & 667 & 0,13 & 539 & 2,35 \\
\hline 116 & 670 & 0,03 & 535 & 2,56 & 144 & 676 & 0,14 & 542 & $2,15 B$ \\
\hline 117 & 668 & 0,03 & 536 & 2,58 & 145 & 668 & 0,10 & 537 & 2,44 \\
\hline 118 & 670 & 0,00 & 533 & 2,61 & 146 & 673 & 0,08 & 536 & 2,42 \\
\hline 119 & 668 & 0,01 & 533 & 2,59 & 147 & 682 & 0,07 & 542 & 2,05 \\
\hline 120 & 687 & 0,00 & 528 & 2,53 & 148 & 676 & 0,05 & 535 & 2,44 \\
\hline 121 & 678 & 0,03 & 530 & 2,54 & 149 & 682 & 0,06 & 542 & 2,00 \\
\hline 122 & 681 & 0,00 & 528 & 2,56 & 150 & 677 & 0,01 & 530 & 2,58 \\
\hline 123 & 687 & 0,00 & 528 & 2,46 & 151 & 689 & 0,02 & 531 & 2,42 \\
\hline 124 & 676 & 0,01 & 531 & 2,59 & 152 & 681 & 0,04 & 532 & 2,47 \\
\hline 125 & 677 & 0,00 & 535 & 2,50 & 153 & 680 & 0,02 & 533 & 2,45 \\
\hline 126 & 671 & 0,01 & 535 & 2,57 & 154 & 668 & 0,08 & 537 & 2,50 \\
\hline 127 & 659 & 0,01 & 541 & 2,56 & 155 & 680 & 0,01 & 531 & 2,53 \\
\hline 128 & 658 & 0,05 & 551 & 2,32 & 156 & 705 & 0,01 & 531 & 1,95 \\
\hline 129 & 650 & 0,06 & 545 & 2,51 & 157 & 674 & 0,01 & 531 & 2,59 \\
\hline 130 & 664 & 0,03 & 539 & 2,54 & 158 & 669 & 0,03 & 532 & 2,56 \\
\hline 131 & 652 & 0,08 & 556 & 2,28 & 159 & 691 & 0,00 & 527 & $2,56 C$ \\
\hline 132 & 663 & 0,14 & 541 & 2,40 & 160 & 689 & 0,06 & 535 & 2,21 \\
\hline 133 & 663 & 0,11 & 541 & 2,46 & 161 & 679 & 0,08 & 541 & 2,11 \\
\hline 134 & 677 & 0,04 & 535 & 2,43 & 162 & 682 & 0,06 & 534 & 2,38 \\
\hline 135 & 675 & 0,14 & 543 & 2,11 & 163 & 686 & 0,06 & 539 & 2,08 \\
\hline 136 & 668 & 0,09 & 536 & 2,45 & 164 & 667 & 0,01 & 538 & 2,55 \\
\hline 137 & 673 & 0,12 & 539 & 2,29 & 165 & 678 & 0,06 & 541 & 2,15 \\
\hline 138 & 668 & 0,07 & 534 & 2,46 & 166 & 677 & 0,04 & 536 & 2,35 \\
\hline
\end{tabular}


APÊEDICE B - Comprimento de onda de absorção ( $\lambda$, em nm) e correspondente força do oscilador (f) para o $1^{\circ}$ e o $2^{\circ}$ estado excitado (EE) de cada configuração selecionada da simulação da caixa grande para o dímero do AM

\begin{tabular}{|c|c|c|c|c|c|c|c|c|c|}
\hline & \multicolumn{2}{|c|}{$1^{\circ} \mathrm{EE}$} & \multicolumn{2}{|c|}{$2^{\circ} \mathrm{EE}$} & & \multicolumn{2}{|c|}{$1^{\circ} \mathrm{EE}$} & \multicolumn{2}{|c|}{$2^{\circ} \mathrm{EE}$} \\
\hline & $\lambda(\mathbf{n m})$ & $\mathbf{f}$ & $\lambda(\mathrm{nm})$ & $\mathbf{F}$ & & $\lambda(\mathrm{nm})$ & $\mathbf{f}$ & $\lambda(\mathbf{n m})$ & f \\
\hline 1 & 658 & 0,02 & 549 & 2,35 & 28 & 688 & 0,00 & 531 & 2,33 \\
\hline 2 & 651 & 0,06 & 549 & 2,39 & 29 & 661 & 0,06 & 540 & 2,45 \\
\hline 3 & 657 & 0,04 & 546 & 2,35 & 30 & 669 & 0,02 & 534 & 2,57 \\
\hline 4 & 650 & 0,02 & 549 & 2,45 & 31 & 663 & 0,01 & 536 & 2,56 \\
\hline 5 & 660 & 0,02 & 537 & 2,56 & 32 & 678 & 0,01 & 534 & 2,43 \\
\hline 6 & 668 & 0,04 & 533 & 2,54 & 33 & 658 & 0,02 & 542 & 2,49 \\
\hline 7 & 663 & 0,00 & 534 & 2,60 & 34 & 680 & 0,02 & 537 & 2,31 \\
\hline 8 & 667 & 0,01 & 534 & 2,59 & 35 & 670 & 0,05 & 538 & 2,44 \\
\hline 9 & 662 & 0,01 & 536 & 2,56 & 36 & 655 & 0,01 & 542 & 2,53 \\
\hline 10 & 667 & 0,00 & 532 & 2,58 & 37 & 650 & 0,03 & 544 & 2,52 \\
\hline 11 & 682 & 0,01 & 531 & 2,51 & 38 & 660 & 0,01 & 539 & 2,53 \\
\hline 12 & 676 & 0,05 & 534 & 2,50 & 39 & 675 & 0,03 & 539 & 2,38 \\
\hline 13 & 676 & 0,02 & 532 & 2,43 & 40 & 648 & 0,04 & 547 & 2,47 \\
\hline 14 & 670 & 0,04 & 533 & 2,54 & 41 & 667 & 0,03 & 533 & 2,56 \\
\hline 15 & 683 & 0,03 & 540 & 2,33 & 42 & 674 & 0,01 & 532 & 2,55 \\
\hline 16 & 672 & 0,03 & 533 & 2,56 & 43 & 660 & 0,01 & 535 & 2,60 \\
\hline 17 & 677 & 0,01 & 534 & 1,96 & 44 & 666 & 0,00 & 543 & 2,41 \\
\hline 18 & 675 & 0,01 & 534 & 2,52 & 45 & 672 & 0,00 & 532 & 2,58 \\
\hline 19 & 679 & 0,01 & 532 & 2,29 & 46 & 662 & 0,02 & 536 & 2,58 \\
\hline 20 & 665 & 0,01 & 533 & 2,60 & 47 & 668 & 0,00 & 534 & 2,54 \\
\hline 21 & 668 & 0,06 & 537 & 2,47 & 48 & 666 & 0,04 & 536 & 2,53 \\
\hline 22 & 675 & 0,03 & 532 & 2,40 & 49 & 666 & 0,02 & 533 & 2,57 \\
\hline 23 & 676 & 0,02 & 534 & 2,26 & 50 & 666 & 0,00 & 532 & 2,60 \\
\hline 24 & 683 & 0,01 & 530 & 2,43 & 51 & 669 & 0,00 & 534 & 2,58 \\
\hline 25 & 673 & 0,00 & 531 & 2,58 & 52 & 673 & 0,02 & 533 & 2,56 \\
\hline 26 & 680 & 0,00 & 529 & 2,51 & 53 & 663 & 0,04 & 537 & 2,53 \\
\hline 27 & 659 & 0,01 & 538 & 2,55 & 54 & 673 & 0,01 & 530 & $\begin{array}{r}2,56 \\
\text { contint }\end{array}$ \\
\hline
\end{tabular}


Apêndice B - continuação. Comprimento de onda de absorção $(\lambda$, em nm) e correspondente força do oscilador (f) para o $1^{\circ}$ e o $2^{\circ}$ estado excitado (EE) de cada configuração selecionada da simulação da caixa grande para o dímero do AM

\begin{tabular}{|c|c|c|c|c|c|c|c|c|c|}
\hline & \multicolumn{2}{|c|}{$1^{\circ} \mathrm{EE}$} & \multicolumn{2}{|c|}{$2^{\circ} \mathrm{EE}$} & & \multicolumn{2}{|c|}{$1^{\circ} \mathrm{EE}$} & \multicolumn{2}{|c|}{$2^{\circ} \mathrm{EE}$} \\
\hline & $\lambda(\mathrm{nm})$ & $\mathbf{f}$ & $\lambda(\mathrm{nm})$ & $\mathbf{F}$ & & $\lambda(\mathrm{nm})$ & $\mathbf{f}$ & $\lambda(\mathbf{n m})$ & f \\
\hline 55 & 665 & 0,03 & 538 & 2,49 & 83 & 666 & 0,01 & 536 & 2,57 \\
\hline 56 & 671 & 0,00 & 531 & 2,60 & 84 & 666 & 0,00 & 533 & 2,58 \\
\hline 57 & 672 & 0,02 & 532 & 2,52 & 85 & 665 & 0,00 & 535 & 2,60 \\
\hline 58 & 670 & 0,03 & 532 & 2,55 & 86 & 663 & 0,01 & 541 & 2,49 \\
\hline 59 & 655 & 0,15 & 548 & 2,28 & 87 & 669 & 0,00 & 531 & 2,60 \\
\hline 60 & 679 & 0,06 & 537 & 2,49 & 88 & 646 & 0,01 & 549 & 2,50 \\
\hline 61 & 657 & 0,11 & 557 & 2,11 & 89 & 659 & 0,01 & 535 & 2,59 \\
\hline 62 & 679 & 0,06 & 537 & 2,30 & 90 & 658 & 0,02 & 542 & 2,51 \\
\hline 63 & 658 & 0,07 & 549 & 2,30 & 91 & 667 & 0,06 & 535 & 2,49 \\
\hline 64 & 652 & 0,09 & 551 & 2,31 & 92 & 679 & 0,06 & 540 & 2,40 \\
\hline 65 & 624 & 0,16 & 563 & 2,35 & 93 & 671 & 0,01 & 539 & 2,41 \\
\hline 66 & 669 & 0,11 & 551 & 2,09 & 94 & 673 & 0,03 & 542 & 2,35 \\
\hline 67 & 660 & 0,09 & 546 & 2,32 & 95 & 645 & 0,08 & 552 & 2,40 \\
\hline 68 & 648 & 0,10 & 550 & 2,36 & 96 & 674 & 0,04 & 532 & 2,43 \\
\hline 69 & 668 & 0,06 & 533 & 2,51 & 97 & 661 & 0,01 & 540 & 2,53 \\
\hline 70 & 668 & 0,06 & 534 & 2,50 & 98 & 636 & 0,01 & 553 & 2,54 \\
\hline 71 & 657 & 0,01 & 542 & 2,51 & 99 & 622 & 0,03 & 563 & 2,52 \\
\hline 72 & 658 & 0,00 & 542 & 2,51 & 100 & 629 & 0,01 & 558 & 2,54 \\
\hline 73 & 651 & 0,01 & 543 & 2,55 & 101 & 641 & 0,03 & 554 & 2,44 \\
\hline 74 & 661 & 0,00 & 538 & 2,53 & 102 & 669 & 0,02 & 546 & 2,36 \\
\hline 75 & 655 & 0,01 & 546 & 2,46 & 103 & 665 & 0,04 & 540 & 2,44 \\
\hline 76 & 677 & 0,01 & 531 & 2,55 & 104 & 649 & 0,02 & 544 & 2,53 \\
\hline 77 & 669 & 0,02 & 534 & 2,54 & 105 & 654 & 0,02 & 547 & 2,45 \\
\hline 78 & 674 & 0,06 & 535 & 2,49 & 106 & 654 & 0,01 & 547 & 2,44 \\
\hline 79 & 673 & 0,05 & 532 & 2,48 & 107 & 674 & 0,01 & 541 & 2,36 \\
\hline 80 & 662 & 0,08 & 538 & 2,48 & 108 & 669 & 0,01 & 532 & 2,57 \\
\hline 81 & 667 & 0,01 & 532 & 2,60 & 109 & 666 & 0,01 & 536 & 2,59 \\
\hline 82 & 660 & 0,02 & 545 & 2,44 & 110 & 683 & 0,04 & 538 & $\begin{array}{r}2,35 \\
\text { contin }\end{array}$ \\
\hline
\end{tabular}


Apêndice B - continuação. Comprimento de onda de absorção $(\lambda$, em nm) e correspondente força do oscilador (f) para o $1^{\circ}$ e o $2^{\circ}$ estado excitado (EE) de cada configuração selecionada da simulação da caixa grande para o dímero do AM

\begin{tabular}{|c|c|c|c|c|c|c|c|c|c|}
\hline & \multicolumn{2}{|c|}{$1^{\circ} \mathrm{EE}$} & \multicolumn{2}{|c|}{$2^{\circ} \mathrm{EE}$} & & \multicolumn{2}{|c|}{$1^{\circ} \mathrm{EE}$} & \multicolumn{2}{|c|}{$2^{\circ} \mathrm{EE}$} \\
\hline & $\lambda(\mathbf{n m})$ & $\mathbf{f}$ & $\lambda(\mathbf{n m})$ & $\mathbf{F}$ & & $\lambda(\mathbf{n m})$ & $\mathbf{f}$ & $\lambda(\mathbf{n m})$ & $\mathbf{f}$ \\
\hline 111 & 667 & 0,03 & 536 & 2,56 & 139 & 657 & 0,03 & 540 & 2,54 \\
\hline 112 & 668 & 0,02 & 533 & 2,56 & 140 & 672 & 0,07 & 534 & 2,35 \\
\hline 113 & 673 & 0,01 & 531 & 2,56 & 141 & 641 & 0,18 & 558 & 2,20 \\
\hline 114 & 669 & 0,08 & 537 & 2,29 & 142 & 663 & 0,11 & 537 & 2,44 \\
\hline 115 & 669 & 0,08 & 537 & 2,29 & 143 & 667 & 0,11 & 543 & 2,30 \\
\hline 116 & 657 & 0,23 & 547 & 2,18 & 144 & 663 & 0,13 & 540 & 2,38 \\
\hline 117 & 662 & 0,12 & 541 & 2,40 & 145 & 658 & 0,08 & 543 & 2,44 \\
\hline 118 & 658 & 0,16 & 543 & 2,35 & 146 & 664 & 0,03 & 538 & 2,48 \\
\hline 119 & 687 & 0,08 & 537 & 2,31 & 147 & 656 & 0,01 & 544 & 2,48 \\
\hline 120 & 670 & 0,21 & 551 & 2,08 & 148 & 659 & 0,01 & 539 & 2,55 \\
\hline 121 & 671 & 0,13 & 544 & 1,96 & 149 & 650 & 0,00 & 546 & 2,52 \\
\hline 122 & 668 & 0,14 & 545 & 1,87 & 150 & 665 & 0,01 & 543 & 2,40 \\
\hline 123 & 646 & 0,23 & 547 & 2,29 & 151 & 632 & 0,10 & 556 & 2,43 \\
\hline 124 & 645 & 0,37 & 557 & 2,01 & 152 & 663 & 0,01 & 538 & 2,52 \\
\hline 125 & 653 & 0,34 & 567 & 1,74 & 153 & 654 & 0,04 & 541 & 2,54 \\
\hline 126 & 656 & 0,22 & 545 & 2,24 & 154 & 655 & 0,00 & 540 & 2,58 \\
\hline 127 & 675 & 0,10 & 539 & 2,22 & 155 & 665 & 0,01 & 538 & 2,52 \\
\hline 128 & 683 & 0,03 & 533 & 2,45 & 156 & 664 & 0,00 & 533 & 2,60 \\
\hline 129 & 675 & 0,08 & 538 & 2,11 & 157 & 664 & 0,00 & 533 & 2,61 \\
\hline 130 & 670 & 0,02 & 531 & 2,56 & 158 & 646 & 0,05 & 557 & 2,30 \\
\hline 131 & 664 & 0,10 & 536 & 2,46 & 159 & 657 & 0,01 & 542 & 2,53 \\
\hline 132 & 662 & 0,09 & 536 & 2,46 & 160 & 673 & 0,00 & 537 & 2,53 \\
\hline 133 & 664 & 0,16 & 541 & 2,26 & 161 & 669 & 0,00 & 533 & 2,58 \\
\hline 134 & 670 & 0,06 & 534 & 2,45 & 162 & 661 & 0,13 & 546 & 2,29 \\
\hline 135 & 661 & 0,08 & 538 & 2,47 & 163 & 689 & 0,08 & 542 & 1,78 \\
\hline 136 & 665 & 0,06 & 535 & 2,52 & 164 & 675 & 0,10 & 537 & 2,40 \\
\hline 137 & 663 & 0,06 & 538 & 2,51 & 165 & 669 & 0,08 & 543 & 2,27 \\
\hline 138 & 669 & 0,08 & 535 & 2,40 & 166 & 668 & 0,07 & 535 & $\begin{array}{l}2,48 \\
\text { contin }\end{array}$ \\
\hline
\end{tabular}


Apêndice B - conclusão. Comprimento de onda de absorção $(\lambda$, em $\mathrm{nm})$ e correspondente força do oscilador (f) para o $1^{\circ}$ e o $2^{\circ}$ estado excitado (EE) de cada configuração selecionada da simulação da caixa grande para o dímero do AM

\begin{tabular}{lccccccccc}
\hline & \multicolumn{2}{c}{$\mathbf{1}^{\mathbf{0}} \mathbf{E E}$} & \multicolumn{2}{c}{$\mathbf{2}^{\mathbf{0}} \mathbf{E E}$} & & \multicolumn{2}{c}{$\mathbf{1}^{\mathbf{0}} \mathbf{E E}$} & \multicolumn{2}{c}{$\mathbf{2}^{\mathbf{0}} \mathbf{E E}$} \\
& $\lambda(\mathbf{n m})$ & $\mathbf{f}$ & $\lambda(\mathbf{n m})$ & $\mathbf{f}$ & & $\lambda(\mathbf{n m})$ & $\mathbf{f}$ & $\lambda(\mathbf{n m})$ & $\mathbf{f}$ \\
\hline 167 & 672 & 0,08 & 540 & 2,34 & 173 & 637 & 0,01 & 551 & 2,54 \\
168 & 670 & 0,05 & 548 & 2,19 & 174 & 649 & 0,00 & 547 & 2,52 \\
169 & 667 & 0,07 & 539 & 2,40 & 175 & 674 & 0,00 & 532 & 2,56 \\
170 & 654 & 0,06 & 544 & 2,46 & 176 & 666 & 0,01 & 533 & 2,56 \\
171 & 629 & 0,06 & 554 & 2,51 & 177 & 649 & 0,03 & 545 & 2,51 \\
172 & 645 & 0,01 & 547 & 2,53 & & & & & \\
\hline
\end{tabular}

